\title{
Abstract
}

"Double-poly" bipolar transistors with polysilicon emitters self-aligned to polysilicon base contacts have been reported by a number of investigators to provide improved electrical performance compared to conventional, non-self-aligned devices. However, it is known that the double-poly structure increases exposure of the silicon crystal in the intrinsic base region to reactive ion etching (RIE). RIE introduces surface damage which can adversely affect junction electrical characteristics. This problem has been recognized in the literature, but very little information has been presented regarding its importance. It is known that IBM follows a processing approach which minimizes exposure to RIE at the cost of increased manufacturing complexity. In their approach, the patterning of in-situ doped base poly is completed by preferential wet etching.

A major goal of this thesis is the study of the effect of RIE damage on the double-poly structure.

To this end, the electrical effect of RIE etch damage on diodes formed by diffusion of arsenic from a polysilicon emitter layer was investigated. A sacrificial amorphous-Si layer was selectively included in the diode process flow and then removed by RIE to introduce etch damage. This approach allowed the establishment, without the need to process complete double-poly bipolar transistors, of a dry etching process whereby a base electrode directly deposited on crystalline $\mathrm{Si}$ could be patterned without affecting the base-eminer junction I-V characteristics.

In the second experimental par of this study, a relatively simple processing approach was developed to fabricate complete self-aligned double-poly BJTs. In this approach, the base electrode is deposited directly on the Si substrate as an undoped amorphous-Si layer, implanted with boron, covered by a deposited oxide, and completely patterned by dry etching. Fabricated transistors showed gains of about 57 for 6 orders of magnitude in $I_{c}$, and reverse bias emitter-base current of $0.5 \mathrm{nA}$ at $3 \mathrm{~V}$. 
The quality of this microform is heavily dependent upon the quality of the original thesis submitted for microfilming. Every effort has been made to ensure the highest quality of reproduction possible.

If pages are missing, contact the university which granted the legree.

Some pages may have indistinct print especially if the original pages were typed with a poor typewriter ribbon or if the university sent us an inferior photocopy.
La qualité de cette microforme dépend grandement de la qualité de la thèse soumise au microfilmage. Nous avons tout fait pour assurer une qualité supérieure de reproduction.

S'il manque des pages, veuillez communiquer avec l'université qui a conféré le grade.

La qualité d'impression de certaines pages peut laisser à désirer, surtout si les pages originales ont été diztylographiées à l'aide d'un ruban usé ou si l'université nous a fait parvenir une photocopie de qualité inférieure.

La reproduction, même partielle, de cette microforme est soumise à la Loi canadienne sur le droit d'auteur, SRC 1970, c. C-30, et ses amendements subséquents. 


\section{Implementation of a Double-Poly Bipolar Transistor Technology}

by

François Pagette, B.S.(Physics)

This thesis is submitted to the Faculty of Graduate

Studies and Research in partial fulfillment of the requirements for the degree of

Master of Engineering

Ottawa-Carleton Institutc for Electrical Engineering

Department of Electronics

Faculty of Engineering

Carleton University

Ottawa, Canada

January, 1994 
National Library

of Canada

Acquisitions and Bibliographuc Services Branch

395 Wellington Street Otlawa. Ontano KIAON4
Bibliothique nationale

du Canada

Direction des acquisitions et des services bibliographiques

395. ne Wellungton

Ottama (Ontano)

KIA ONA
THE AUTHOR HAS GRANTED AN IRREVOCABLE NON-EXCLUSIVE LICENCE ALLOWING THE NATIONAL LIBRARY OF CANADA TO REPRODUCE, LOAN, DISTRIBUTE OR SELL COPIES OF HIS/HER THESIS BY ANY MEANS AND IN ANY FORM OR FORMAT, MAKING THIS THESIS AVAILABLE TO INTERESTED PERSONS.
L'AUTEUR A ACCORDE UNE LICENCE IRREVOCABLE ET NON EXCLUSIVE PERMETTANT A LA BIBLIOTHEQUE NATIONALE DU CANADA DE REPRODUIRE, PRETER, DISTRIBUER OU VENDRE DES COPIES DE SA THESE DE QUELQUE MANIERE ET SOUS QUELQUE FORME QUE CE SOIT POUR METTRE DES EXEMPLAIRES DE CETTE THESE A LA DISPOSITION DES PERSONNE INTERESSEES.

L'AUTEUR CONSERVE LA PROPRIETE DU DROIT D'AUTEUR QUI PROTEGE SA THESE. NI LA THESE NI DES EXTRAITS SUBSTANTIELS DE CELLECI NE DOIVENT ETRE IMPRIMES OU AUTREMENT REPRODUITS SANS SON AUTORISATION.

ISBN $\quad 0-612-03033-4$ 
Nome FRANCOIS PAKETIL'

Dissentation Abstracts International is arranged by brond, general subject categories. Please select the one subject which most nearly describes the content of your dissertation. Entr. the corresponding four-digit code in the spaces provided

ELECTRONICS AND ELECTRICAC $0|5| 4 \mid 4$ U.M.I

\section{Subject Colegories}

\section{TuE humanitis ano social selinets}

\begin{tabular}{|c|c|}
\hline $\begin{array}{l}\text { Architecture } \\
\text { Ant History } \\
\text { Cinemo } \\
\text { Donce } \\
\text { Fine Arts } \\
\text { Informotion Science } \\
\text { Journalism } \\
\text { Library Science } \\
\text { Moss Communic Jtions } \\
\text { Music } \\
\text { Speech Communicotion } \\
\text { Theoter }\end{array}$ & $\begin{array}{l}0729 \\
0377 \\
0900 \\
0378 \\
0357 \\
0723 \\
0391 \\
0399 \\
0708 \\
0413 \\
0459 \\
0465\end{array}$ \\
\hline 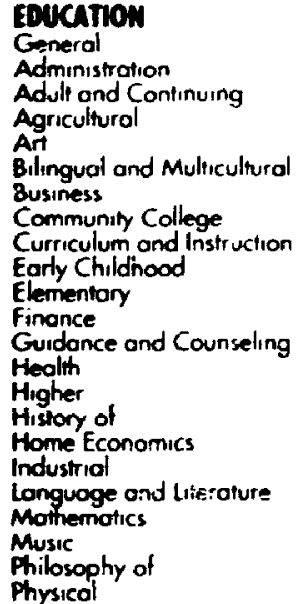 & $\begin{array}{l}0515 \\
0514 \\
0516 \\
0517 \\
0273 \\
0282 \\
0688 \\
0276 \\
0727 \\
0518 \\
0514 \\
0277 \\
0519 \\
0680 \\
0745 \\
0520 \\
0278 \\
0521 \\
0279 \\
0280 \\
0522 \\
0998 \\
0523\end{array}$ \\
\hline
\end{tabular}

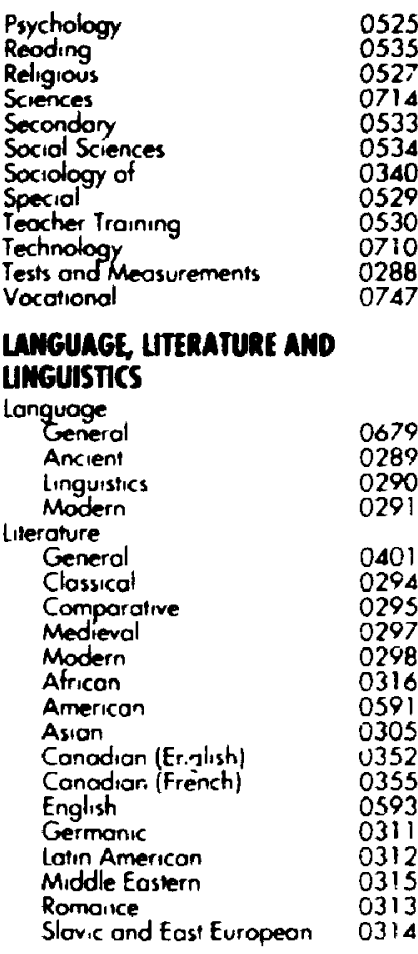

\section{PHILOSOPHY, RELGHON ANO}

THEOLOGY

phitosophy

Religion

General

Biblical Studies

Clergy

Philosiophy

Theology

American Studies

Anthropology

Archoeology

Culfural

Physical

Business Administrotion General

Accounting

Banking

Monogernent

Moriketing

Canudian Studies

Economics

Generol

Comimerce Business

finance

History

Labor

theory

Folklore

Geography

Gerortology

Geneia

\section{social salmas}

0422

0318

0321

0319

0320

0322
0469

0323

0320

0326

0327

0310

0272

0770

0454

0338
0385

050 !

0503
0505

0505

0509

0510

0511

0358

0366

0578 sestact cos
THE SCIENCES AND ENGINEERING

mological saencts

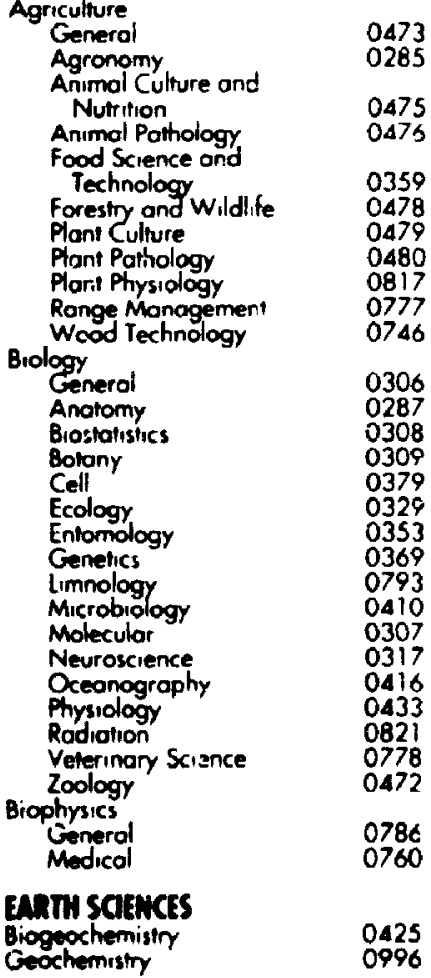

$\begin{array}{ll}\text { Geodesy } & 0370 \\ \text { Geoiogy } & 0372 \\ \text { Geophysics } & 0373 \\ \text { Hydrology } & 0388 \\ \text { Mineralogy } & 0411 \\ \text { Poleobotony } & 0345 \\ \text { Poleoecology } & 0426 \\ \text { Poleontology } & 0418 \\ \text { Poleozoology } & 0985 \\ \text { Polynology } & 0427 \\ \text { Physical Geography } & 0368 \\ \text { Physicul Oceonography } & 0415\end{array}$

HEAtTH AMD ENVIRONMENTA SCIENCS

Environmenial Sciences $\quad 0768$

Health sciences

General

Audiologr

Chemothercpy 0992

Dentistry 0567

Education

Hospital Management 0769

Humon Development $\quad 0758$

Immunology 0982

Medicine ond Surgery 0564

Medial Health

Nursing 0569

Nutrition 0570

Obstetrics and Gynecology 0380

Occupational Healiti and 0354

Ophithalmology 0381

Ophthamology 057

Pathology

Phormogy

Physical theropy

Public Health

Radidogy 0574

Rodidogy
Speech Pathology

Home Economics

\section{PHYSICAL SCIENCES}

Pure Sciences

Chemistry

General

Analytica!

Biochemistry

Inorganic

Nuclenr

Orgonic

Ptiarmaceulica

Physical

Radiation

Mathemalics

Physics

General

Acoustics

Astronomy and

Astrophys'cs

Amospteric Science

Alomic

Electronics and Electricity

Eleme, tary Particles and

High Energy

Fluid and Plasmo

Molecular

Nucleor

Oplics

Rodiation
Solid Stale

Statistics

Applied Sciences

Applied Mechonics

Computer Science
0460

0383

0485

0749

0486

0488

0738

0490

0491

0495

0754

0405

0605

0986

0606

1608

0748

0607

0798

0759

0609

0610

0752

0756

0611

0463

0344
Engineering

Aerospace

Aaricultural

Automotive

B.omedical

Chemical

Civil

Electronics and Electrical

Heat and Thermodynomics

Hydroulic

Industrial

Marine

Materials Science

Mechanical

Metalurgy

Mining

Nuclear

Pockoging

Petroleum

Sonitory and Municipal

System Science

Geolechnology

Operotions Reseorch

Plastics Technology

Textile Technology

\section{PSTCHOLOGY}

Geneial

Behoviorol

Clinical

Developmental

Experimento

industrial

Personaliny

Physiologica!

Psychobiology

Psychometrics

Soxiol
0537

0538

0539
0540

0541

0542
0543

0544

0348

0545

0546
0547

0794

0548

0743

0551
0552

0549

0765

0554

0428

0796

0795
0994

0521

0384

0622
0620

0623

0824

0625

.

0349
0632

0451 
Thesig containg black \& wite photographe \&/or explanatory tables which when microfilmed may lose their gignificance. The hardcopy of the theala ia avaliable upon request from Carleton University Library. 
The undersigned recommend to the Faculty of Graduate Studies and Research the acceptance of the thesis:

"Implementation of a double-poly bipolar transistor technology"

submitted by Francois Pagette in partial fulfillment of the requirements for the degree of Master of Engineering
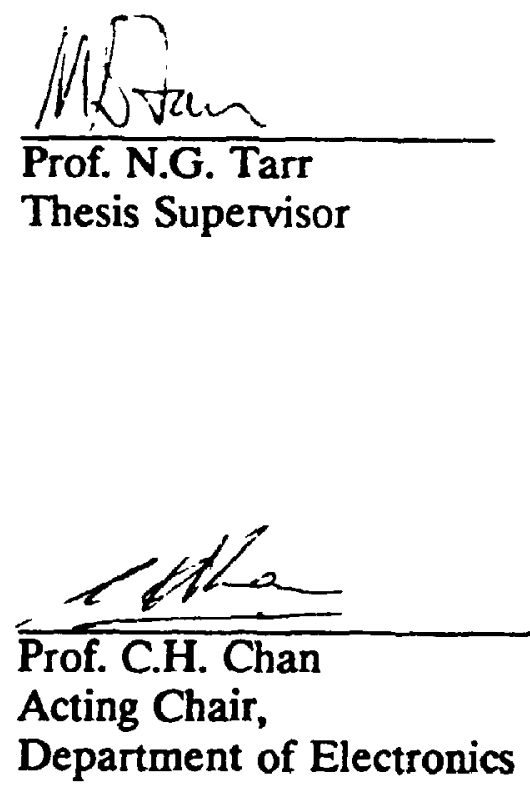

Carleton University

February, 1995 


\section{Abstract}

"Double-poly" bipolar transistors with polysilicon emitters self-aligned to polysilicon base contacts have been reported by a number of investigators to provide improved electrical performance compared to conventional, non-self-aligned devices. However, it is known that the double-poly structure increases exposure of the silicon crystal in the intrinsic base region to reactive ion etching (RIE). RIE introduces surface damage which can adversely affect junction electrical characteristics. This problem has been recognized in the literature, but very little information has been presented regarding its importance. It is known that IBM follows a processing approach which minimizes exposure to RIE at the cost of increased manufacturing complexity. In their approach, the patteming of in-situ doped base poly is completed by preferential wet etching.

A major goal of this thesis is the study of the effect of RIE damage on the double-poly structure. To this end, the electrical effect of RIE etch damage on diodes formed by diffusion of arsenic from a polysilicon emitter layer was investigated. A sacrificial amorphous-Si layer was selectively included in the diode process flow and then removed by RIE to introduce etch damage. This approach allowed the establishment, without the need to process complete double-poly bipolar transistors, of a dry etching process whereby a base electrode directly deposited on crystalline $\mathrm{Si}$ could be patterned without affecting the base-eminer junction I-V characteristics.

In the second experimental part of this study, a relatively simple processing approach was developed to fabricate complete self-aligned double-poly BJTs. In this approach, the base electrode is deposited directly on the Si substrate as an undoped amorphous-Si layer, implanted with boron, covered by a deposited oxide, and completely patterned by dry etching. Fabricated transistors showed gains of about 57 for 6 orders of magnitude in $\mathrm{I}_{c}$, and reverse bias emitter-base current of $0.5 \mathrm{nA}$ at $3 \mathrm{~V}$. 


\section{Acknowledgments}

This project was supported technically by the Semiconductor Components Group (SCG) of Northem Teleccm Electronics Ltd. The author would like to thank Dr. Garry Tarr (Carleton) for his overall supervision and technical advice; Dr. Ian Wylie (SCG) for his help on processing issues for the first year of this study; Mr. Xiaoming Li (SCG) for continuing this task; Dr. Peter Schvan (SCG) for his support to this project; Mr. Robert Hadaway (SCG) and Mr. Paul Kempf (SCG) for managerial support; Members of the Silicon Technology Department (SCG) for technical support; Members of MOD4 (SCG) and Mrs. Carol Adams (Carleton) for wafer manufacturing; Members of the Physical Analyses Group (SCG) for their scanning electron microscopy work. This project was supported financially by Northern Telecom and, the "Fonds pour la formation de chercheurs et l'aide à la recherche (FCAR)" from the Quebec governement. 
À mes parents, Lorraine et André, en reccnnaissance de leur soutien tout au long de mes études. 


\section{Table of Contents}

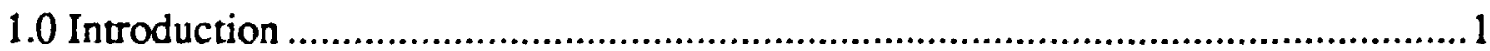

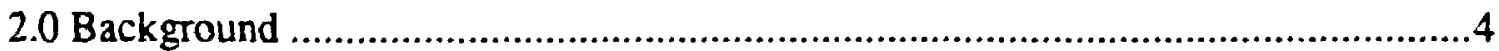

2.1 Double-Poly Bipolar Fabrication Approaches....................................4

2.1.1 NTT Approach (SST) .................................................. 4

2.1.2 IBM Approach ...........................................................6

2.1.3 Tektronix Approach .........................................................

2.1.4 Other Self-Aligned Double-Poiy Bipolar Technologies ...............8

2.2 Physical Effects at the Perimeter of Self-Aligned Double-Poly Bipolar .........9

2.2.1 Effects of the Lateral Encroachment of the Extrinsic-Base

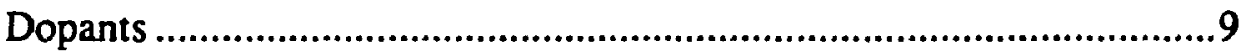

2.2.2 Perimeter Depletion Effect .................................................11

2.2.3 Shadowing Effect in Implanted Base Transistors ........................ 12

2.3 Effect of Etch Damage in Double-Poly Bipolar ..................................... 13

2.4 Chapter Conclusion ...................................................................... 15

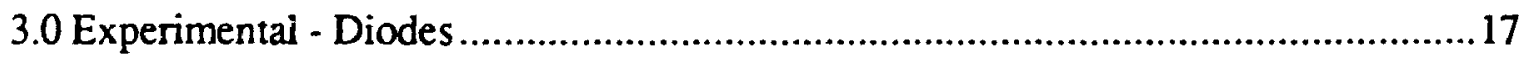

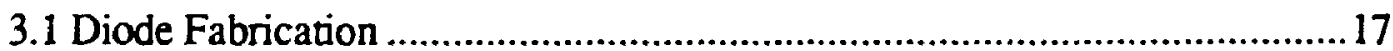

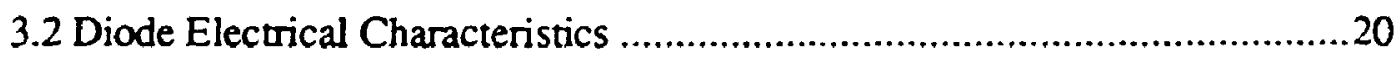

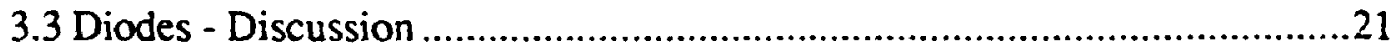

3.4 Chapter Conclusion .............................................................22

4.0 Fabrication and characterization of double-poly bipolar transistors......................23

4.1 Processing Approach Chosen.........................................................23

4.2 Experimental Procedure ..................................................................24

4.3 Preliminary Work.......................................................................26

4.3.1 Base Poly Material and Diffusion Characteristics .....................26

4.3.2 Base Poly Etch ...............................................................30

4.3.3 Poly to Poly Isolation - Processing Difficulties and Electrical

Consequences .........................................................................33

4.3.4 Field Oxide Loss ............................................................45

4.3.5 Transistor Topography ...................................................44

4.4 Double-Poly Bipolars - Batch V.................................................48

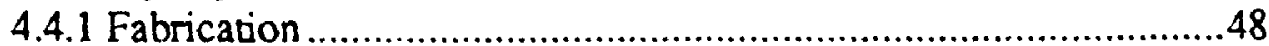

4.4.2 Electrical Results..........................................................55

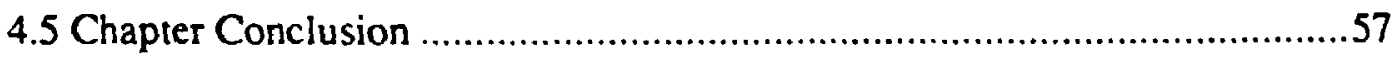

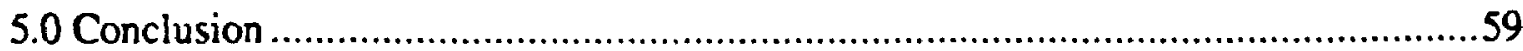

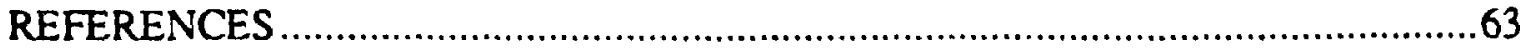




\section{List of Figures and Tables}

Figure 1 Cross-sectional views of (a) a conventional single poly, non-self-aligned bipolar and (b) a self-aligned double-poly BJT.

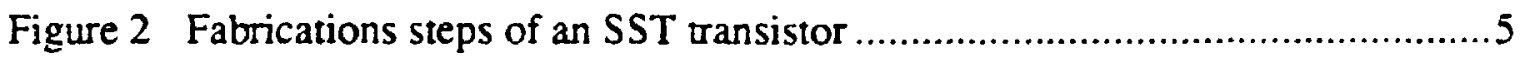

Figure 3 Fabrication steps of IBM's double-poly bipolar transistor ............................7

Figure 4 Concept of Borosenic-Poly emitter-base with link implant .........................8

Figure 5 Schematic cross section of a double-poly bipolar transistor with a blow-up of the region under the sidewall spacer........................................... 10

Figure 6 Ilustration of the perimeter depletion effect............................................11

Figure 7 Illustration of the shadowing effect ..........................................................12

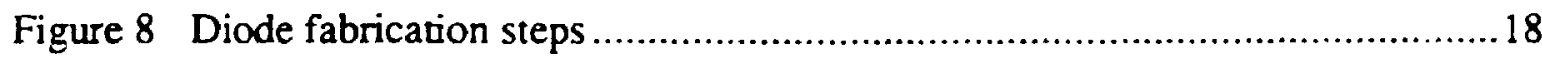

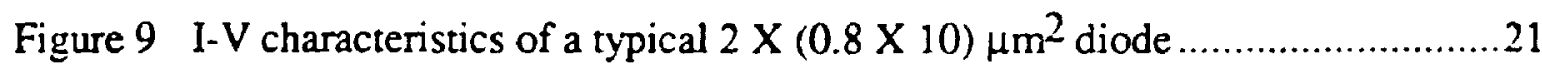

Figure 10 Process flow of the fabricated double-poly bipolar transistor........................25

Figure 11 Boron and oxygen profiles diffused from recrystallized amorphous-Si and Si deposited in the polycrystalline phase .28

Figure 12 Cross-sectional SEM picture of the emitter opening of a partially processed double-poly transistor patterned with $\mathrm{Cl}_{2}$ poly etch

Figure 13 Amount of crystalline Si lost versus overetch time for different wafer series.. 32

Figure 14 Cross-sectional SEM picture of the emitter opening of a partially processed double-poly transistor patterned with $\mathrm{Cl}_{2}$ poly etch that received the nitric:acetic:HF delineation etch

Figure 15 Cross-sectional SEM picrure of a typical double-poly tansistor from Batch I

Figure 16 Gummel plot of a typical $2 \times(0.8 \times 10) \mu \mathrm{m}^{2}$ transistor from Batch I

Figure 17 Reverse mode I-V characteristics of the base-emitter junction of a typical $2 \times(0.8 \times 10) \mu \mathrm{m}^{2}$ transistor from Batch I

Figure 18 Cross-sectional SEM picture of a double-poly transistor from Batch II ..........36 
Figure 19 Gummel plot of a typical $2 \times(0.8 \times 10) \mu \mathrm{m}^{2}$ transistor from Batch II .........36

Figure 20 Gummel plot of a transistor with good DC characteristics from Batch II.......37

Figure 21 Cross-sectional SEM picture of a transistor from Batch III showing no poly to poly shorts.

Figure 22 Cross-sectional SEM picture of a typical double-poly transistor from Batch III 39

Figure 23 Gummel plot of a typical $2 \times(0.8 \times 10) \mu \mathrm{m}^{2}$ transistor from Batch III ........40

Figure 24 Cross-sectional SEM picture of a typical double-poly transistor from Batch IV

Figure 25 High magnification cross-sectional SEM picture of a double-poly transistor from a mechanical batch

Figure 26 Cross-sectional SEM picture of a typical double-poly transistor from Batch IV that received the nitric:acetic:HF delineation etch

Figure 27 Gummel plot of a typical $2 \times(0.8 \times 10) \mu \mathrm{m}^{2}$ transistor from Batch IV

Figure $28 \mathrm{I}-\mathrm{V}$ characteristics of the base-emitter junction of a $2 \mathrm{X}(0.8 \times 10) \mu \mathrm{m}^{2}$ transistor with good DC characteristics. Im Batch IV....

Figure 29 Cross-sectional SEM picture showing a transistor for which all the field was lost (extreme case)

Figure 30 Cross-sectional SEM picture showing the overall topography of the fabricated double-poly bipolar

Figure 31 Cross-sectional SEM picture of a typical double-poly transistor from Batch $V$ after emitter poly deposition

Figure 32 Cross-sectional SEM picture of a typical double-poly transistor from Batch $\mathrm{V}$ after emitter poly deposition

Figure 33 Gummel plot of a typical $2 \times(0.8 \times 10) \mu \mathrm{m}^{2}$ transistor from Batch $\mathrm{V}$

Figure 34 Gurnmel plot of a typical $1.6 \times 8 \mu \mathrm{m}^{2}$ transistor from Batch $V$ wafers 1,2 , and 3

Figure $35 \mathrm{I} \cdot \mathrm{V}$ characteristics of the base-emitter junction of a typical $1.6 \times 8 \mu \mathrm{m}^{2}$ transistor from Batch V wafers 1, 2, and 3 . 
Figure 36 Hfe versus log Ic curve of a typical $1.6 \times 8 \mu \mathrm{m}^{2}$ transistor from Batch $V$ wafers 1,2 , and 3

Figure 37 Ic versus Vce curve of a typical $1.6 \times 8 \mu \mathrm{m}^{2}$ transistor from Batch $\mathrm{V}$ wafers 1,2 , and 3

Figure 38 Gummel plot of a typical $1.6 \times 8 \mu \mathrm{m}^{2}$ transistor from Batch $V$ wafer $7 \ldots \ldots . .55$

Figure 39 Base current for $0.4 \mathrm{~V}$ base-emitter junction forward bias for the different wafers and transistor sizes from Batch $V$

Figure 40 Base current for $3 \mathrm{~V}$ base-eminter junction reverse bias for the different wafers and transistor sizes from Batch $V$

Figure 41 Current gain at $0.8 \mathrm{~V}$ base-emiter bias for the different wafers and device sizes from Batch $V$

Table 1 Processing splits of fabricated diodes

Table 2 Measured depth in crystalline silicon of the $1 \times 10^{18} \mathrm{~cm}^{-3}$ and

$1 \times 10^{19} \mathrm{~cm}^{-3}$ concentration level for boron diffused from a Si layer and pre.essed with different conditions.

Table 3 Processing splits on Batch V of double-poly bipolar 50 


\subsection{INTRODUCTION}

As demand for reduced gate delay increases, Emitter-Coupled Logic (ECL) bipolar integrated circuits will be more extensively employed. Fast ECL type circuitry requires low power, high speed bipolar transistors. In particular, transistors with lower parasitic capacitance, reduced base resistance and higher $\mathrm{f}_{\mathrm{T}}$ are needed. A "self-aligned double-polysilicon" bipolar transistor structure has been reported by a number of investigators to offer improved performance when compared to conventional, non-self-aligned devices. Self-aligned double-polysilicon bipolar transistors with peak $f_{T}$ and $f_{\max }$ of $41 \mathrm{GHz}$ and $B V_{\text {ceo }}$ of $3.6 \mathrm{~V}$ have been reported [1].

Although different processing approaches have been developer to form double-poly bipolar structures, in all ca:?s their higher performance is due to the use of polysilicon (also called "poly") for a base contact. Figure 1 illustrates (a) a conventional single poly, non-self-aligned bipolar and (b) a self-aligned double-poly BJT. Having a poly contacted base allows the metal contact to be placed over the field oxide reducing significantly the base-collector capacitance. The base poly serves also as a mechanical support allowing self-alignment of the emitter to the base contact. The emitter-to-base contact separation of this transistor is only the thickness of an oxide spacer, allowing a reduction in the base resistance and a further reduction in the base-collector junction area. The double-poly self-aligned structure allows not only downscaling of the lateral dimensions of the BJT but also ":lps to optimize its vertical doping profile. Having the base poly serve as a diffusion source to form the extrinsic base allows formation of the extrinsic and intrinsic base at different stages of the fabrication process. The extrinsic base can then be heavily doped to reduce the total base resistance. In contrast, the intrinsic base should receive low doping and the least amount of thermal budget to achieve $a$ thin base width and therefore a high $f_{T}$. 

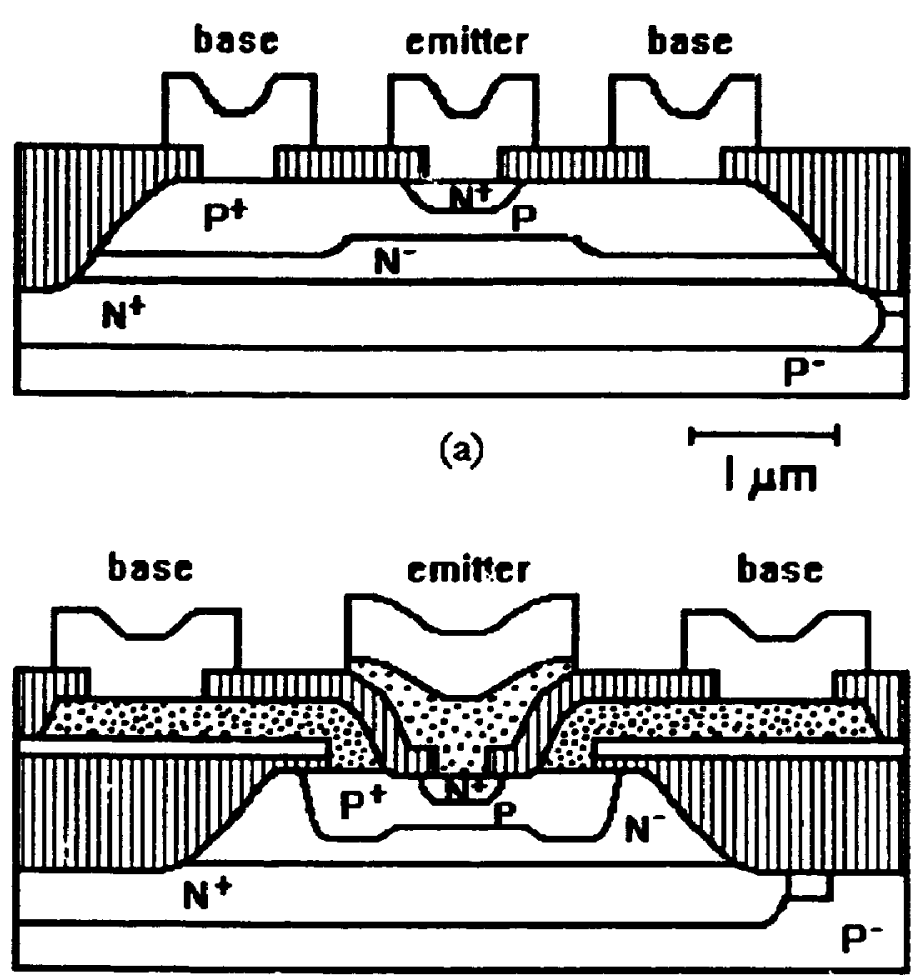

(b)

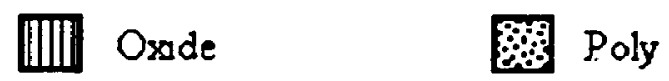

Figure 1 Cross-sectional views of (a) a conventional single poly, non-self-aligned bipolar and (b) a self-aligned double-poly BJT (SST) [2].

One disadvantage of a double-poly tipolar process when compared to a non-self-aligned bipolar is increased $c$ iposure of the intrinsic region of the transistor to reactive ion etching (RIE). The Si crystal in the intrinsic region of a double-poly bipolar is exposed to the base poly electrode patterning etch before the formation of the intrinsic base and emitter. Plasma etching produces surface damage which can modify junction electrical characteristics. This problem has been mentioned in the literature, but there is no general agreement regarding its effect on the transistor characteristics. The degree of exposure to RIE varies depending on the processing approach used to form the base electrode. For example, the IBM processing approach minimizes the exposire at the cost of increased manufacturing complexity. In their process, the patterning of the in-situ doped base poly layer is completed by preferential wet etching. The literature related to doublepoly bipolar fabrication, etch damage in the context of its effect on bipolar transistors and other 
physical effects specific to double-poly bipolars or enhanced in these devices is reviewed in chapter 2.0.

In the first experimental part of this study, the electrical effect of etch damage on diodes formed by diffusion of arsenic from a polysilicon layer was investigated. A sacrificial amorphous-Si layer was deposited on the diode surface, and then removed by RIE prior to emitter formation. The effect of this etch on the diode electrical characteristics was determined. Means for damage removal such as surface re-oxidation after the etch were also considered. This approach allowed insight to be obtained into the effect of etch damage on the double-poly bipolar without the need for full processing of tansistors. This work is presented in chapter 3.

In the second experimental part of this study, the results of chapter 3 were used to develop a relatively simple processing appreach to form a self-aligned double-poly bipolar with good DC electrical characteristics. Northern Telecom's conventional single poly bipolar was thereby successfully transformed into a double-poly BJT. This work is presented in chapter 4 . The conclusions of this study are presented in chapter 5 . 


\subsection{BACKGROUND}

The literature related to double-poly bipolar transistor fabrication is reviewed in section 2.1 . Physical effects specific to double-poly bipolars or enhanced in these devices are presented in section 2.2. In section 2.3, the literature on etch damage in the context of its effect on bipolar transistors is dicussed. A chapter conclusion is presented in section 2.4 .

\subsection{Double-Poly Bipolar Fabrication Approaches}

Use of doped polysilicon as a diffusion source and an electrical contact to the diffused extrinsic base, was first reported by Twente University of Technology [3] and NEC-Toshiba with the advanced polysilicon self-aligned technology (APSA) $[4,5]$. These bipolar transistors presented reduced base-collector junction area compared to a conventional BJT. Further reduction in the base-collector junction area was later achieved by self-aligning the base to emitter contact rather than relying on lithography. Sections 2.1.1 to 2.1.4 discuss the different fabrication approaches used to form these self-aligned double-poly bipolar technologies.

\subsubsection{NTT Approach (SST)}

Figure 2 shows the fabrication steps of NTT's super self-aligned process technology (SST) transistor $[2,7,8,9$ ! Oxide, nitride, and poly are successively deposited on an n-type epitaxial layer after isolation. Unnecessary poly outside of the transistor region is locally oxidized. The poly in the area corresponding to the transistor intrinsic region is etched away (figure 2a). The base poly electrode is oxidized. The nitride layer is sideways etched followed by etching of the underlying oxide layer (figure 2b). A second polysilicon layer is deposited to fill the space under the base poly and connect the first poly to the single-crystal Si. The excess poly is etched away (figure 2c). 
(a)

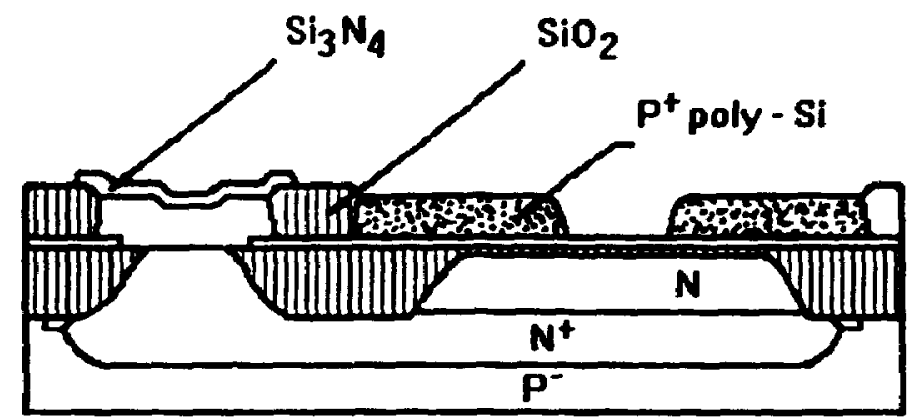

(b)

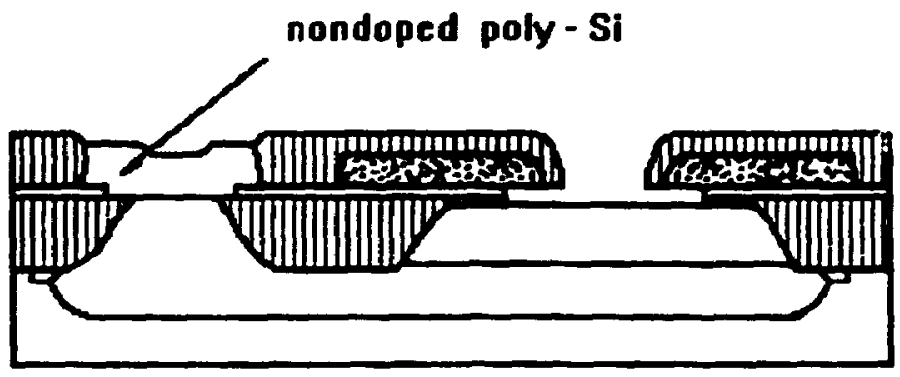

(c)

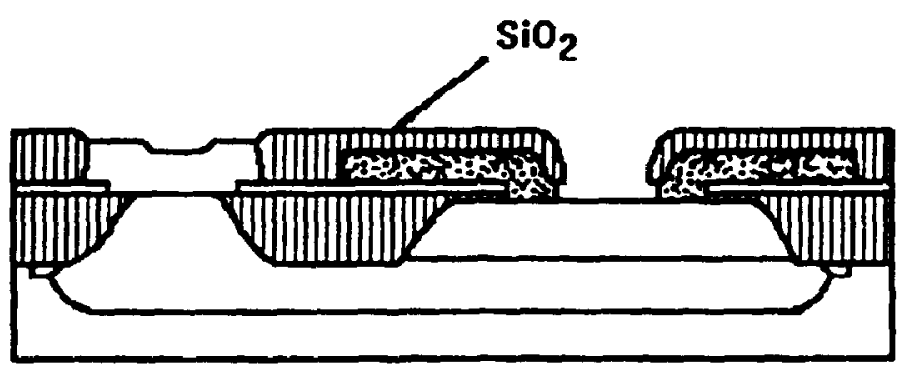

(d)

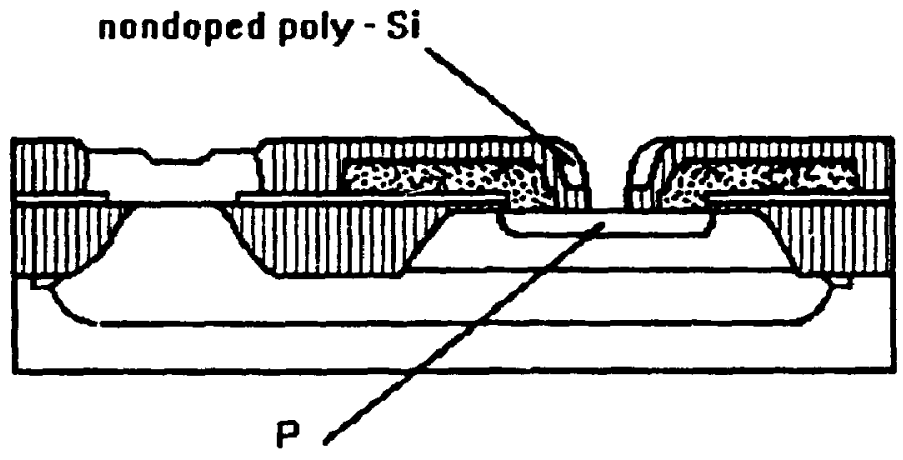

(e)

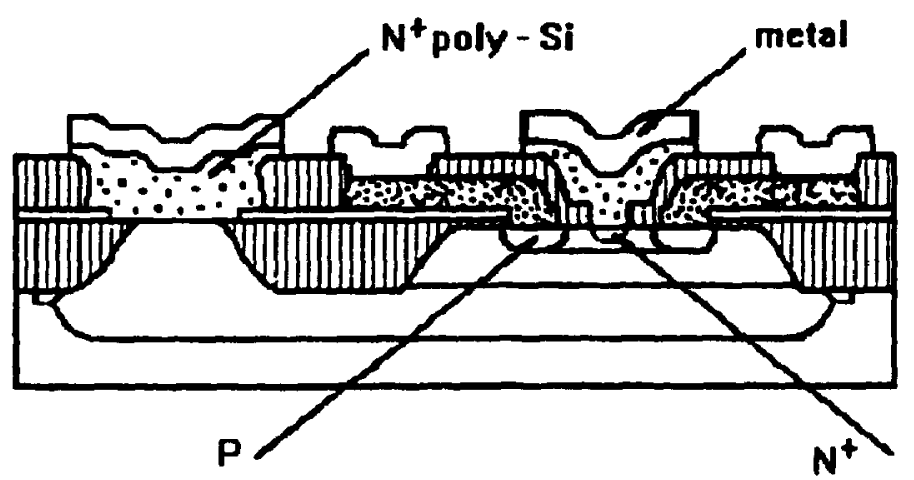

Figure 2 Fabrications steps of an SST transistor [7]. 
Thermal oxide is formed over both the epitaxial Si surface and the poly sidewall. The intrinsic base region is formed by boron ion implantation through the thermal oxide. U'se of a Selectively Implanted Collector (SIC), a phosphorus implant into the base-collector junction to counter dope the base implant tail and locally increase collector doping, has been repored $[1,10,11,12]$. CVD oxide and polysilicon are then deposited. The poly is etched by RIE to form a SWS. A second poly deposition and etch back have also been used to further reduce the emitter width [2]. The exposed oxide is then etched by RIE forming an "L" shaped oxide "spacer" to separate emitter contact from base electrodes (figure $2 \mathrm{~d}$ ). The emitter area is diffused from an arsenic-implanted polysilicon layer. $\mathrm{Al}$ interconnect is then formed (figure 2e).

A recen: version of the process includes several innovations [1]. To provide device isolation, phosphorus-doped poly filled trenches were used. This material was also used to fill a plug to contact the collector. This collector contact sc heme allowed a $40 \%$ reduction in transistor area compared to the conventional SST approach. A new base formation scheme was introduced; the base was diffused by $R T A$ from a $B F_{2}$ ion implanted oxide film.

\subsubsection{IB.M Approach}

IBM's double-poly bipolar technology has been extensively discussed in the literature $[13,14,15,16,17,18,19,20]$. After epitaxial layer and isolation formation which can be based on LOCOS o: trench, in-situ boron-doped polysilicon and oxide are successively deposited (figure 3a). A nitride layer was later added to cover the oxide [20]. The passivation and the poly layers are patterned by RIE completely through the passivation and only partially through the poly layer. The patterning is completed by preferential etching in a $\mathrm{HF} / \mathrm{HNO}_{3} / \mathrm{CH}_{3} \mathrm{COOH}$ (HNA) solution, which etches heavily doped silicon but not the lightly doped substrate or the protecting nirride (figure $3 b$ ). A thin oxide layer is grown, followed by the deposition of a thicker oxide layer. 
Additional doping of the exurinsic base is carried out at this point, as desired by diffusing boron from the $\mathrm{p}^{+}$polysilicon layer (figure $3 \mathrm{c}$ ). These two oxide layers were then completely removed by a maskless reactive-ion etch to form an isolaticn sidewall spacer (SWS). After the intrinsic base boron implantation, the emitter is formed (figure 3d).

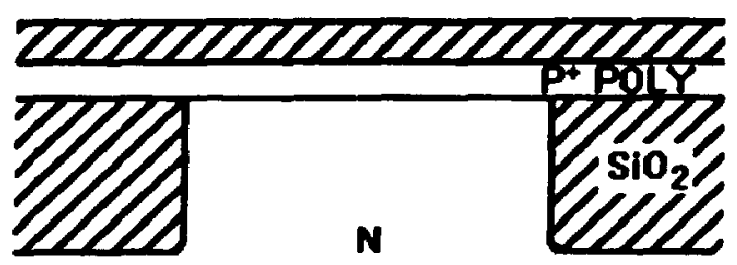

(a)

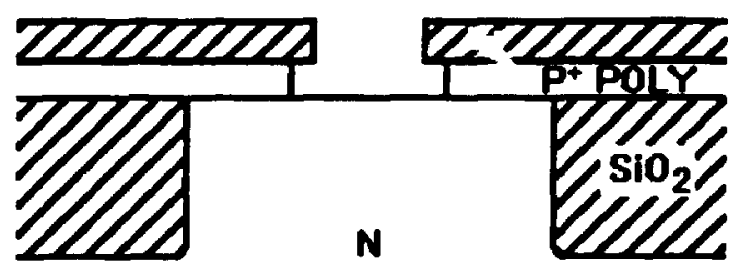

(b)

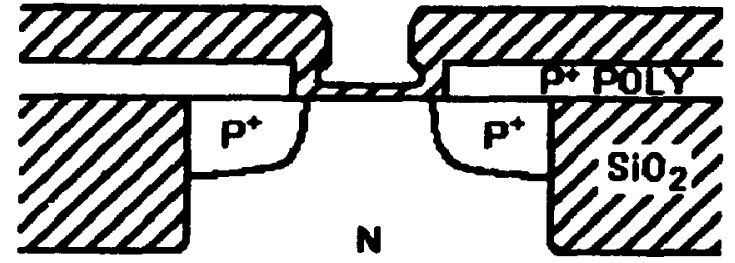

(c)

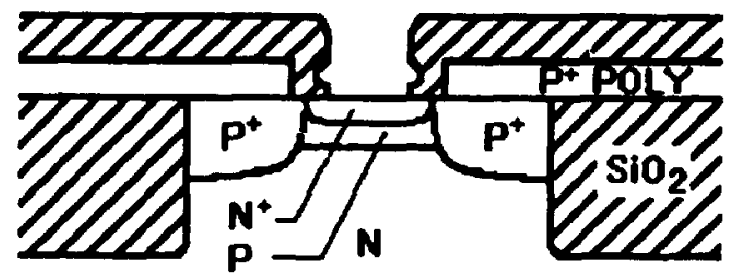

(d)

Figure 3 Fabrication steps of IBM's double-poly bipolar transistor [14].

\subsubsection{Tektronix Approach}

Tektronix's double-poly bipolar is another technology that has been discussed extensively in the literature $[21,22,23,24,25]$. After buried layer and epitaxial layer formation, the device area is defined by LOCOS or trench isolation. A polysilicon layer is deposited and implanted with boron. An oxide film is deposited. The base electrode is defined in this sandwich structure by photolithography and RIE. A thin thermal oxide is grown. To achieve firm linkage between the eventual extrinsic and intrinsic base regions, a light boron ion implant, called the "link" implant was later added to the flow after the oxidation (see figure 4a) [25]. An additional oxide layer is deposited and etched back using an RIE process to form a SWS around the base electrode. The intrinsic base and emitter are formed by double-diffusion of boron and arsenic through a second 
polysilicon film (Borosenic-Poly emitter-base process) (see figures $4 \mathrm{~b}$ and $4 \mathrm{c}$ ). Metal contacts are then formed.

A recent version of the process includes $\mathrm{BF}_{2}$ link and intrinsic base implants, and a Selectively Implanted Collector (SIC) layer after SWS formation [21].

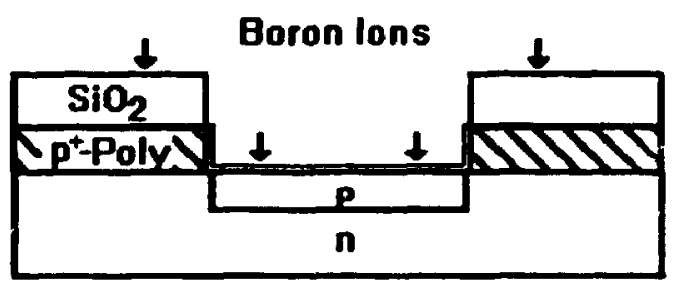

(a)

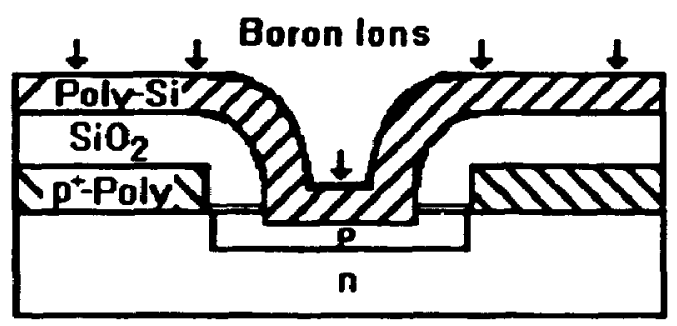

(b)

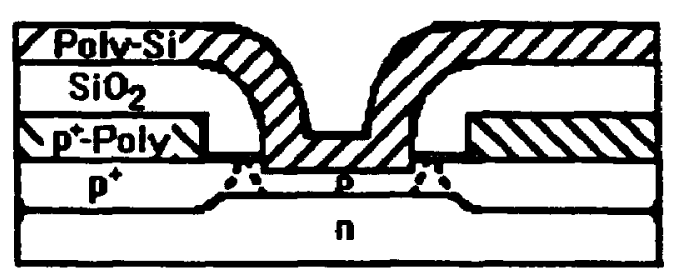

(c)

Figure 4 Concept of Borosenic-Poly emitter-base with link implant [25].

\subsubsection{Other Self-Aligned Double-Poly Bipolar Technologies}

Several other self-aligned double-poly bipolar technologies have been developed. Motorola, for example, have reported several innovative processing approaches $[26,27,28,29]$. An original approach reported is the use of a disposable $\mathrm{BF}_{2}$-implanted poly spacer as a diffusion source for a link base [28]. After boron diffusion through a thin underlying oxide, the poly SWS is removed to be replaced by an oxide SWS. Motorola also fabricated a double-poly bipolar in a lightly-doped p-well to minimize parasitic capacitances [29]. An n-type buried layer and juncrion isolarion were used. An SIC-like scheme was used to form a self-aligned collector. 
A double-poly bipolar technology from NEC uses a CVD-BSG film as a diffusion source for the intrinsic base and link as well as for the SWS material [30].

Double-poly bipolar technologies have also been developed by Texas Instruments (ExCL) [31], Fujitsu (ESPER) [32,33], Fairchild Research (SAPT) [34], Hitachi [35,36], Siemens [37,38] and others.

\subsection{Physical Effects at the Perimeter of Self-Aligned Double-Poly Bipolar}

Physical effects not encountered in conventional single-poly bipolar transistors can affect the double-poly BJT due to its lateral downscaling potential and its high topography. These effects are presented in section 2.2.1 to 2.2.3. They are important concerns for or e developing a double-poly BJT and so, they influenced the development of existing double-poly technologies. Furthermore, understanding of these physical effects is important as they are emitter perimeter dependant. Longer and narrower emitter stripes are used to reduce transistor base resistance, making the transistor characteristics more dependant on perimeter properties.

\subsubsection{Effects of the Lateral Encroachment of the Extrinsic-Base Dopants}

Having the base poly serve as a diffusion source allows independent optimization of the intrinsic and extrinsic base. But, the link-up of the two base regions becomes a concem in contrast to conventional bipolar transistors. Due to the self-alignment, the extrinsic base, diffused from the base poly, can be placed near the emitter edge, providing a low resistance connection to the intrinsic base and preventing peripheral punchthrough [39]. New device concerns arise as the extrinsic base reaches and disturbs the intrinsic profile (see figure 5). First, the current gain is diminished due to a reduction in the active device area and to the emitter/extrinsic-base 
overlap $[40,41,42]$. This causes the current gain to decrease as the transistor emitter width is scaled down.

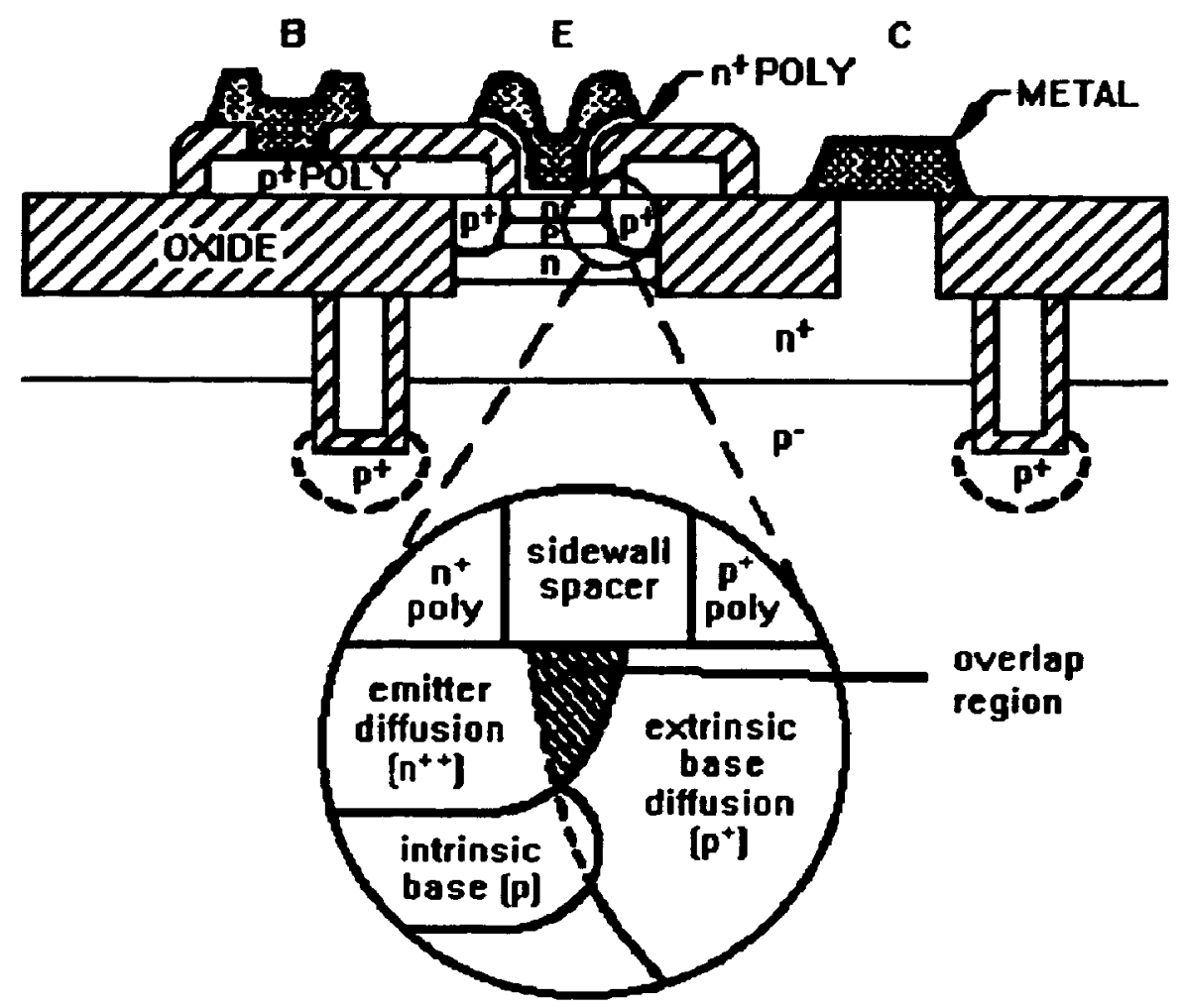

Figure 5 Schematic cross section of a double-poly bipolar transistor with a blow-up of the region under the sidewall spacer [44].

Second, the cutoff frequency is reduced due to the existence of a parasitic wide-base transistor in parallel with the thin-base transistor [42].

Third, for a severe encroachment, the overlap region of the heavily doped extrinsic base and emitter under the SWS leads to excessive perimeter tunneling current $[43,44,45]$. Typically, the leakage current modifies the I- $V$ characteristics of the base-emitter junction as an increased reverse current by many orders of magnitude. Also, a non-ideal base current is observed under low forward bias, with an ideality factor possibly greater than two. The origin of the current leakage was verified by measuring its dependency on temperature, bias voltage, and device perimeter/area ratio. 


\subsubsection{Perimeter Depletion Effect}

Electrical effects similar to those discussed in the previous section have also been reported to be due to reduced doping concentration in the emitter poly, near the emitter edges (see figure 6). This effect called "Perimeter depletion", has been reported for both conventional single-poly bipolar and double-poly BJT. Three possible causes are mentioned in the literature: 1) the implanted arsenic dopant along the perimeter has to diffuse a longer distance to reach the poly/Si interface as the poly is thicker in this area [46] 2) a lower implant dose can be expected at the emitter window sidewall where the polys:licon surface becomes nearly parallel to the ion trajectories $[47,48] 3$ ) vertical diffusion rate in the perimeter area is reduced as the poly columns grow perpendicular to the poly surface [48]. The shallower emitter junction depth at the emitter edge results in a larger base Gummel number and hence a smaller effective emitter width. As the base current is proportional to the physical emitter contact opening whereas $I_{c}$ is proportional to the effective emitter width, this leads to a decreasing gain with decreasing eminter width. Also, the insufficient supply of emitter dopants at the perimeter may cause part of the depletion layer to be located inside the emitter poly film where many generation-recombination centers exist, causing large leakage current. The non-ideal base current for low forward bias and the large reverse leakage

current were found to be reduced with increased RTA temperature for emitter drive-in [21].

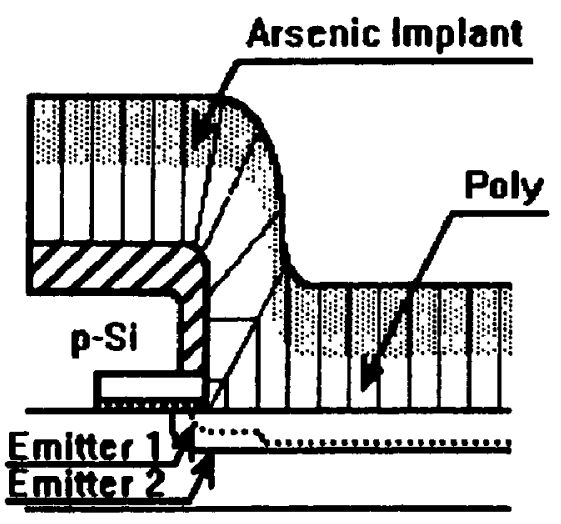

Figure 6 Ilustration of the perimeter depletion effect [46]. 


\subsubsection{Shadowing Effect in Implanted Base Transistors}

Rough topography is inherent to double-poly bipolar as the process relies on a step formed by the patterned base electrode to provide self-alignment of the emitter contact. In order to achieve high performance a shallow intrinsic-base is required. Boron ion implantation is a widely used method to form the intrinsic base and has been shown to be capable of providing very high performances. Implanted-base transistors with $\mathrm{f}_{\mathrm{T}}$ as high as $60 \mathrm{GHz}$ has been demonstrated for silicon bipolar [19]. In order to minimize channeling of the ions, the implanted wafer is generally inclined by 7 degrees to the beam axis. The combination of the topography and the 7 degree off-axis implant results in an offset of the base profile with respect to the emitter opening, called the "shadowing effect"(see figure 7) [49]. For example, a $0.5 \mu \mathrm{m}$ high stack will give raise to an $61 \mathrm{~nm}$ offset. The offset reduces the doping in the intrinsic-extrinsic base overlap region at one of the emitter edges and enhances the doping at the other. Hence, while one edge becomes more vulnerable to perimeter punchthrough, the other will suffer from more severe perimeter tunneling. Also, the shadowing effect will depend on the transistor orientation, causing orientation-dependent perimeter punchthrough and orientation-dependent perimeter tunneling.

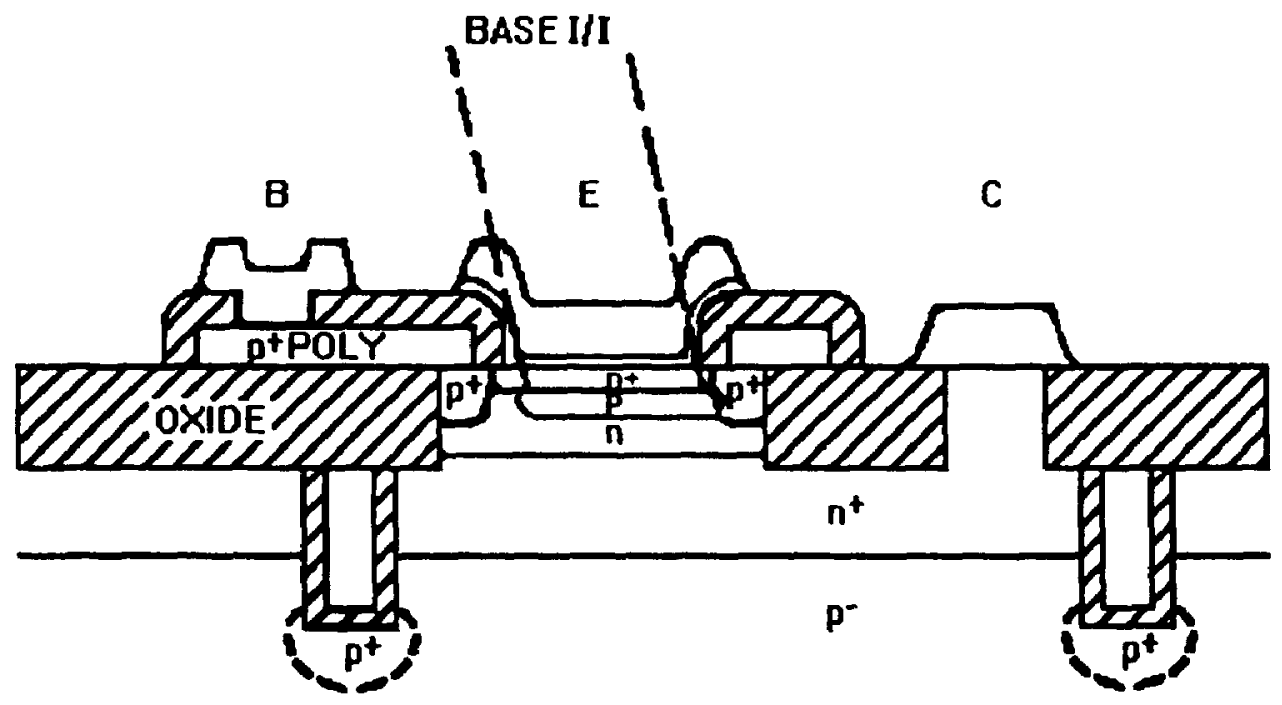

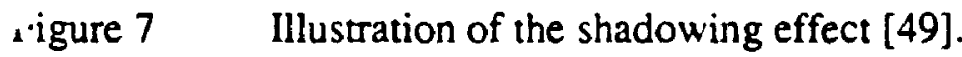




\subsection{Effect of Etch Damage in Double-Poly Bipolar}

One important feature particular to self-aligned double-poly bipolar when compared to conventional single poly bipolar is increased exposure of the intrinsic region of the transistor to reactive ion etching. The silicon crystal in the intrinsic region of both non-self-aligned and selfaligned bipolars is exposed to oxide overetch. The intrinsic region of a double-poly bipolar is also exposed to dry etching of polysilicon, generally through the base poly etch.

Damage to the Si crystal surface due to plasma etching has been studied by a number of investigators. Gate oxide integrity of MOS devices has received considerable attention [50,51,52]. Si surface damage has been characterized by several techniques. Use of physical characteriza.ion techniques, such as Secondary Ion Mass Spectroscopy (SIMS), Thermal Wave Modulated Reflectance (TWMR), X-ray Photoelectron Spectroscopy (XPS), Photoluminescence, Auger and Transmission Electron Microscopy (TEM), have been reported [51,52,53,54,55]. I-V electrical characteristics of Schottky-diodes are widely used $[52,53,56]$. These techniques allowed categorization of plasma etch damage; metallic contamination, polymer deposition, crystal damage due to energetic ion bombardment were reported.

The effect of reactive ion etching to form the emitter opening of non-self-aligned poly emit.er bipolars has been investigated. Misra et al., from the University of Waterloo, compared the DC electrical characteristics of non-self-aligned bipolar transistors produced by wet etching or RIE etching [57]. For transistors with no oxide intentionally left prior to emitter poly deposition, there were no differences in the electrical characteristics.

Misra et al.'s conclusion that dry etching damaje has no undesirable effect on electrical characteristics of poly contacted emitter transistors can not be directly extended to the case of a double-poly bipolar. One can expect the damage to the silicon surface of a double-poly device to 
be more important than the damage to a non-self-aligned bipolar because of exposure to an $\mathrm{Si}$ etch, as mentioned previously. Polysilicon etches could produce more surface damage than oxide etches. Yamaguchi and Yuzuriha of Tektronix investigated the gate oxide breakdown voltage of MOS transistors in a BiCMOS technology which incorporated a double-poly bipolar transistor $[23,24]$. In the initıal Tektronix process, the Si in the device wells of the MOS transistors was exposed to the base poly plasma etch. The second poly film was used not only as the emitter poly but also for the gate electrode of the $n$ - and p-channel MOS devices. A negative effect of base-poly etch on the gate oxide breakdown distribution was observed. But, the double-poly sidewall spacer oxide etch did not result in a noticeable difference in the gate oxide breakdown occurrence.

It is known that two industrial concerns which developed the double-poly structure, Hitachi and IBM, both had difficulties with etch damages created by RIE patterning of the base electrode. At a seminar, presented at Northem Telecom Electronics, K. Washio of Hitachi Central Research Labs noted that Hitachi had encountered much difficulty in implementing double-poly bipolar when only dry etching was used to remove the base poly and open the emitter region [58].

In the IBM process, the exposure of the intrinsic single-crystal Si to etch damage is minimized by completing the base electrode patteming by wet etching (see section 2.1.2). Li et al. from IBM mention: "The process of combining partially RIE and wet etching on polysilicon layer at the emitter opening step can avoid RIE-induced silicon surface damage. Hence, the integrity of silicon device area can be preserved for better control in subsequent base and emitter formation" [20]. But, they do not present any data to show an improvement of the transistor's characteristics. One developing a double-poly bipolar technology wants to know how advantageous the addition of wet etching is as it requires extra processing complexity as in-situ doped silicon deposition. timed partial dry etch of the base poly and wet etching with the HNA solution are required. 
One has also to note that wet etching affects the controllability of the base electrode inner opening dimension. IBM reported a wide variation in base-emitter leakage (up to 4 order of magnitude) for devices with apparently identical process conditions [45]. They believe the spread to be due to the variation in the sidewall thickness caused by the lateral undercut in the $\mathrm{p}^{+}$poly during the HNA wet etch step.

In most of the reported double-poly bipolar processes, including IBM's, a thin oxide is grown after the base electrode etch. One might speculate that this high temperature oxidation step helps repair silicon surface damage in the intrinsic area of the transistor. Burghartz et al., of IBM, who developed a double-poly bipolar using a selective epitaxial base, mentioned in the process flow description that: "A sacrificial oxide was grown thermally to remove RIE damage before epitaxy" [59]. But, here again, no data was presented.

\subsection{Chapter Conclusion}

Double-poly bipolar transistors have been reported by a number of investigators to provide imprc .ed electrical performance compared to conventional, non-self-aligned devices. However, it is known that the double-poly structure increases exposure of the silicon crystal in the intrinsic base region to reactive ion etching (RIE). RIE introduces surface damage which can adversely affect junction electrical characteristics. This problem has been recognized is the literature, but very little information has been presented regarding its importance.

Study of the electrical effect of etch damage on diodes formed by diffusion of arsenic from a polysilicon layer was felt to be of interest to gain insight into its consequences for the double-poly bipolar structure, and as a potential damage characterization technique. A sacrificial amorphous-Si layer was deposited on the diode surface, and then removed by RIE prior to emitter formation. 
Characterization of etch damage with a poly-Si diode could provide some advantages over the widely used Schottky-diode-technique because of its greater energy barrier height. 


\subsection{EXPERIMENTAL - DIODES}

Diodes formed by diffusion of arsenic from a polysilicon layer were fabricated to investigate etch damage effects on junction electrical characteristics. Section 3.1 discusses the basic process flow for diode fabrication and the different processing splits used to selectively include a sacrificial Si layer and a thermal oxidation step after the sacrificial silicon layer etch. I-V electrical characteristics of the diodes are presented in section 3.2. A discussion on the experiment and a chapter conclusion are presented in section 3.3 and 3.4, respectively. The experimental work presented in these sections was carried out at Northern Telecom Electronics.

\subsection{Diode Fabrication}

The main fabrication steps for the diodes are shown schematically in figure 8 . The substrates used were p-type (100) silicon wafers of $13-17 \mathrm{ohm} * \mathrm{~cm}$ resistivity. A blanket boron implant $\left(2.1 \times 10^{12} \mathrm{~cm}^{-2}, 20 \mathrm{keV}\right)$ and a long drive-in ( 2 hours 30 minutes at $1000^{\circ} \mathrm{C}$ ) were used to raise the surface doping concentration to about $10^{16} \mathrm{~cm}^{-3}$. To provide diode-to-diode isolation, a Poly Buffered Locos scheme was used. A $40 \mathrm{~nm}$ sacrificial oxide was grown in the device wells to passivate the siiicon surface. The active areas of the diode were defined by photolithography and etching in a $80 \mathrm{~nm}$ CVD oxide. An RCA clean and an HF clean were carried out prior to a $400 \mathrm{~nm}$ amorphous-silicon deposition. The silicon layer was implanted with arsenic $\left(1.5 \times 10^{16} \mathrm{~cm}^{-2}\right.$, $100 \mathrm{keV}$ ) and photolithographically parterned. Following the deposition of a $220 \mathrm{~nm}$ CVD silicon dioxide film, the implanted arsenic impurities were diffused within the silicon film at a temperature of $850^{\circ} \mathrm{C}$ for 50 minutes. The $220 \mathrm{~nm}$ silicon dioxide layer was etched back by using an RIE process to form a sidewall spacer around the recrystallized silicon electrode. A blanket boron implant $\left(3 \times 10^{15} \mathrm{~cm}^{-2}, 5 \mathrm{keV}\right)$ ensured ohmic contact to the substrate. A Rapid Thermal Annealing (RTA) step $\left(1025^{\circ} \mathrm{C} 40\right.$ seconds) activated the implanted arsenic and boron ions. A selfaligned silicide layer, called "salicide", was formed on the silicon area by blanket deposition of 


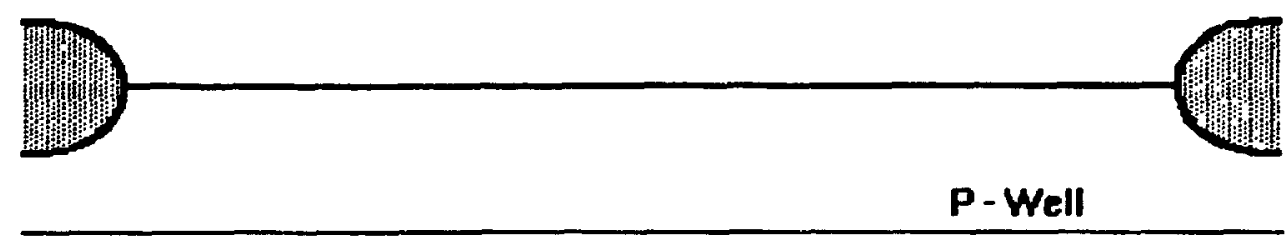

(a)

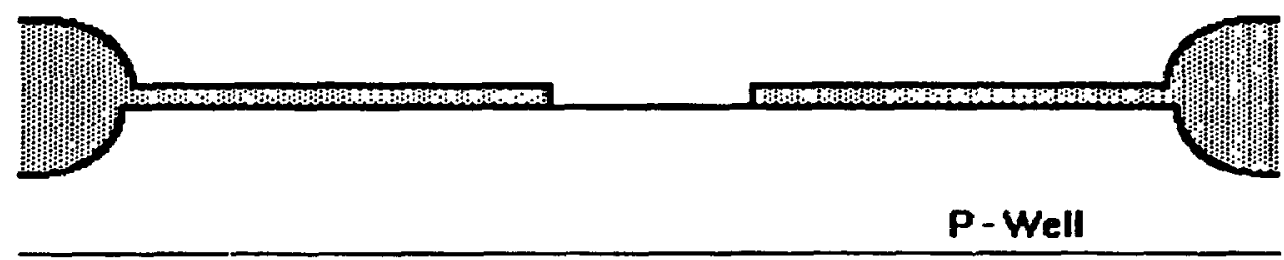

(b)

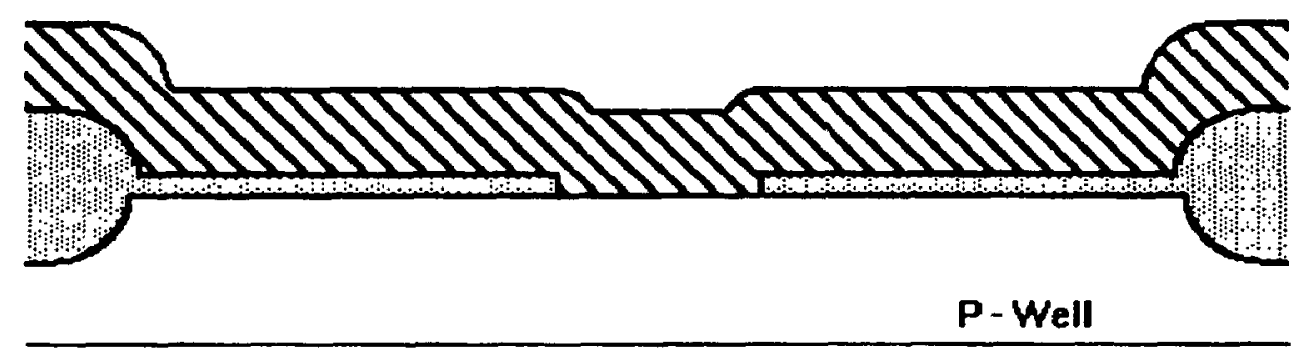

(c)

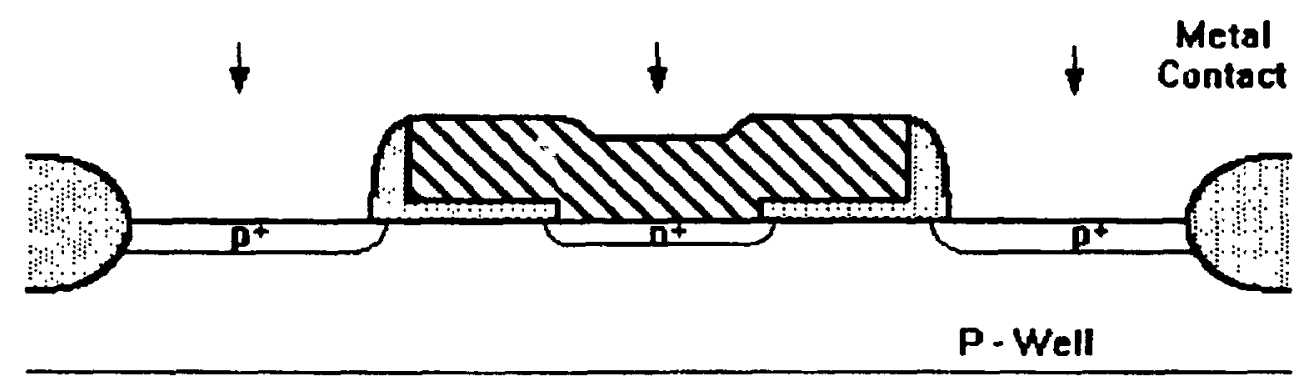

(d)

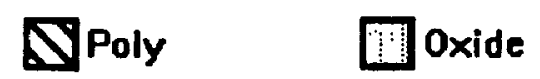

Figure 8 Diode fabrication steps. 
titanium followed by a short anneal and a blanket etch back of the non-silicided titanium. A dielectric passivation layer was then deposited and tungsten plugs and aluminium interconnect formed.

In order to investigate the effect of RIE on polysilicon diode characteristics, different processivas modifications were added to the basic flow described above (these processing splits are detailed in table 1). The active areas of the diodes were opened by two different process sequences: Group 1 by using conventional wet etching and Group 2 by using RIE. For most of the wafers of those two groups, a sacrificial $400 \mathrm{~nm}$ amorphous-silicon layer was added to the flow. This sacrificial silicon layer was included to investigate the effect of silicon dry etching. The layer was inserted at two different steps in the flow: Group A - the sacrificial layer was deposited and etched back before the $80 \mathrm{~nm}$ CVD oxide deposition (before the split of Group ) and 2), Group B - the sacrificial layer was inserted after the definition of the active part of the device. Thereby, for Group A the

\begin{tabular}{|c|c|c|c|c|c|c|}
\hline Wafer \# & \multicolumn{2}{|c|}{ Group } & \multicolumn{2}{c|}{ Group } & overetch & Oxidation \\
& A & B & 1 & 2 & $(\%)$ & \\
\hline 1 & & & $\sqrt{ }$ & & & \\
\hline 2 & & & $\sqrt{ }$ & & & $30 \mathrm{~min}, 900^{\circ} \mathrm{C}, \mathrm{HCl} / \mathrm{O}_{2}$ \\
\hline 3 & $\sqrt{ }$ & & $\sqrt{ }$ & & 30 & \\
\hline 4 & $\sqrt{ }$ & & $\sqrt{ }$ & & 30 & \\
\hline 5 & $\sqrt{ }$ & & $\sqrt{ }$ & & 60 & \\
\hline 6 & $\sqrt{ }$ & & $\sqrt{ }$ & & 30 & $30 \mathrm{~min}, 900^{\circ} \mathrm{C}, \mathrm{HCl} / \mathrm{O}_{2}$ \\
\hline 7 & $\sqrt{ }$ & & $\sqrt{ }$ & & 30 & $50 \mathrm{~min}, 800^{\circ} \mathrm{C}, \mathrm{O}_{2}$ \\
\hline 8 & $\sqrt{ }$ & & $\sqrt{ }$ & & 60 & $50 \mathrm{~min}, 800^{\circ} \mathrm{C}, \mathrm{O}_{2}$ \\
\hline 9 & & & & $\sqrt{ }$ & & \\
\hline 10 & & & & $\sqrt{ }$ & & \\
\hline 11 & & $\sqrt{ }$ & & $\sqrt{ }$ & 30 & \\
\hline 12 & & $\sqrt{ }$ & & $\sqrt{ }$ & 30 & \\
\hline 13 & & $\sqrt{ }$ & & $\sqrt{ }$ & 60 & \\
\hline 15 & & $\sqrt{ }$ & & $\sqrt{ }$ & 30 & $30 \mathrm{~min}, 900^{\circ} \mathrm{C}, \mathrm{HCl} / \mathrm{O}_{2}$ \\
\hline 16 & & $\sqrt{ }$ & & $\sqrt{ }$ & 30 & $50 \mathrm{~min}, 800^{\circ} \mathrm{C}, \mathrm{O}_{2}$ \\
\hline 17 & & $\sqrt{ }$ & & $\sqrt{ }$ & 60 & $50 \mathrm{~min}, 800^{\circ} \mathrm{C}, \mathrm{O}_{2}$ \\
\hline
\end{tabular}

Table 1 Processing splits of fabricated diodes. 
complete device well area was exposed to the sacrificial silicon etch in contrast to Group B, for which only the active part of the device was exposed. To remove the sacrificial silicon layer a $\mathrm{Cl}_{2}$ etch is performed in a Lam Research Corporation Rainbow etcher. The main etch (the etch used up to end-point detection) is performed at $450 \mathrm{~W}$ with a total pressure of $650 \mathrm{mT}$ Trr and a partial pressure of $\mathrm{Cl}_{2}$ of $433 \mathrm{mTorr}$. The overetch is performed with power, total pressure and partial pressure of $\mathrm{Cl}_{2}$ reduced to $175 \mathrm{~W}, 150 \mathrm{mTor}$ and $64 \mathrm{mTorr}$, respectively. Light emission spectroscopy is used to detect the etch end-point, which in this case is defined to be reached when the silicon is cleared from the oxide isolation.

To investigate the potential of a thermal oxidation step to anneal etch damage effects, selected wafers received either a 50 minute $800^{\circ} \mathrm{C}$ or a 30 minute $900^{\circ} \mathrm{C}$ dry oxidation giving respectively a $5.5 \mathrm{~nm}$ and a $15.5 \mathrm{~nm}$ thick layer. For the wafers from Group $A$ that received the thermal oxide, it was left on the wafer and covered with the $80 \mathrm{~nm}$ CVD oxide. For the wafers from Group B that received the thermal oxide, this oxide was chemically etched back. All the wafers from Group B had a 30 minute $900^{\circ} \mathrm{C} \mathrm{HCl} / \mathrm{O}_{2}$ oxidation giving a $15.5 \mathrm{~nm}$ thick layer before the $80 \mathrm{~nm} \mathrm{CVD}$ oxide deposition.

\subsection{Diode Electrical Characteristics}

I-V characteristics of the diodes were recorded in both forward and reverse mode operation using an HP4145 Semiconductor Parameter Analyzer. A minimum of ten diodes with two active regions of $0.8 \times 10 \mu \mathrm{m}^{2}$ were measured from each wafer to extract typical characteristics. Diodes of sizes from $0.8 \times 4 \mu \mathrm{m}^{2}$ to $1.6 \times 10 \mu \mathrm{m}^{2}$ were also measured to ensure similar characteristics.

Surprisingly, all diodes showed the same I-V characteristics in a very reproducible manner from wafer to wafer as well as within a wafer. No difference in the electrical characteristics were revealed between the different processing splits. The I-V characteristics of a typical 
$2 \times(0.8 \times 10) \mu \mathrm{m}^{2}$ diode are presented in figure 9. The diode current exhibits almost ideal I.V characteristics, i.e. $I=C \exp (q V / n k T)$ with $n=1.0$.

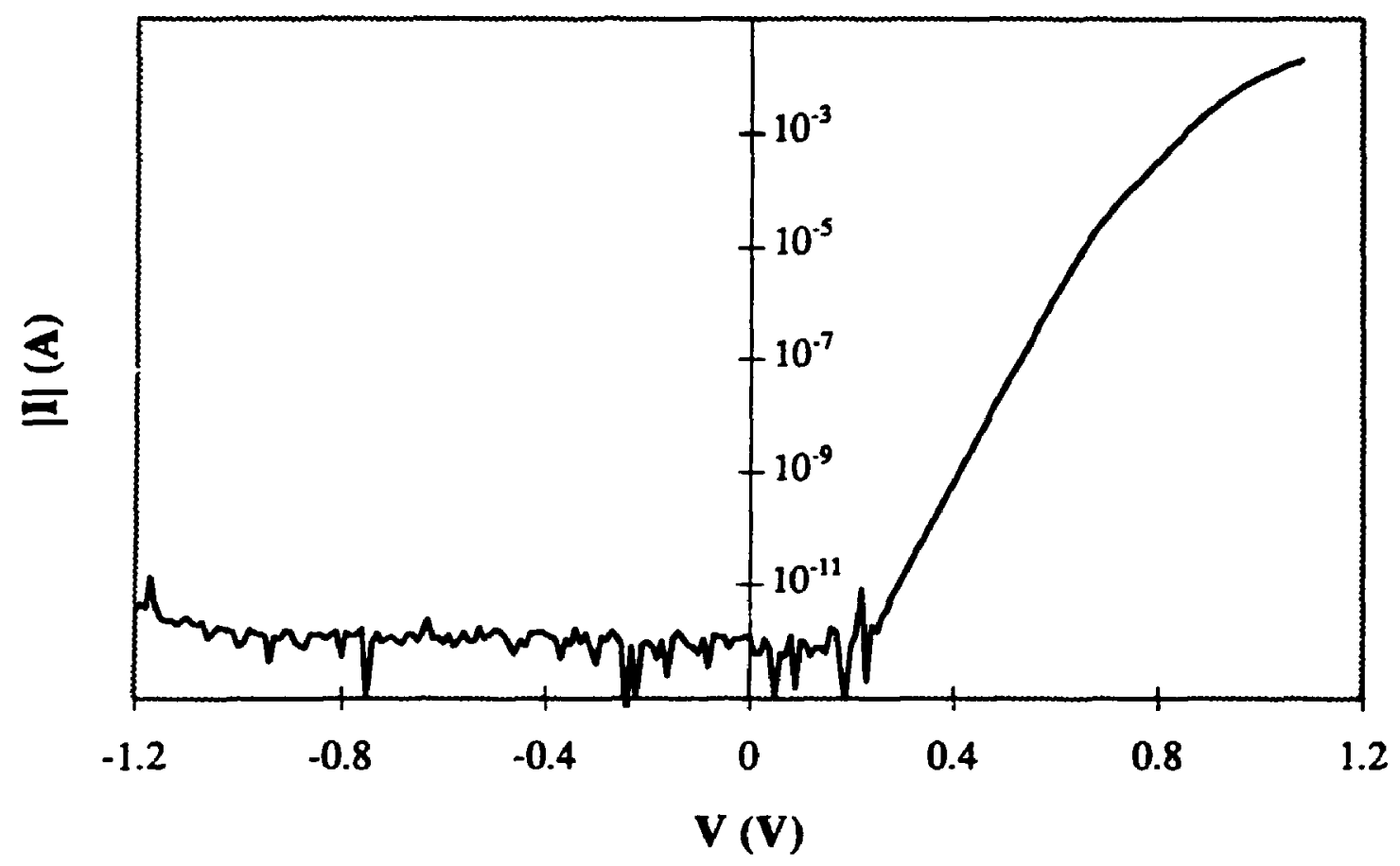

Figure 9 I-V characteristics of a typical $2 \times(0.8 \times 10) \mu \mathrm{m}^{2}$ diode.

\subsection{Diodes - Discussion}

One has to conclude, from these results, that damage caused to the diodes during the etching of the sacrificial polysilicon layer had no noticeable effect on the electrical characteristics. It is also observed comparing the results for wafers 1,2,9 and 10 (wafers processed without the sacrificial Si layer) that dry oxide etching did not have any significant effect on the I-V characteristics compared to samples processed by HF etching confirming Misra et al.'s conclusion. It is worth nothing that diodes with no thermal oxide under the $80 \mathrm{~nm}$ CVD oxide showed similar electrical characteristics to the diodes with a thermal oxide. Passivation from the CVD oxide was therefore sufficient to prevent edge leakage. 


\subsection{Chapter Conclusion}

The electrical effect of etch damage on diodes formed by diffusion of arsenic from a polysilicon layer was invesigated. A sacrificial amorphous-Si layer was deposited on the diode surface, and then removed by RIE prior to emitter formation. Surprisingly the diode characteristics seemed insensitive to this etch. This result suggests that dry etching of a base electrode directly deposited on the crystalline substrate would probably not affect the base-emitter junction current-voltage characteristics. One has to note that measured plasma contamination is know to depend on many etch parameters, including plasma potential and its uniformity, electron temperature, plasma density uniformity, gas chemistry, reactor design and materials [51]. It is also known that etch damage can be removed to some degree by annealing.

Implementation of a double-poly bipolar process by depositing the base poly layer directly on the crystalline substrate and completely patterning it by dry etching was felt to be an interesting approach because of its relative simplicity. To minize the risk that the transisto would be affected by etch damage, the base poly would be pattemed with the same etch parameters that was used for the removal of the sacrificial silicon layer in the diode experiment. Also, the furnace and rapid thermal anneals used in the diode experiment would be incorporated in the double-poly bipolar process flow. 


\subsection{FABRICATION AND CHARACTERIZATION OF DOUBLE-POLY BIPOLAR TRANSISTORS}

This chapter discusses the development of a complete fabrication process for double-poly bipolar transistors based on the results of the etching experiments presented in chapter 3 . The starting point for the development of the process was an existing conventional single-poly bipolar flow incorporated in a BiCMOS technology at Northem Telecom. Section 4.1 describes how the process flow used here was chosen by comparing the approaches to double-poly BJT technology already reported in the literature (these were reviewed in section 2.1 ). The process flow and the mask set used to implement the transistors are described in section 4.2. Section 4.3 discusses the development of the new processing techniques required. Section 4.4.1 discusses the most successful implementation of the process during this study, while section 4.4.2 presents the results of the electrical characterization of the transistors produced. A chapter conclusion is presented in section 4.5. The experimental work presented in these sections was carried out at Northern Telecom Electronics.

\subsection{Processing Approach Chosen}

In section 2.1 , the many processing approaches which have been taken to form a self-aligned double-poly bipolar transistor were reviewed. Each one of the approaches presented required the use of one or more special processing techniques. The NTT approach requires sideways etching of underlying passivation to the base electrode, poly deposition and etch back to form the contact between the crystalline Si and the overhanging poly, and formation of a poly SWS. The IBM approach requires in-situ doped silicon deposition, timed partial dry etch of the base poly and final wet etching with the HNA solution. In the Tektronix approach, the intrinsic base and emitter are formed by double-diffusion of boron and arsenic through a second polysilicon film (Borosenic-Poly eminer-base process). 
None of these techniques were in use at Northem Telecom when this project began, so a simpler approach was used. It was decided to deposit the base poly as an undoped Si layer directly on the Si substrate and subsequently dope it by ion implantation. The base electrode would be completely patterned by dry etching. The intrinsic base would be implanted before SWS formation.

\subsection{Experimental Procedure}

For processing investigation purposes, a mask to pattern the base poly electrodes was added to a set of masks originally intended to produce non-self-aligned bipolar transistors to form a structure similar to a double-poly bipolar. As in the case of a conventional bipolar transistor, the base metal contact is placed over the large extrinsic base area (figure 10e). Although one would expect this transistor to show reduced AC electrical performance compared to a typical double-poly bipolar, their processing requirements are very similar. The mask set contains transistors with $10 \mu \mathrm{m}$ long emitter opening and width varying from $0.6 \mu \mathrm{m}$ to $1.6 \mu \mathrm{m}$ as well as transistors with $0.8 \mu \mathrm{m}$ wide emitter opening and area varying from $3.2 \mu \mathrm{m}^{2}$ to $48 \mu \mathrm{m}^{2}$. Several of the electrical characteristics shown are from a transistor with two emitter stripes of $0.8 \times 10 \mu \mathrm{m}^{2}$ identified as

$2 \times(0.8 \times 10) \mu \mathrm{m}^{2}$. Note that the dimensions given above are the mask dimensions for the emitter opening: not the actual emitter size as the laster is smaller due to the presence of the SWS.

A process description follows; a pictorial description taking into account the mask set described above can also be found in figure 10. After isolation which is based on LOCOS, a Si layer is deposited and implanted with boron. Silicon dioxide is then deposited (figure 10a). The base electrode is defined in this sandwich structure by photolithography and etching. A thin thermal oxide could be grown. The intrinsic base is formed by ion implantation (figure 10b). A silicon dioxide layer is deposited (figure 10c) and etched back by RIE to form a sidewall spacer around the base electrode (figure 10d). Following an RCA clean and a HF silicon surface clean, an amorphous-Si film is deposited, implanted with arsenic and pattemed to form the eminter electrode. 


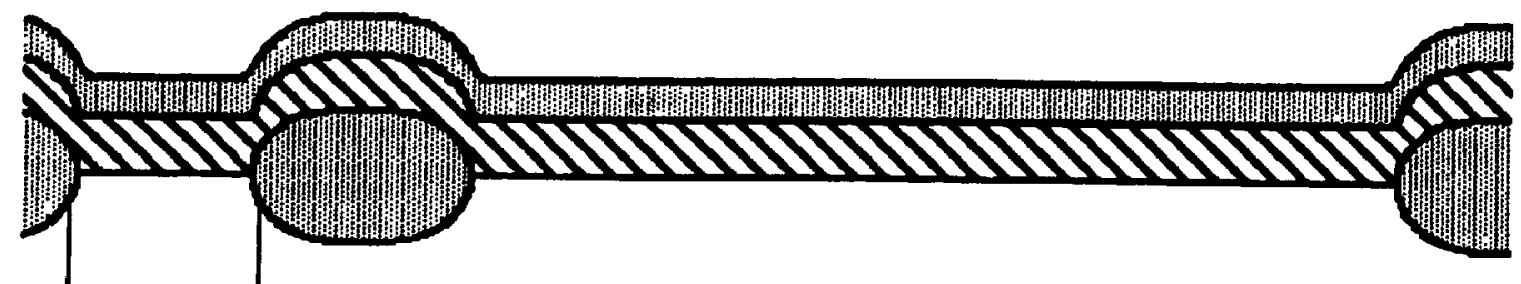

(a)

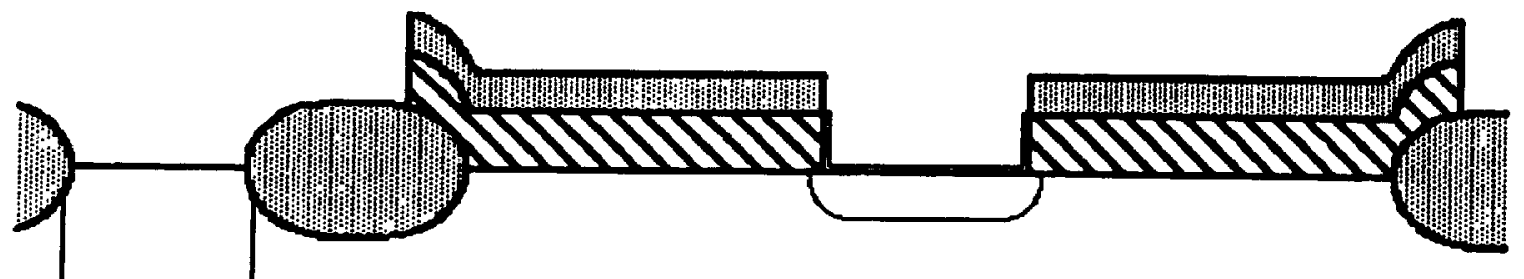

(b)

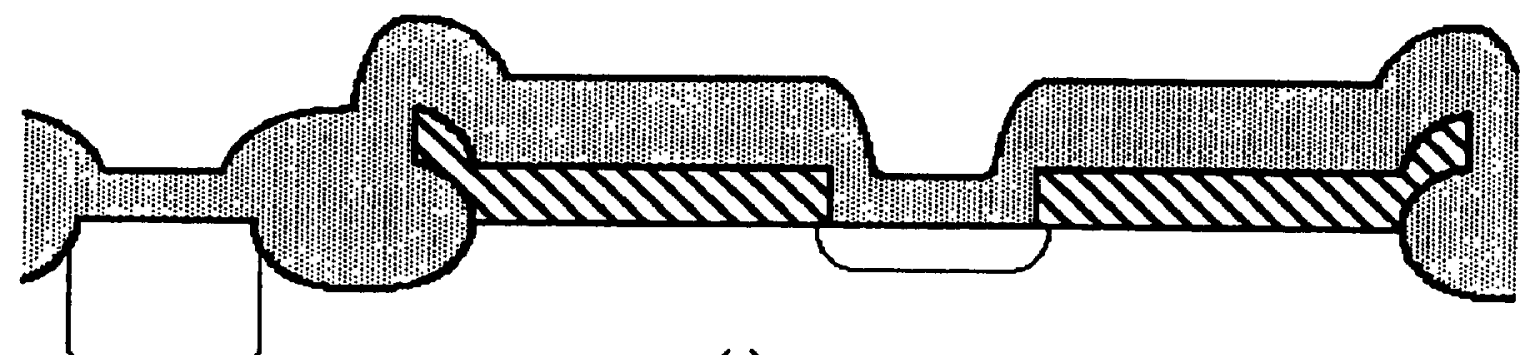

(c)
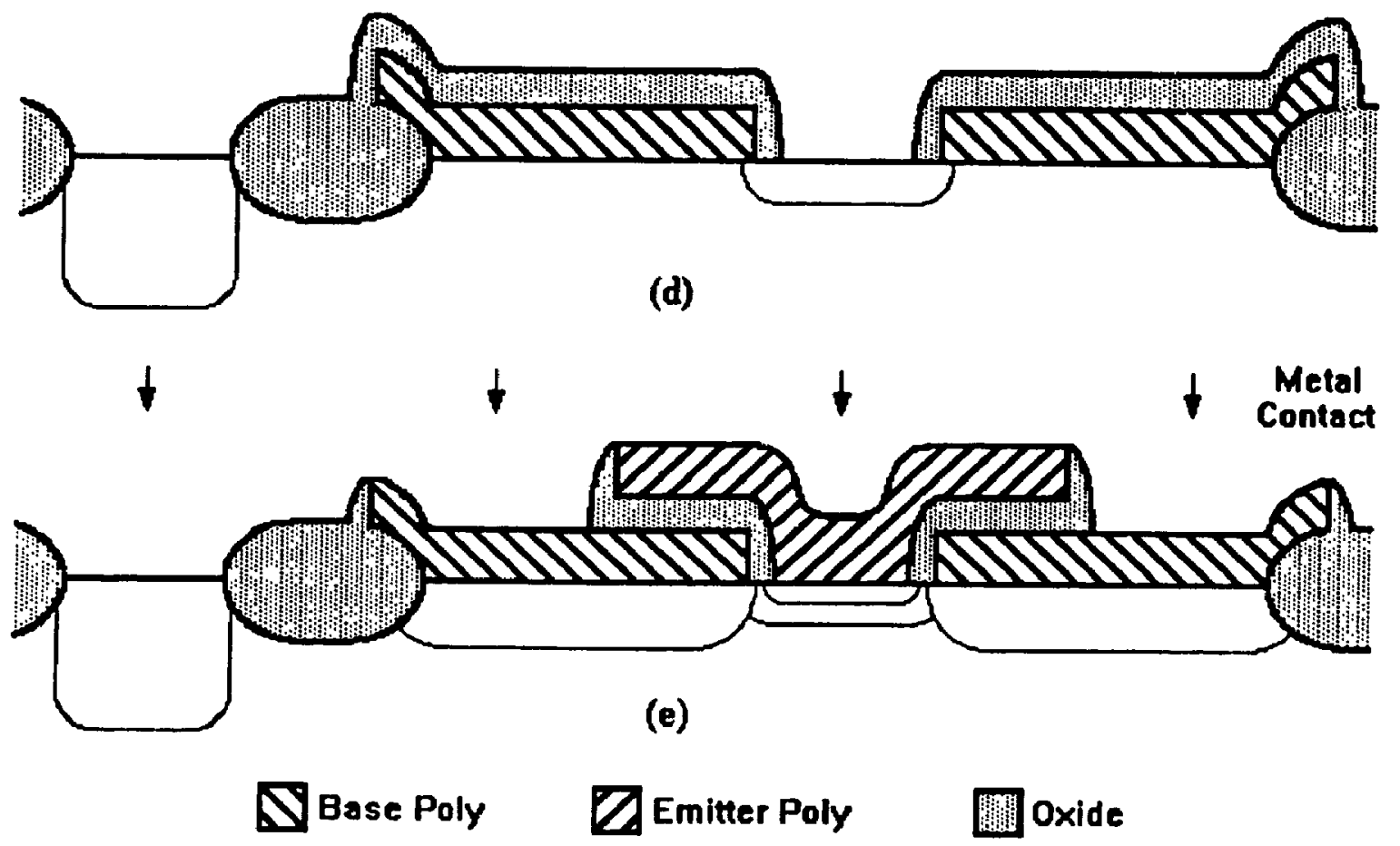

Figure 10 Process flow of the fabricated double-poly bipolar transistor. 
A second SWS is formed around the emitter electrode and the arsenic is driven-in. After a thin oxide deposion, a RTA step activated the implanted arsenic and boron ions (figure 10e). Salicide and metal contacts were then formed.

\subsection{Preliminary Work}

Although care was taken to choose a simple processing approach, several processing techniques had to be developed: diffusion of boron from the base poly layer, emitter opening in a Si layer and formation of the poly to poly isolation. The requirements that must be met by these techniques and processing information gained from shor experiments and unsuccessful electrical batches, are described in section 4.3.1 to 4.3.3 (The term "electrical" batch is used in opposition to "mechanical" batch which refers to a batch processed with the intent of gaining only structural information). The electrical batches discussed in these sections suffered from insufficient emitter poly to base poly isolation causing poor electrical characteristics (section 4.3.3). Also, information gained from these batches on processing problems associated with the double-poly structure, field oxide loss and transistor topography are discussed in section 4.3.4 and 4.3.5.

\subsubsection{Base Poly Material and Diffusion Characteristics}

The first poly layer of a double-poly BJT serves both as a contact to the base and as a mechanical suppor, allowing self-alignment of the emitter to the base electrode. Recrystallized amorphous-Si as the base electrode material has the advantage that there is no channelling effect during the base poly implant, in contrast to the situation encountered when the base electrode is deposited in the polycrystalline phase. This could allow a decrease in the base poly thickness and thereby reduce the overall topography of the transistor. The heavy extrinsic base implant must not penetrate the base poly, since this would modify the surface doping level in the intrinsic area of the transistor (see section 4.3.5). 
But, an important consideration when choosing the deposition phase of the base contact polysilicon layer is its characteristic as a diffusion source, since the extrinsic base of the doublepoly bipolar is formed by outdiffusion of boron from this first poly layer. The boron diffusion must be sufficient to assure a good contact to the intrinsic base, to avoid high base resistance and perimeter punchthrough. However the boron must not diffuse laterally too close to the emitter, since this would cause large emitter-base leakage (see section 2.2.1), for the base poly and the emitter poly are separated only by a SWS. Although use of a link implant gives some additional process margin, tuning of the boron diffusion profile from the base poly is required. Dopant diffusion characteristics of poly layers depend strongly on processing conditions and, in particular, the grain structure in the poly. For this reason, the diffusion profile can not be determined with confidence by simulation or from the literature.

A preliminary experiment was therefore performed to compare the characteristics of recrystallized amorphous-Si and material deposited in the polycrystalline phase as a boron diffusion source.

A $325 \mathrm{~nm}$ thick layer of amorphous-Si or polysilicon was deposited on blanket (100) $13-15 \mathrm{ohm} * \mathrm{~cm}$ p-type wafers. Boron doses from $4 \times 10^{15} \mathrm{~cm}^{-2}$ to $1.5 \times 10^{16} \mathrm{~cm}^{-2}$ were implanted with an energy of 10 to $20 \mathrm{keV}$. A $220 \mathrm{~nm}$ LPCVD capping oxide overlayer was then deposited to prevent boron loss during annealing. Samples were fumace annealed at $850^{\circ} \mathrm{C}$ for various times and then given a $1025^{\circ} \mathrm{C} 40$ seconds RTA. The capping oxide was then etched away in HF. Boron and oxygen profiles were characterized by SIMS using cesium and oxygen as sputtering ions.

In figure 11, boron profiles diffused from recrystallized amorphous-Si and $\mathrm{Si}$ deposited in the polycrystalline phase are compared. Both samples were doped at $7 \times 10^{15} \mathrm{~cm}^{-2}$ and furnace annealed for 50 minutes. The boron distribution in the silicon layers is fairly flat as one could 
expect. A "bump" in the boron profile at about $40 \mathrm{~nm}$ depth in silicon for the recrystallized amorphous-Si layer indicates that not all the implanted ions were redistributed. The small bump in the boron profile at about $330 \mathrm{~nm}$ corresponds to an oxygen peak and to the silicon crystal interface (the oxygen concentration was divided by 1000 ). The bump is due to boron segregation. The boron concentration reduces quickly in the crystalline Si substrate due to the lower diffusion rate there. The profile is shallower for the boron diffused from the recrystallized material. Table 2 shows the measured depth in crystalline silicon of the $1 \times 10^{19} \mathrm{~cm}^{-3}$ and $1 \times 10^{18} \mathrm{~cm}^{-3}$ boron concentration level for the different processing conditions. Most profiles were obts" ied using $\mathrm{Cs}^{+}$ as the sputtering ion although $\mathrm{O}_{2}{ }^{+}$ions were used on samples 3 and 5 to confirm the $\mathrm{Cs}^{+}$SIMS measurements. The measured depth difference obtained using the two different sputtering ions are somewhat large (10 $\mathrm{nm}$ to $23 \mathrm{~nm})$.

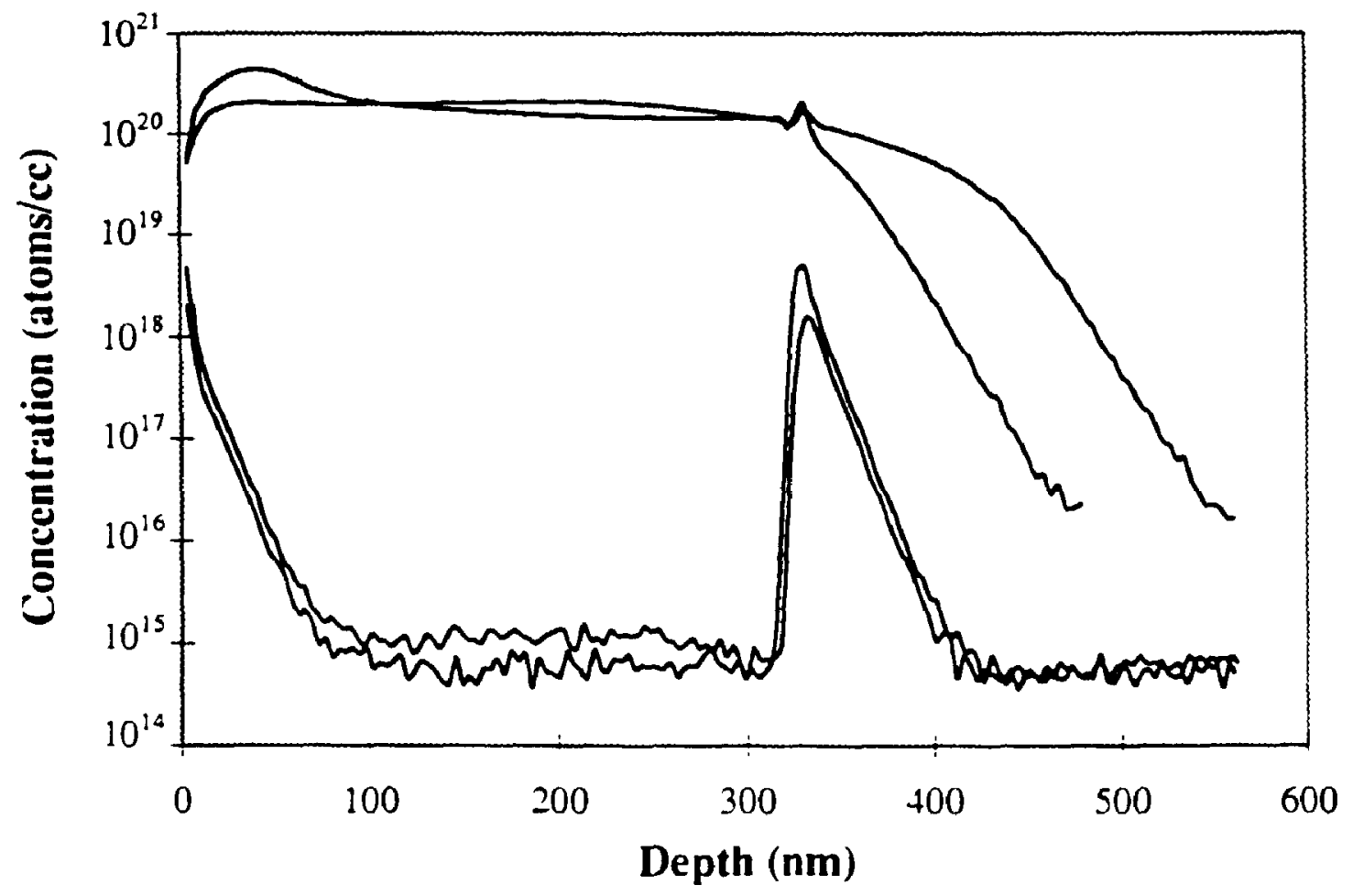

Figure 11 Boron and oxygen profiles diffused from recrystallized amorphous-Si and Si deposited in the polycrystalline phase (the oxygen concentration was divided by 1000 ). 


\begin{tabular}{|c|c|c|c|c|c|c|c|c|}
\hline & \multicolumn{4}{|c|}{ Wafers fabrication } & \multicolumn{4}{|c|}{ SIMS measurements } \\
\hline $\begin{array}{l}\text { Sam } \\
\text { ple \# }\end{array}$ & $\begin{array}{c}\mathrm{Si} \\
\text { Phase }\end{array}$ & $\begin{array}{c}\text { Implant } \\
\text { Energy } \\
(\mathrm{keV})\end{array}$ & $\begin{array}{c}\text { Implanted } \\
\text { Dose } \\
\left(\mathrm{cm}^{-2}\right)\end{array}$ & $\begin{array}{c}\text { Fumace } \\
\text { Anneal } \\
\text { time } \\
\text { (minutes) }\end{array}$ & Vendor & $\begin{array}{l}\text { Sput } \\
\text { tering } \\
\text { Ion }\end{array}$ & $\begin{array}{c}\text { Depth of } \\
1 \times 10^{19} \mathrm{~cm}^{-3} \\
\text { doping level } \\
(\mathrm{nm})\end{array}$ & $\begin{array}{c}\text { Depth of } \\
1 \times 1018 \mathrm{~cm}^{-3} \\
\text { doping level } \\
(\mathrm{nm})\end{array}$ \\
\hline 1 & $\overline{\mathrm{a}-\mathrm{Si}}$ & 20 & $4 \times 10^{15}$ & 50 & 1 & $\mathrm{Cs}_{\mathrm{s}}$ & 34 & 64 \\
\hline 2 & $\overline{a-S i}$ & 20 & $7 \times 10^{15}$ & 50 & 1 & $\mathrm{Cs}^{+}$ & 50 & 82 \\
\hline 3 & $\mathrm{a}-\mathrm{Si}$ & 20 & $7 \times 1015$ & 100 & $\begin{array}{l}1 \\
1\end{array}$ & $\begin{array}{l}\mathrm{Cs}^{+} \\
\mathrm{O}_{7}^{+}\end{array}$ & $\begin{array}{l}53 \\
42\end{array}$ & $\begin{array}{l}86 \\
63\end{array}$ \\
\hline 4 & Poly & 20 & $4 \times 1015$ & 50 & 1 & $\mathrm{Cs}^{+}$ & 92 & 132 \\
\hline 5 & Poly & 20 & $7 \times 1015$ & 50 & $\begin{array}{l}1 \\
1\end{array}$ & $\begin{array}{l}\mathrm{Cs}^{+} \\
\mathrm{O}_{2}^{+}\end{array}$ & $\begin{array}{l}118 \\
108\end{array}$ & $\begin{array}{l}155 \\
139\end{array}$ \\
\hline 6 & Poly & 20 & $7 \times 1015$ & 100 & 1 & Cst & 127 & 174 \\
\hline 7 & $\mathrm{a}-\mathrm{Si}$ & 10 & $7 \times 1015$ & 50 & 2 & $\mathrm{CS}^{+}$ & 53 & 80 \\
\hline 8 & $\mathrm{a}-\mathrm{Si}$ & 10 & $7 \times 1015$ & 200 & 2 & $\mathrm{Cs}^{+}$ & 110 & 150 \\
\hline 9 & $\mathrm{a}-\mathrm{Si}$ & 10 & $1 \times 1016$ & 50 & 2 & $\mathrm{Cs}^{+}$ & 57 & 90 \\
\hline 10 & $\mathrm{a}-\mathrm{Si}$ & 10 & $1 \times 10^{16}$ & 200 & 2 & $\mathrm{Cs}^{+}$ & 98 & 139 \\
\hline 11 & a-Si & 10 & $1.5 \times 1016$ & 50 & 2 & $\mathrm{Cs}^{+}$ & 69 & 101 \\
\hline 12 & $\mathrm{a}-\mathrm{Si}$ & 10 & $1.5 \times 10^{16}$ & 200 & 2 & $\mathrm{Cs}^{+}$ & 107 & 146 \\
\hline
\end{tabular}

Table 2 Measured depth in crystalline silicon of the $1 \times 10^{18} \mathrm{~cm}^{-3}$ and $1 \times 10^{19} \mathrm{~cm}^{-3}$ concentration level for boron diffused from a $\mathrm{Si}$ layer and processed with different conditions.

The implanted boi, $n$ dose has a fairly small effect on the profile depth in the Si crystal. The dose should therefore be chosen mainly to set the base poly resistance (Bron dose effects on thickness uniformity of the salicide layer could be of concern. A dose of $1 \times 10^{16} \mathrm{~cm}^{-2}$ appears a good choice.) The phase of the deposited silicon is found to have an important effect on the boron diffusion; material deposited in the polycrystalline phase gives deeper boron penetration in the crystalline substrate for the same annealing conditions. This is probably due to the smaller grain size of the material deposited in the polycrystalline phase compared to recrystallized amorphous-Si. Table 2 also shows that furnace anneal time can be used to fine tune the boron profile. 


\subsubsection{Base Poly Etch}

For the fabrication approach chosen there is no etch stop for the base electrode patterning; a $\mathrm{Si}$ layer lying directly on the crystalline Si substrate must be removed (see figure 10b). The end-point for this polysilicon etch is detected when the base poly is cleared from the oxide isolation. One consequence is the creation of silicon crystal damage in the intrinsic area of the double-poly transistor (section 2.3). But, the results from the diode experiment (chapter 3.0) confurmed that a good quality base-eminter junction could be obtained with an appropriate choice of plasma etch parameters. A second consequence is silicon loss in the intrinsic area of the transistor. This Si loss changes the distance from the base electrode to the intrinsic base and modifies the optimum extrinsic base diffusion profile. Thereby, the amount of Si loss and its uniformity over a wafer and from wafer to wafer are of concem.

To minize the risk that the transistor is affected by etch damage, it was decided to pattern the base poly layer with the same etch parameters that was used for the removal of the sacrificial silicon layer in the diode experiment; $\mathrm{Cl}_{2}$ etch performed in a Lam Research Corporation Rainbow etcher with the main etch performed at $450 \mathrm{~W}$ with a total pressure of $650 \mathrm{mTorr}$ and a partial pressure of $\mathrm{Cl}_{2}$ of $433 \mathrm{mTorr}$ and, the overetch performed with power, total pressure and partial pressure of $\mathrm{Cl}_{2}$ reduced to $175 \mathrm{~W}, 150 \mathrm{mTorr}$ and $64 \mathrm{mTorr}$, respectively. Light emission spectroscopy is used to detect the etch end-point. Figure 12 is a cross-sectional SEM picrure of the emitter opening of a partially processed double-poly transistor patterned with the poly etch described above with an overetch of a duration of $20 \%$ of the main etch time. (The poly/Si interface can not be seen on this picture). The figure show that the etch is adequate for base poly patteming. Note that the poly "foot" at the perimeter of the etched window affects the subsequent SWS formation step causing the passivation to be thinner at the bottom of the stripe. 


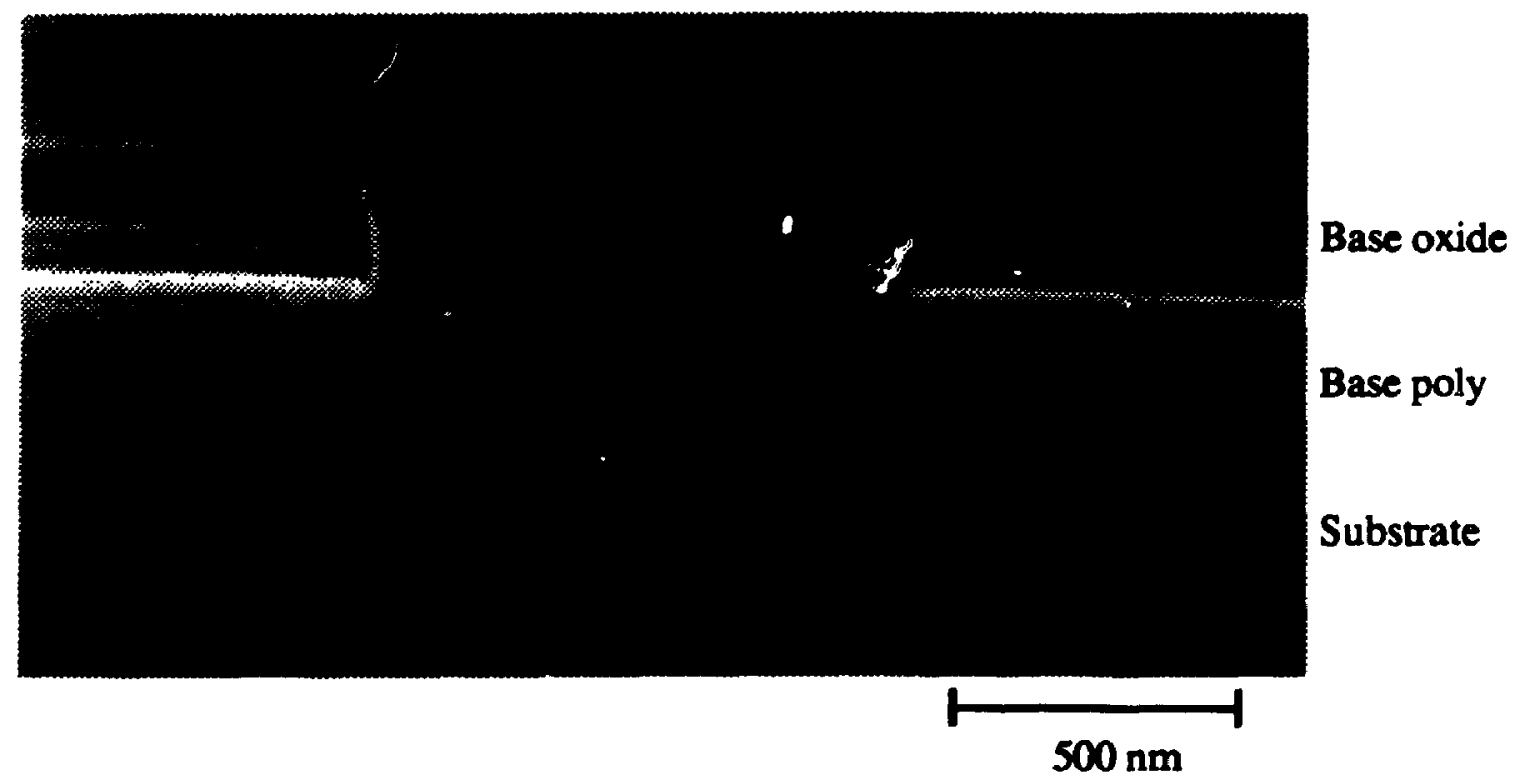

Figure 12 Cross-sectional SEM picture of the emitter opening of a partially processed double-poly transistor patterned with $\mathrm{Cl}_{2}$ poly etch.

As the poly/Si interface could not be seen on the SEM picture in tigure 12, the amount of crystalline Si lost was determined by comparing the emitter window depth in silicon to the amount of Si deposited. The thickness of the latter was $317 \mathrm{~nm}$, determined by examination of a crosssection in a calibrated scanning electron microscope. The overetch was determined to be $23 \mathrm{~nm}$. Etch rate variation across the wafer was measured to be within $5 \%$ by nanospectrometer measurements on a blanket wafer. More information on Si loss during the overetch could be obtained from several other wafers processed at later dates. Figure 13 shows the amount of crystalline Si lost versus overetch time for different wafer series. The results show potential for a small Si loss (in the range of $40 \mathrm{~nm}$ ) while insuring that the poly is removed in the emitter opening of all the transistors on a wafer and from wafer to wafer. Locations on the wafer from which the SEM samples were taken were different and could not be specified as there was no SEM stripe for the double-poly bipolar structure. A SEM suripe for a bipolar transistor would consist of a device several millimeters long with parallel emitter, extrinsic base and collector contact regions. The extreme length of the device makes it relatively straightforward to generate a cross-section by cleaving through a die or a wafer, since even an inaccurately positioned cleave line is very likely to 
intersect such a long structure. Cutting a double-poly transistor by cleaving through an entire wafer width to hit a small array of transistors on one die could be done with some practice.

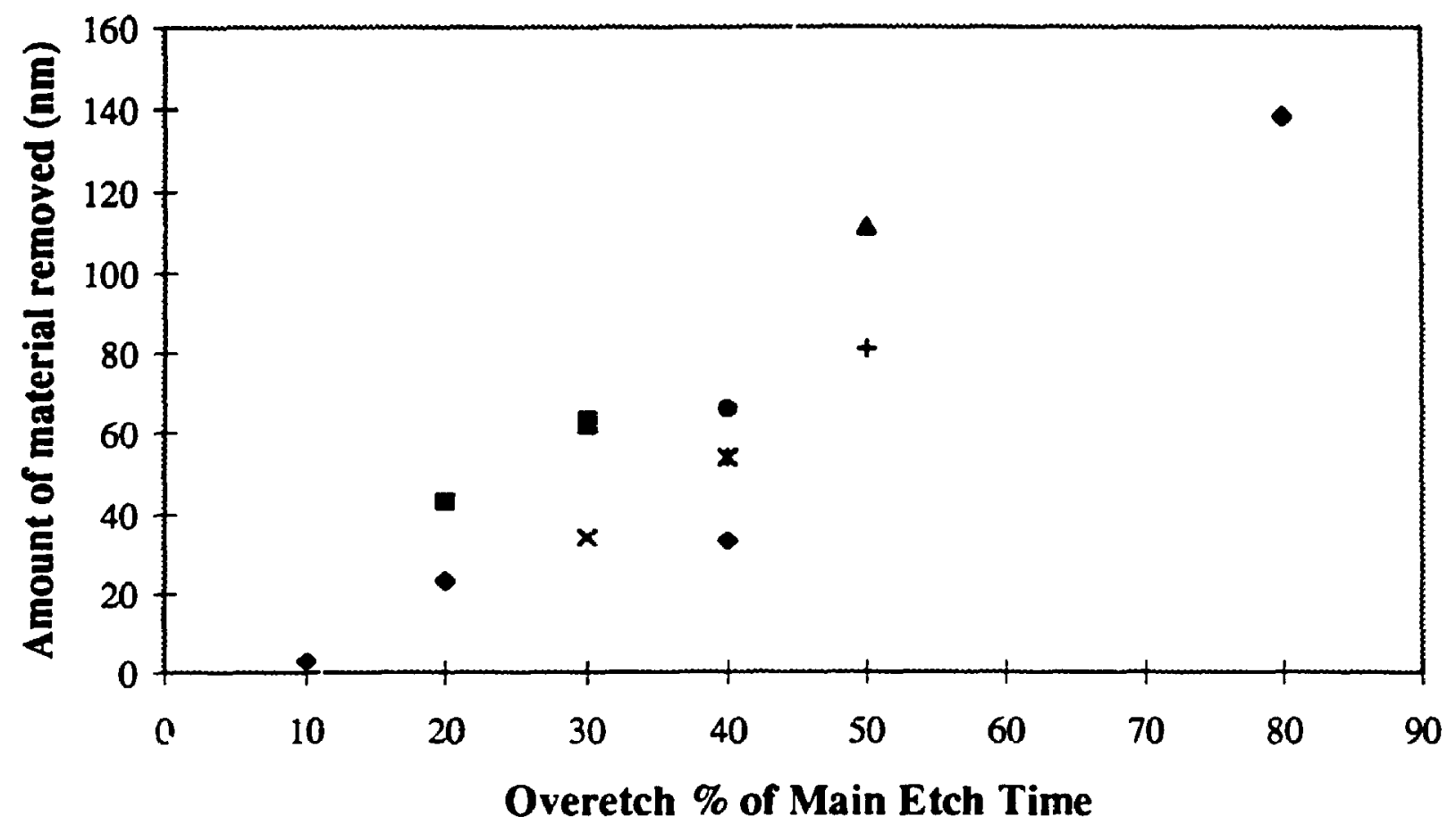

Figure 13 Amount of crystalline Si lost versus overetch time for different wafer series.

A SEM delineation etch that could show the poly/Si interface was felt to be required due to the small amount of crystalline Si loss achieved and to the potential usefulness of such an etch for further development of the double-poly transistor. A few experiments using plasma and wet etching were conducted to find a proper delineation etch. Dipping the SEM sample in a nitric:acetic:HF (3:10:1) solution for about 40 seconds was found to give the best results. Figure 14 is a picture of a cross-sectional SEM sample that received the delineation etch. The sample is from a wafer etched with the $\mathrm{Cl}_{2}$ poly etch with an overetch of a duration of $40 \%$ of the main etch time. The crystalline Si loss measured $66 \mathrm{~nm}$ which correlates well with the other measurements presented in figure 13. The nitric:acetic:HF delineation etch is equally effective on amorphous-Si and polysilicon. 


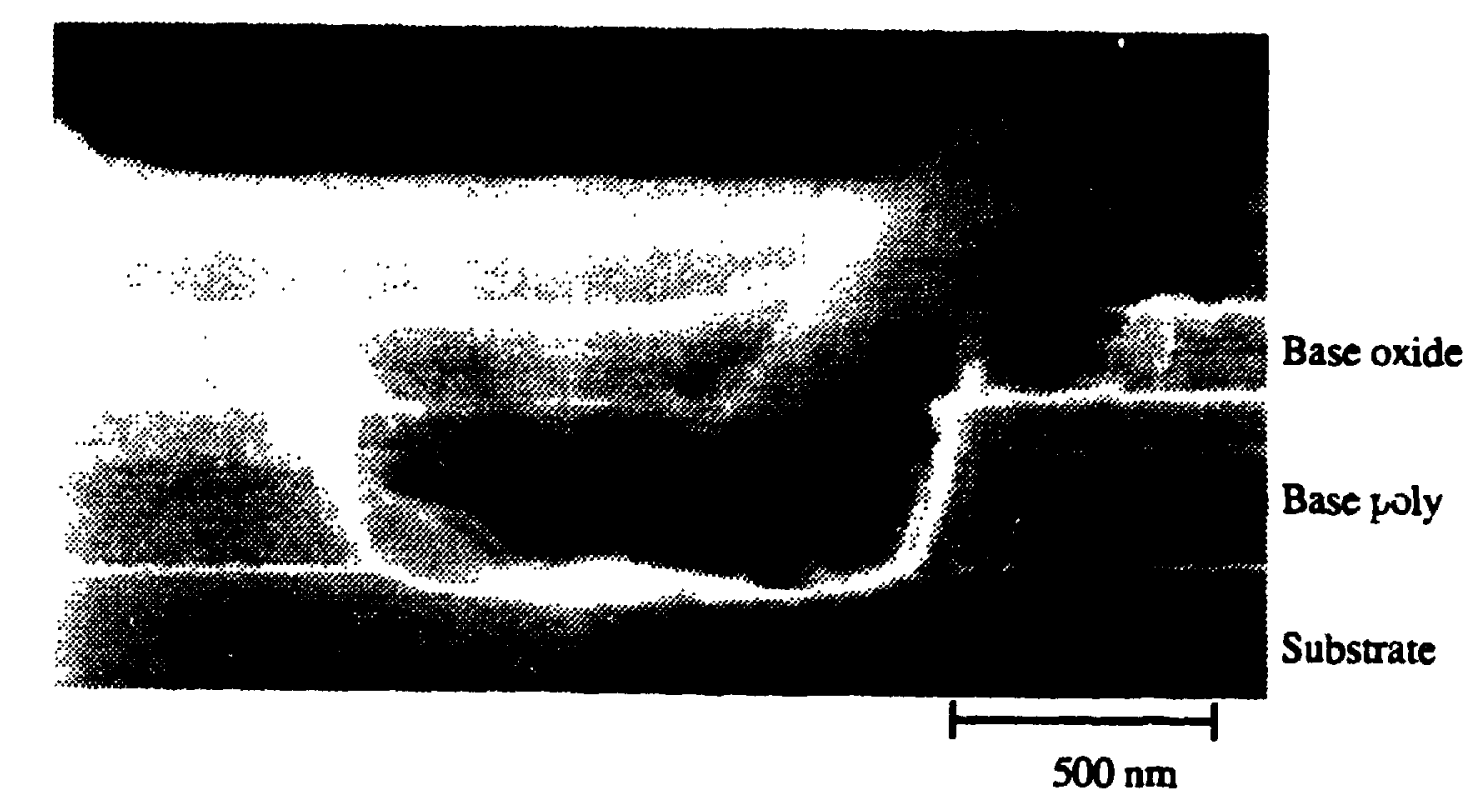

Figure 14 Cross-sectional SEM picture of the emitter opening of a partially processed double-poly transistor patterned with $\mathrm{Cl}_{2}$ poly etch that received the nirric:acetic:HF delineation etch.

\subsubsection{Poly to Poly Isolation - Processing Difficulties and Electrical Consequences}

The self-aligned double-poly bipolar relies on the base oxide and the oxide SWS to isolate the base electrode from the emitter poly contact. Several electrical batches fabricated suffered from insufficient poly to poly isolation. A discussion on the precessing, the SEM cross-sections and the electrical characteristics of the transistors of these batches follows, with paricular regard to poly to poly isolation.

\section{Batch I}

A cross-sectional SEM picture of a double-poly transistor from an early version of the process is presented in figure 15. The picture shows that an overly iong SWS overetch removed most of the $220 \mathrm{~nm}$ base oxide, leading to poor poly to poly isolation. Figure 16, is a Gummel plot of a typical $2 \times(0.8 \times 10) \mu \mathrm{m}^{2}$ transistor. No bias was applied to the base-collector junction so that leakage in the base-collector junction would not interfere with the characteristics. The picture shows a good collector current characteristic with an ideality factor of 1.0. But, the base current shows 
large leakage for small forward bias voltage. Figure 17 shows the I-V characteristics of the baseemitter junction in reverse mode. The figure shows that the transistors also suffer from a large reverse current leakage. Transistors of other sizes showed similar characteristics.

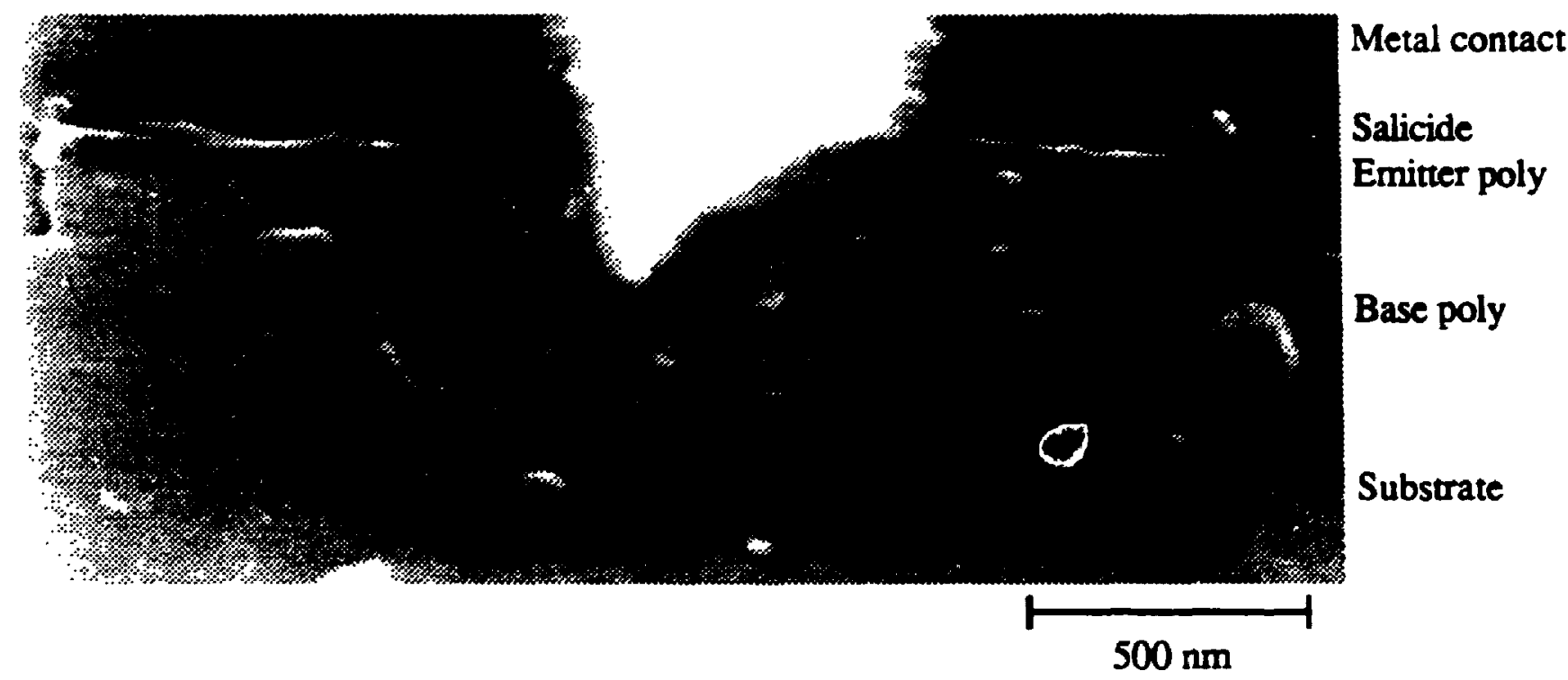

Figure 15 Cross-sectional SEM picture of a typical double-poly transistor from Batch I.

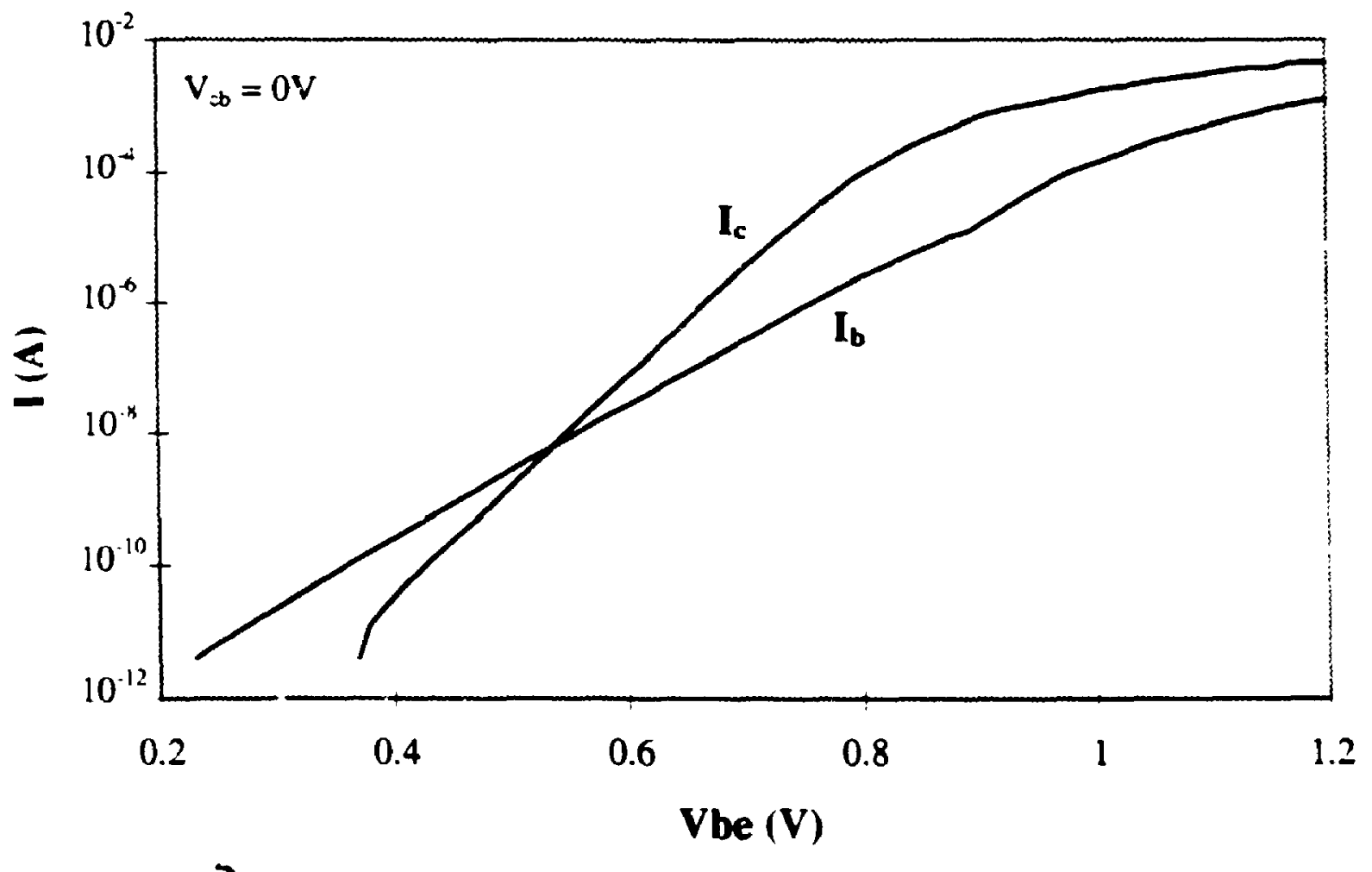

Figure 16 Gummel plot of a typical $2 \times(0.8 \times 10) \mu \mathrm{m}^{2}$ transistor from Batch $\mathrm{I}$. 


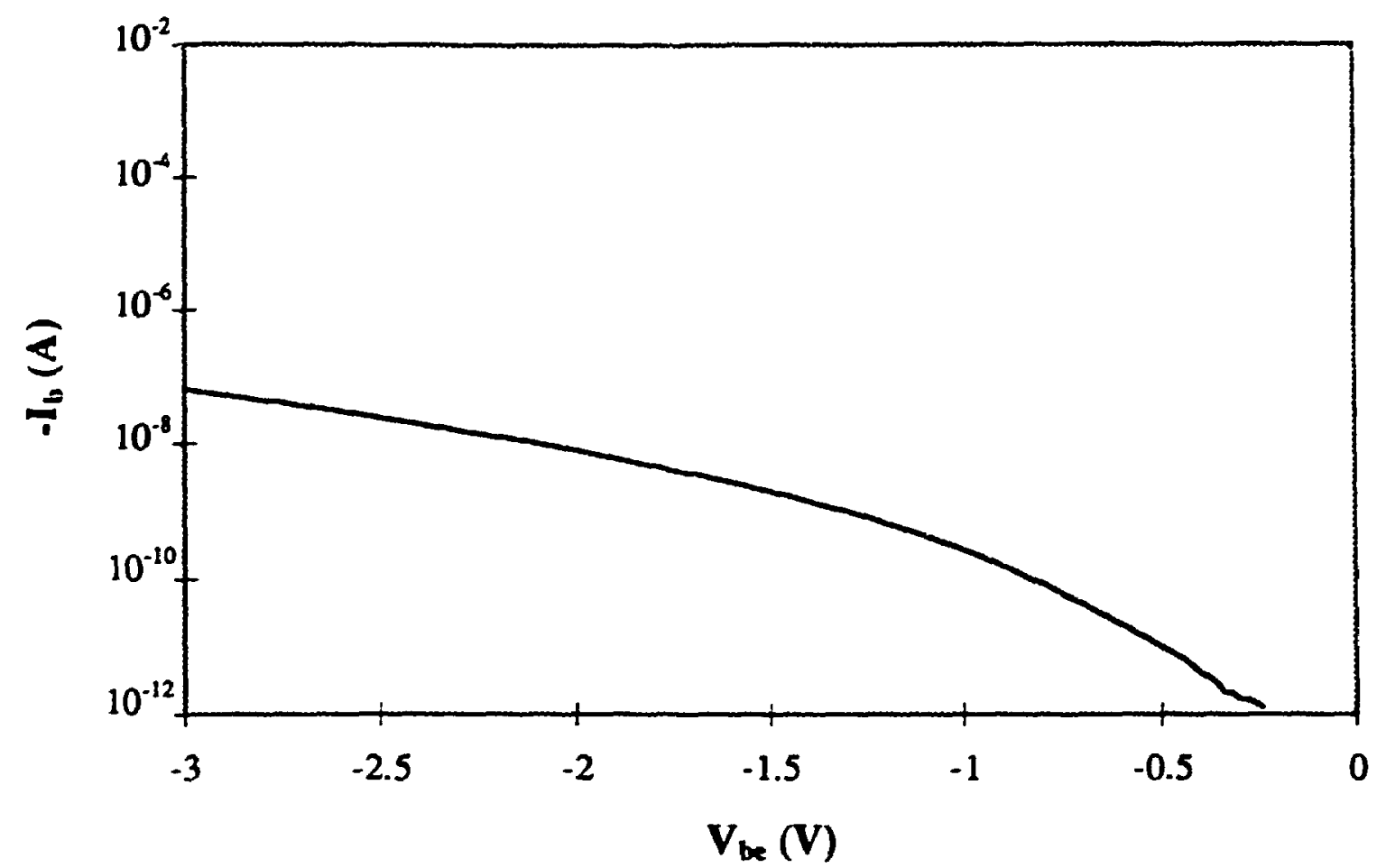

Figure 17 Reverse mode I-V characteristics of the base-emitter junction of a typical $2 \times(0.8 \times 10) \mu \mathrm{m}^{2}$ transistor from Batch $\mathrm{I}$.

\section{Batch II}

Figure 18 is a crcss-sectional SEM picture of a transistor from the second electrical batch which was processed in a way similar to Batch I. Somewhat more base oxide was left after etching on Batch II, about $35 \mathrm{~nm}$ total. Poor insulation at the base poly corner caused the emitter poly to contact the base poly in this area. The Gummel plot, figure 19, still shows a large excess base current component for small forward bias voltage. The measured reverse current leakage is large ( $20 \mathrm{nA}$ at $1.2 \mathrm{~V}$ ). Although the characteristics shown in figure 19 are typical, a few transistors with good DC characteristics could be found. Figure 20 presents the Gummel plot of one of these transistors. The transistor has a base current with an ideality factor of 1.0 and a leakage current of $9 \mathrm{pA}$ at $1.2 \mathrm{~V}$ reverse bias. 


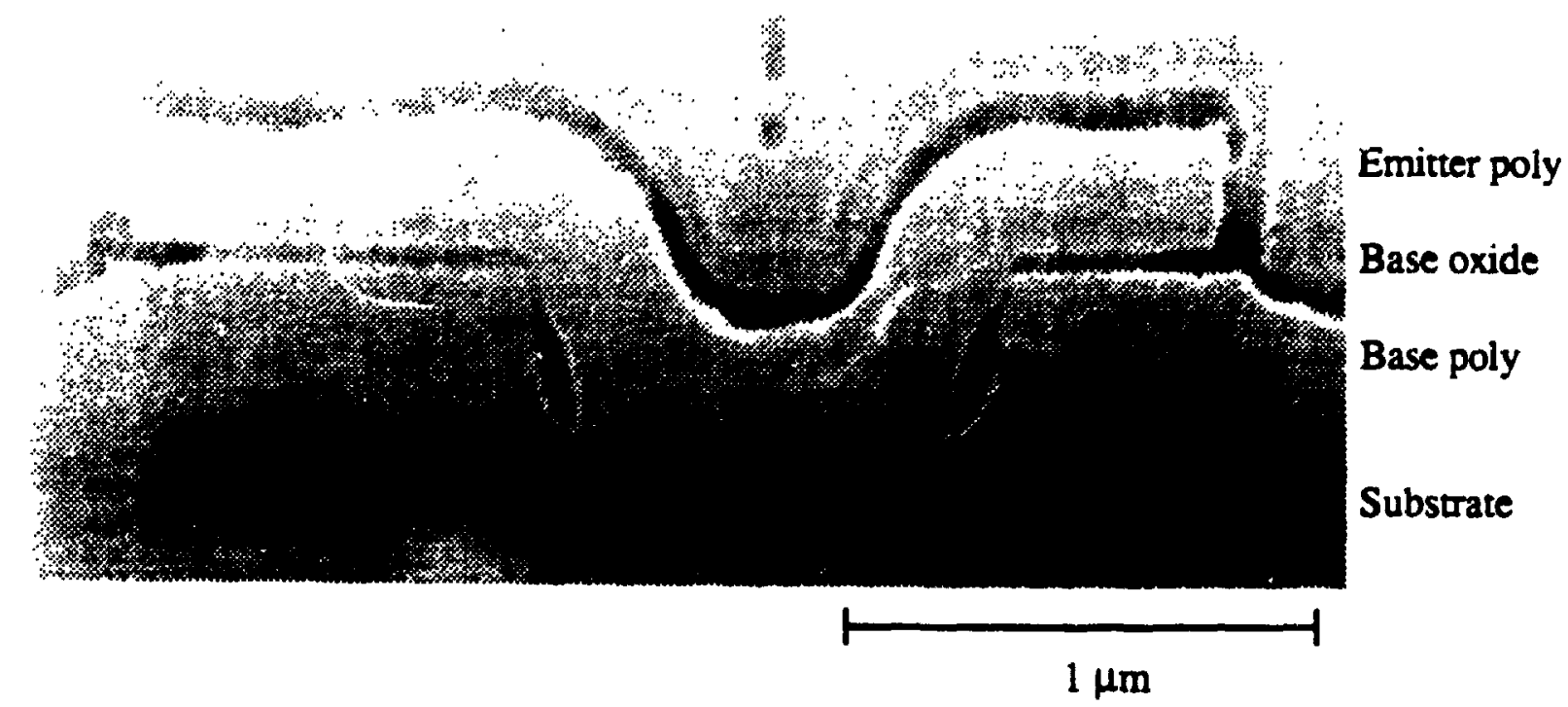

Figure 18 Cross-sectional SEM picture of a double-poly transistor from Batch II.

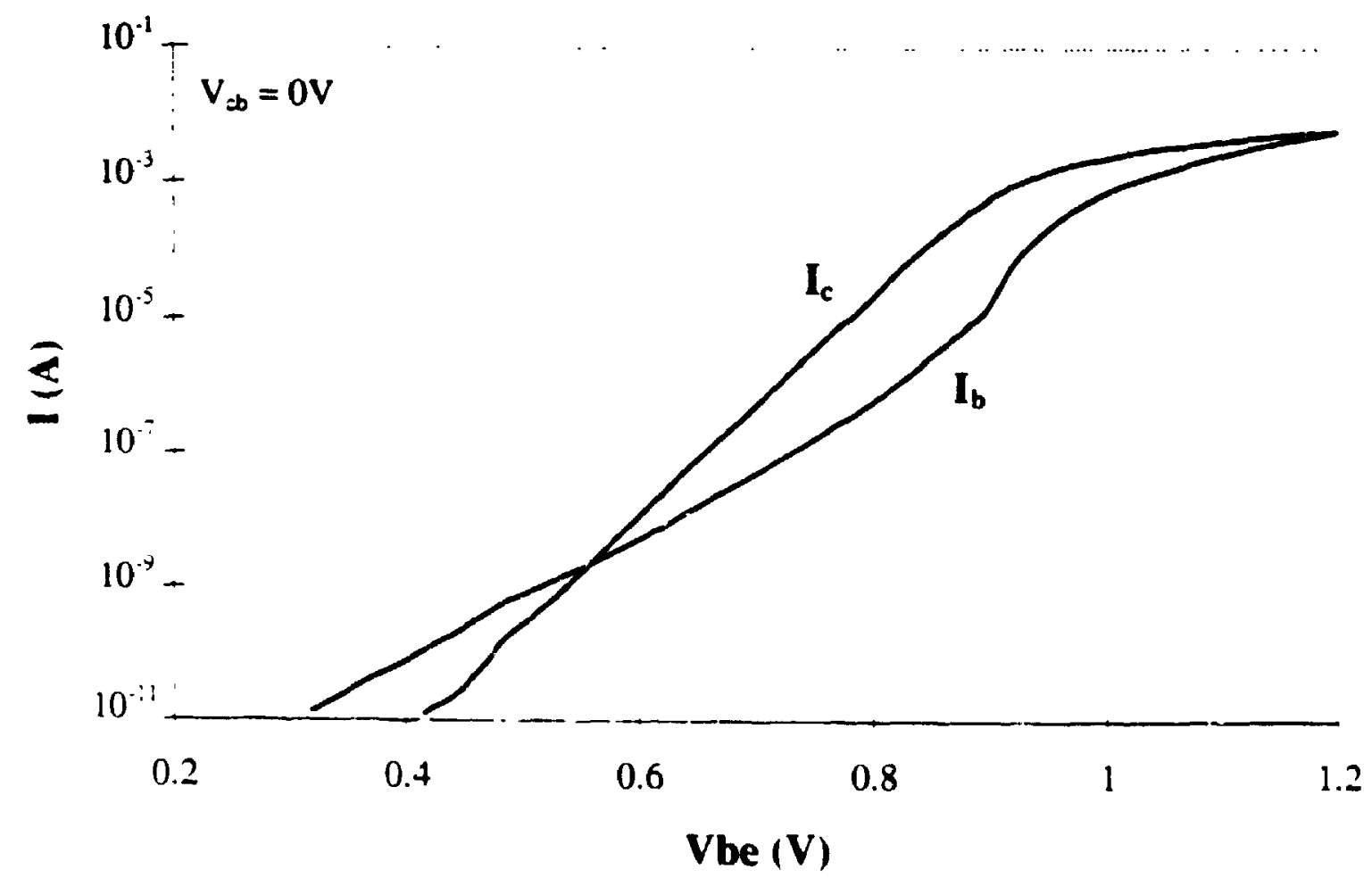

Figure 19 Gummel plot of a typical $0.8 \times 8 \mu \mathrm{m}^{2}$ transistor from Batch II. 


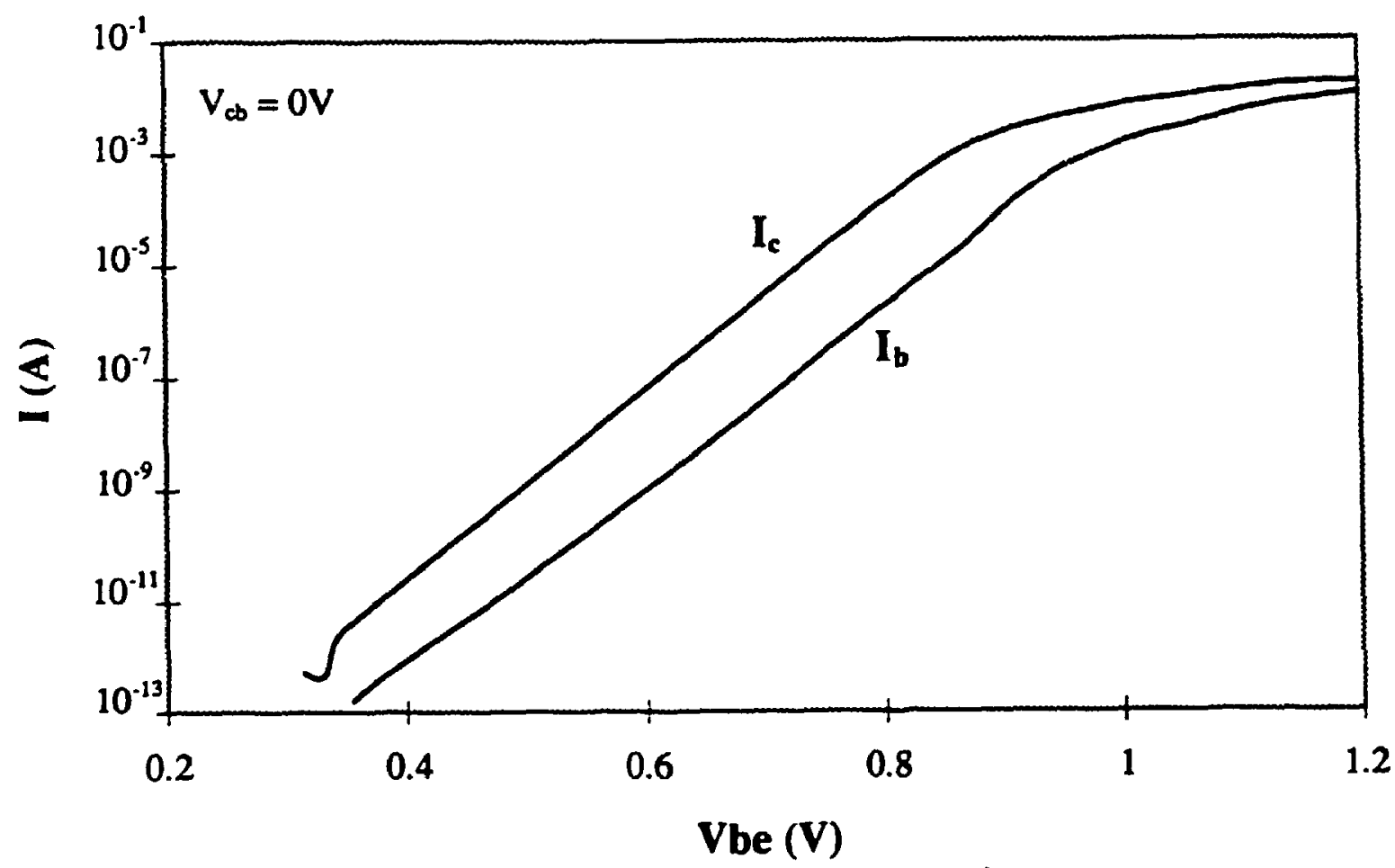

Figure 20 Gummel plot of a $2 \times(0.8 \times 10) \mu \mathrm{m}^{2}$ transistor with good DC characteristics from Batch II.

It should be noted that SEM cross-sections were available only after the second batch was fabricated because of sample preparation problems resulting from, 1) the lack of a SEM suripe for the double-poly bipolar transistor on the mask set and 2) the lack of a capping oxide layer over the metal interconnect. Having no capping oxide makes grinding of a chip to expose a particular structure difficult as the metal tends to smear. Curting a double-poly transistor by cleaving through an entire wafer width to hit a small array of transistors on one die could be done with some practice.

The poor current characteristics of most of the transistors of Batch I and Batch II could be atributed to three causes. The first is shorting between base and emitter poly. The second is runnelling between the extrinsic base and emitter (see section 2.2.1). The last is perimeter depletion (see section 2.2.2). The first and second causes are related to insufficient poly to poly isolation. Preserving this isolation was then identified as the key priority for subsequent experiments. 


\section{Batch III}

The first attempt to solve the isolation problem was to remove from the initial process flow the oxidation and patterning steps that were used to protect the PMOS and NMOS device wells (which were present on the mask set, although irrelevant to the present experiment), and the collector area from direct contact with the base poly layer (Not shown in figure 10 nor discussed in section 4.2). Although having this protecting oxide would be a good practice in a BiCMOS context, it did not serve any purpose from a bipolar-only point of view and required an extra photolithographic step. Moreover, the oxide was causing confusion for the SWS etch end-point detection. After SWS oxide deposition, the oxide thickness in the emitter stripe was only the SWS oxide deposited thickness but over the MOS device well and collector area which where forming most of the device area, the oxide thickness was the SWS oxide deposited thickness plus the $80 \mathrm{~nm}$ protecting oxide. Cross-sectional scanning electrons microscopy photographs of the transistors with the modified process are presented in figures 21 and 22. Figure 21 shows a base oxide overetched by $113 \mathrm{~nm}$ leaving $107 \mathrm{~nm}$ which seems sufficient to prevent poly to poly shorts for these transistors. But, most of the transistors examined by cross-sectional scanning electron microscopy from this batch showed poly to poly shorts at the base poly corner as seen in figure 22 . Although the remaining base oxide is thinner on this wafer (about $85 \mathrm{~nm}$ thick), the short seems more to be due to notches in the base oxide close to the emitter opening. Figure 23 is a Gummel plot of a typical $2 \times(0.8 \times 10) \mu \mathrm{m}^{2}$ transistor from this batch. The figure shows that high base leakage current is still present. The measured reverse current leakage is large ( $1 \mu \mathrm{A}$ at $1.2 \mathrm{~V})$. No transistor with particularly good characteristics could be found on this batch. 


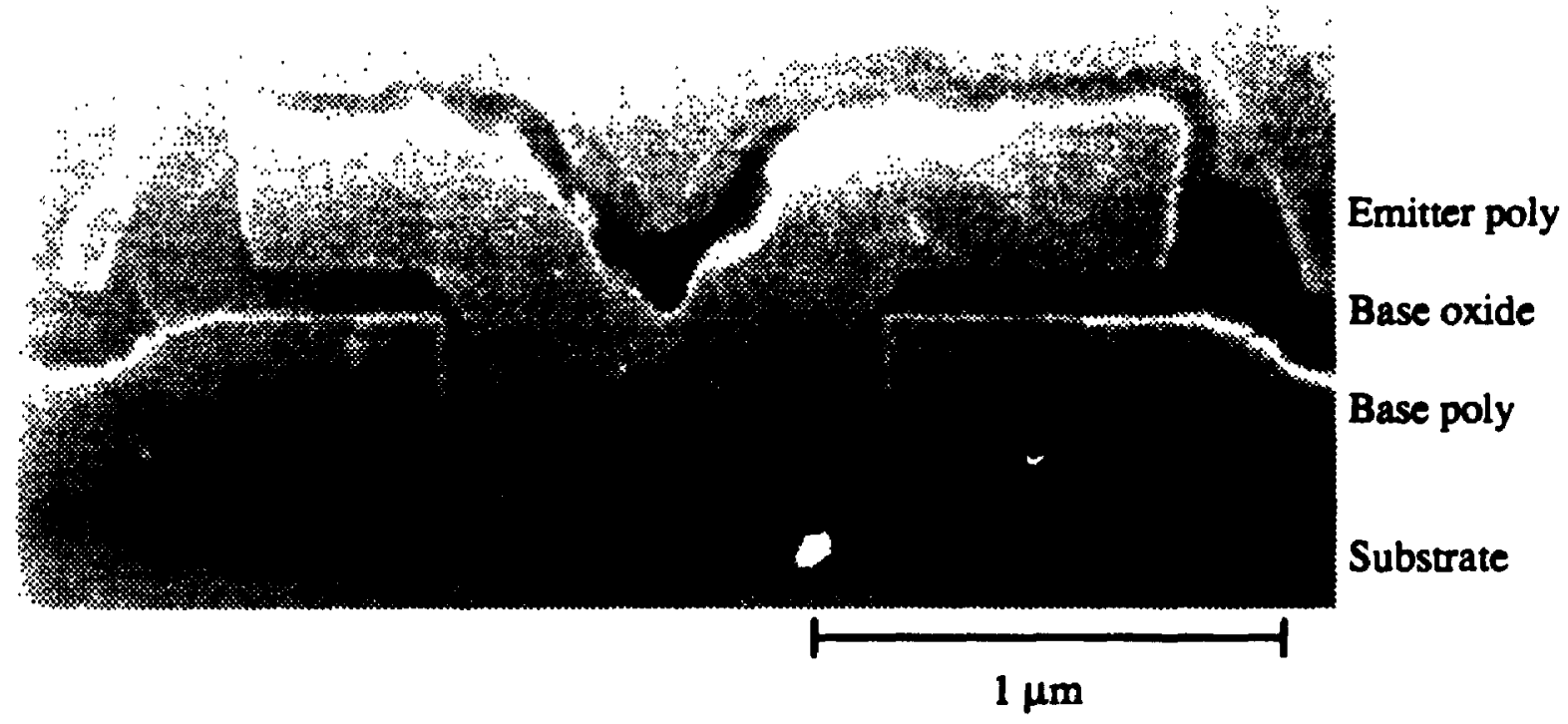

Figure 21 Cross-sectional SEM picture of a transistor from Batch III showing no poly to poly shorts.

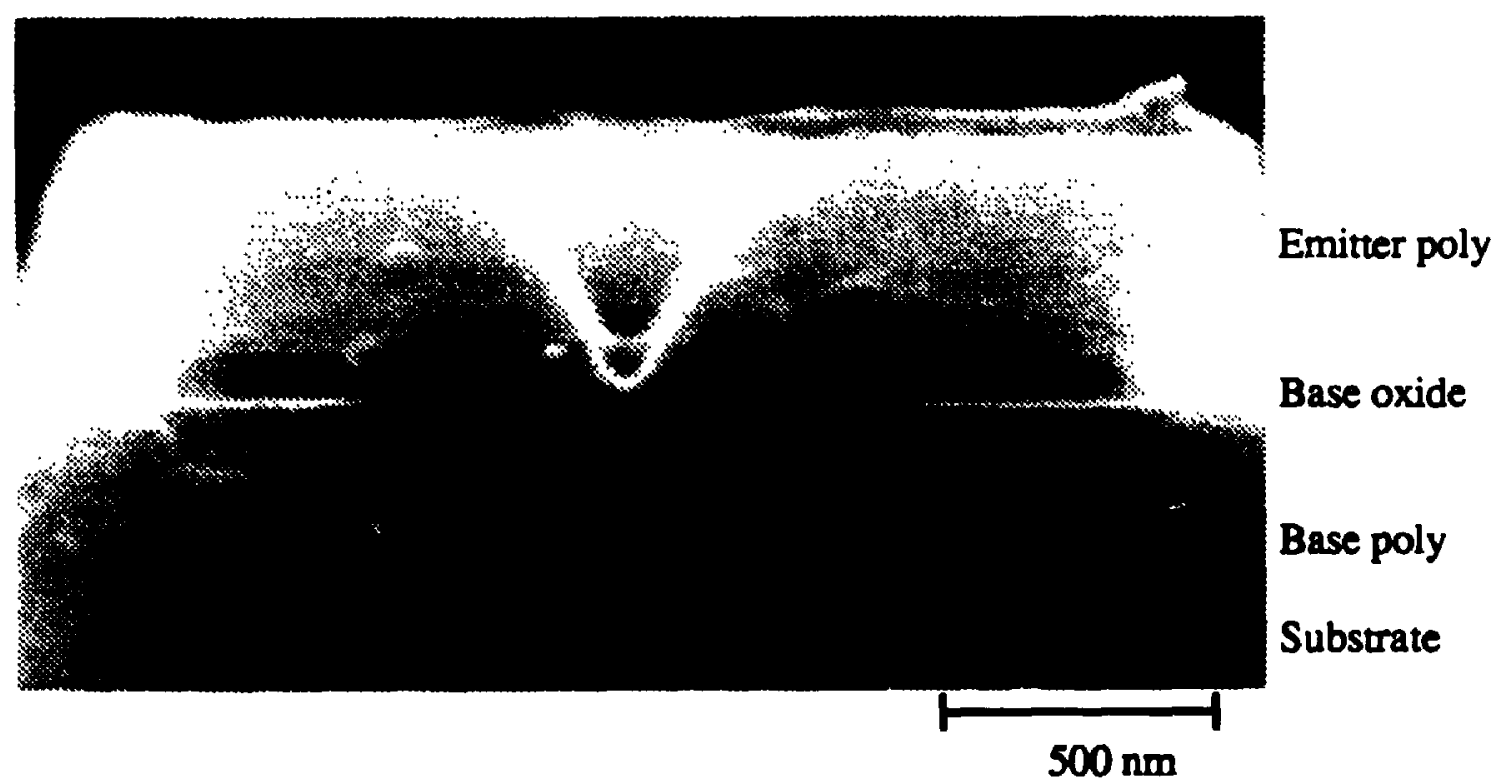

Figure 22 Cross-sectional SEM picture of a typical double-poly transistor from Batch III. 


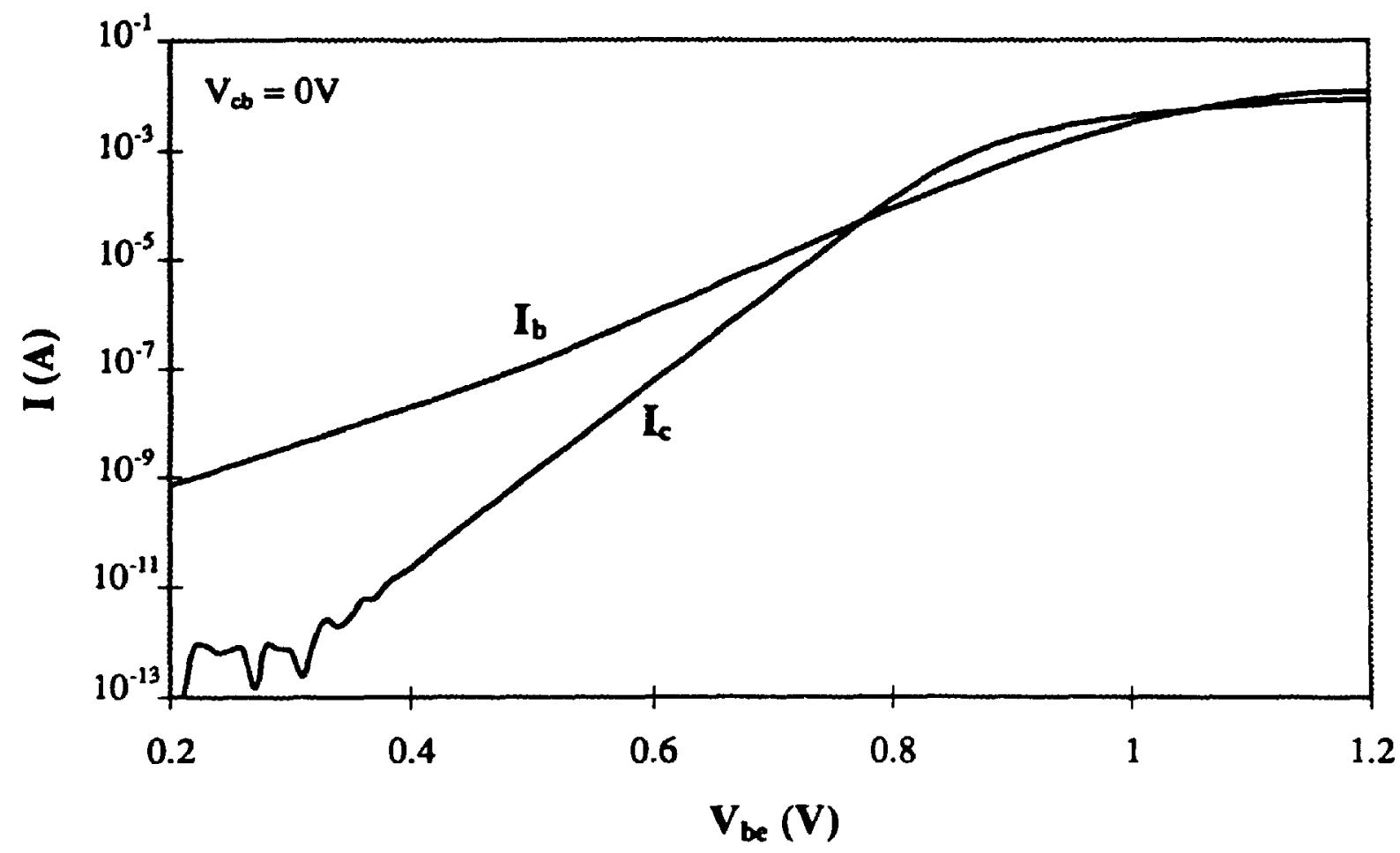

Figure 23 Gummel plot of a typical $2 \times(0.8 \times 10) \mu \mathrm{m}^{2}$ transistor from Batch III.

Up to this point, the double-poly SWS etch was performed on a Precision 5000 plasma etcher (a single wafer etcher). This late-model etcher has laser and chemical (by light emission spectroscopy) end-point detection capability as well as high oxide to Si selectivity i.e. about 15:1. Si lost in the intrinsic part of the double-poly transistor due to SWS overetch could be as small as $6 \mathrm{~nm}$, insuring a small boron dose loss in the intrinsic area of the transistor. But, poor knowledge of the etcher characteristics for SWS formation due to the fact that it had mainly been used for cuntact window etching was thought to be at the source of the overetch problem.

\section{Batch IV}

In an attempt to improve base poly corner insulation and to form a wider SWS, the SWS oxide etch was performed on an Anelva etcher, the etcher used for SWS formation in production processes at Northern Telecom, in subsequent experiments. Also, the thickness of oxide deposited to form the SWS was increased from $220 \mathrm{~nm}$ to $300 \mathrm{~nm}$. Only laser end-point detection is available 
on the Anelva etcher. Since the new oxide thickness is significantly larger than the one used in the production SWS fabrication procedure, the production laser end-point detection routine could not be used. The Anelva plasma etcher is known to have a stable etch rate of about $45 \mathrm{~nm} /$ minute from wafer to wafer and from day to day operation. It was then decided to use a 7 minites 30 seconds long timed etch for the subsequent SWS etch. Concurrently, a few mechanical wafers with the double-poly transistor structures were also etched in the Anelva for SWS formation to estimate the amount of $\mathrm{Si}$ lost in the intrinsic area of the transistor due to SWS overetch. After the etch, the wafers were covered with photoresist instead of the emitter poly to reveal the crystalline $\mathrm{Si}$ interface.

Figure 24 is a cross-sectional SEM picture of one of the electrical wafers. The picture shows that the base oxide has been etched by $119 \mathrm{~nm}$, saving only $101 \mathrm{~nm}$ of it. Although the base oxide left is somewhat thinner than on previous batch, the SWS shape appears better than on the previous batches etched in the Precision 5000. But, again notches in the base oxide close to the emitter opening cause the emitter poly to come close to the base poly. However, no poly to poly contacts were seen on any of the cross-sectional SEM pictures.

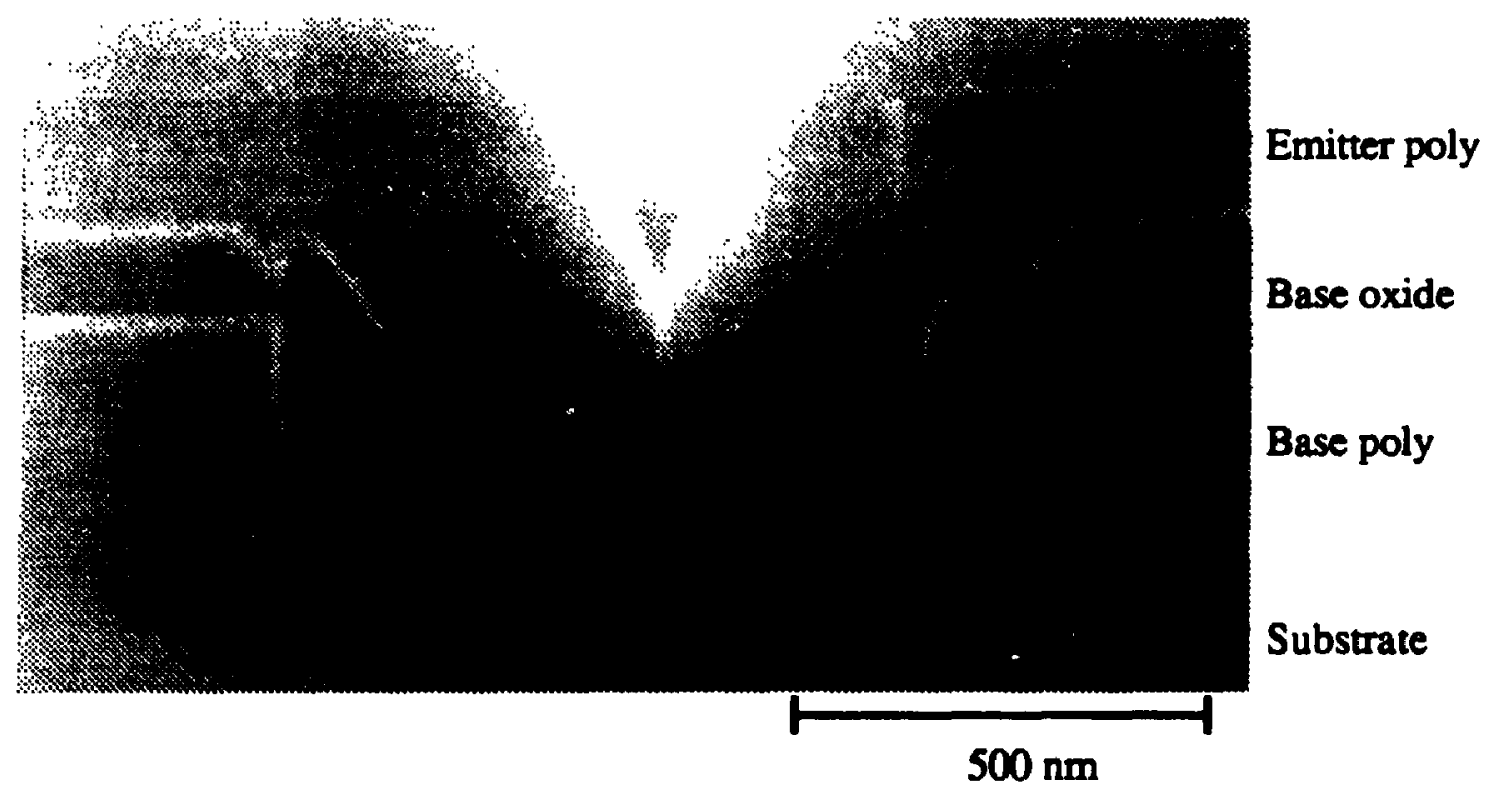

Figure 24 Cross-sectional SEM picture of a typical double-poly transistor from Batch IV. 
Figure 25 is a high magnification cross-sectional SEM picture of the double-poly structure from one of the mechanical wafers. The picture shows that the Si lost due to the SWS overetch measured about $20 \mathrm{~nm}$ (The dark, thin layer seen at the Si interface is probably an artifact caused by photoresist lifting).

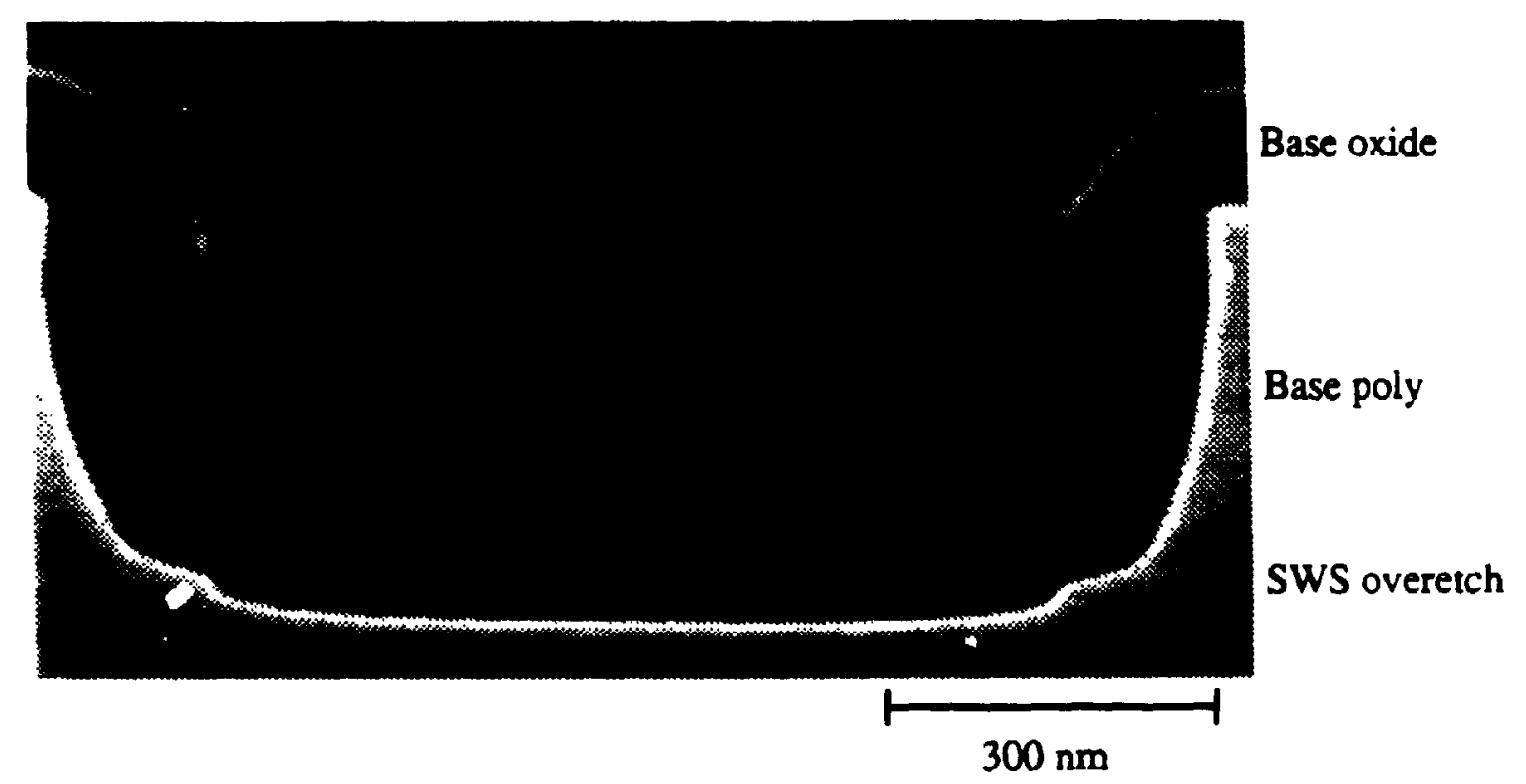

Figure 25 High magnification cross-sectional SEM picture of a double-poly transistor from a mechanical batch.

Another approach to evaluate the amount of Si lost due to the SWS overetch was to take a wafer that received emitter poly deposition and use the nitric:aceric:HF delineation etch instead of the buffered HF etch for SEM sample preparation. The nitric:acetic:HF delineation etch has the capacity to distinguish polysilicon on crystalline $\mathrm{Si}$ as discussed in section 4.3.2. Figure 26, a crosssectional SEM picture of the sample shown in figure 24 after a nitric:acetic:HF delineation etch instead of a buffered HF delineation, shows the poly/Si interfaces revealing the base poly and SWS overetch. The wafer was not implanted for emitter poly doping nor annealed after emitter poly deposition to insure that the interface revealed coincided with the poly/Si interface. The Si lost due to the SWS overetch is in the range of $20 \mathrm{~nm}$ which confirms the previous measurement. 


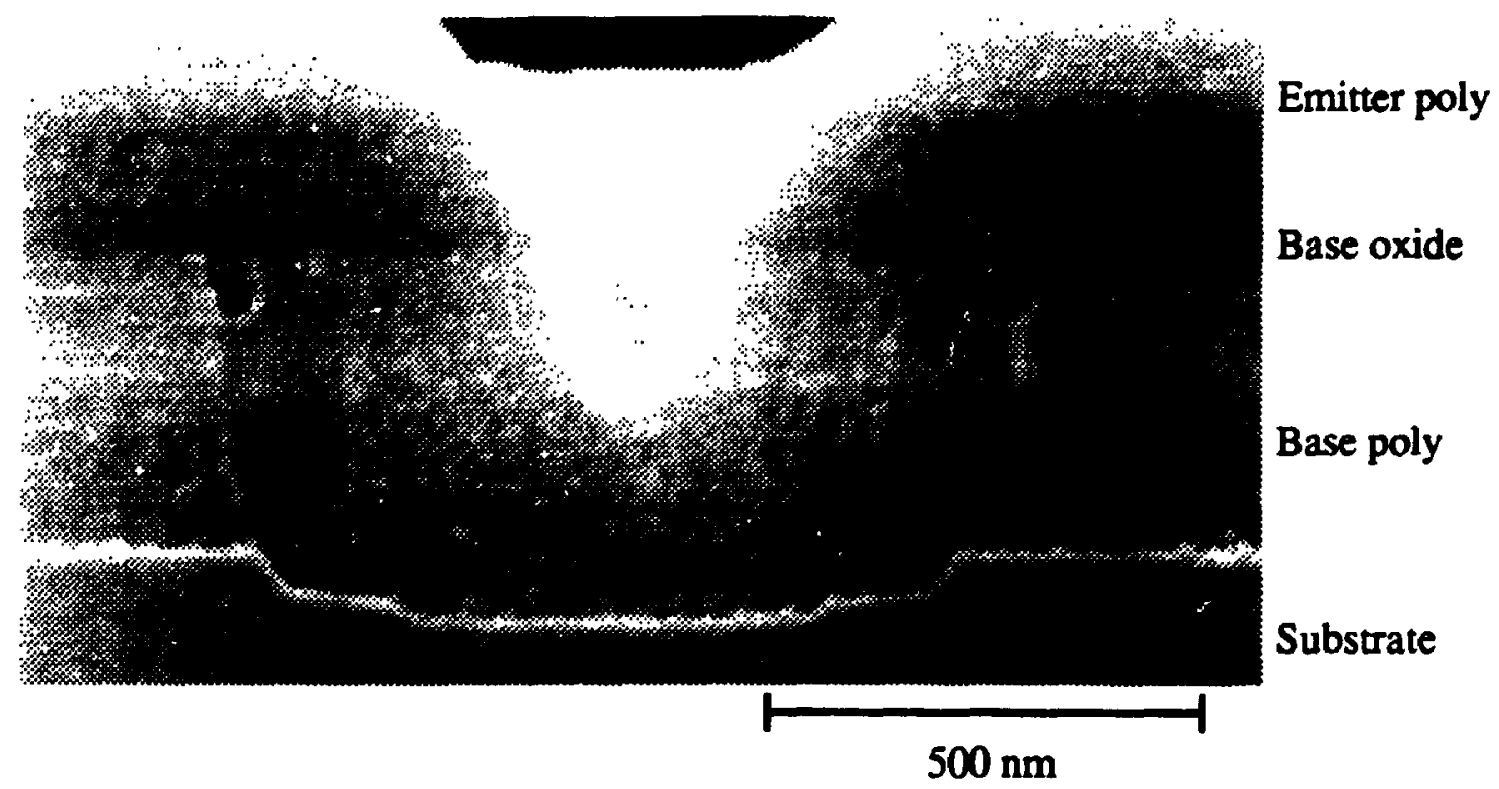

Figure 26 Cross-sectional SEM picture of a typical double-poly transistor from Batch IV that received the nitric:acetic:HF delineation etch.

The boron dupant profile for a $25 \mathrm{keV}$ implant peaks at about $83 \mathrm{~nm}$ depth in Si and contains about $2 \%$ of the total integrated dose in the first $20 \mathrm{~nm}$ from the surface. The amount of Si lost due to the SWS overetch is therefore small enough to use only one implant done before the SWS oxide depcsition to form the intrinsic base. This was seen as a good compromise between baseemitter punchthrough sensitivity, base resistance and process complexity.

Note in figure 26 the darker areas right at the base poly top comers. These dark areas are probably due to the presence of a residue that etches faster than oxide and, is probably related to the oxide isotching problem. The residue is probably formed during the base electrode patterning steps. A wet resist strip was then added to the process flow after the plasma resist strip, before SWS oxide deposition, for subsequent electrical batches. Batches fabricated after this modification did not show any notches. 


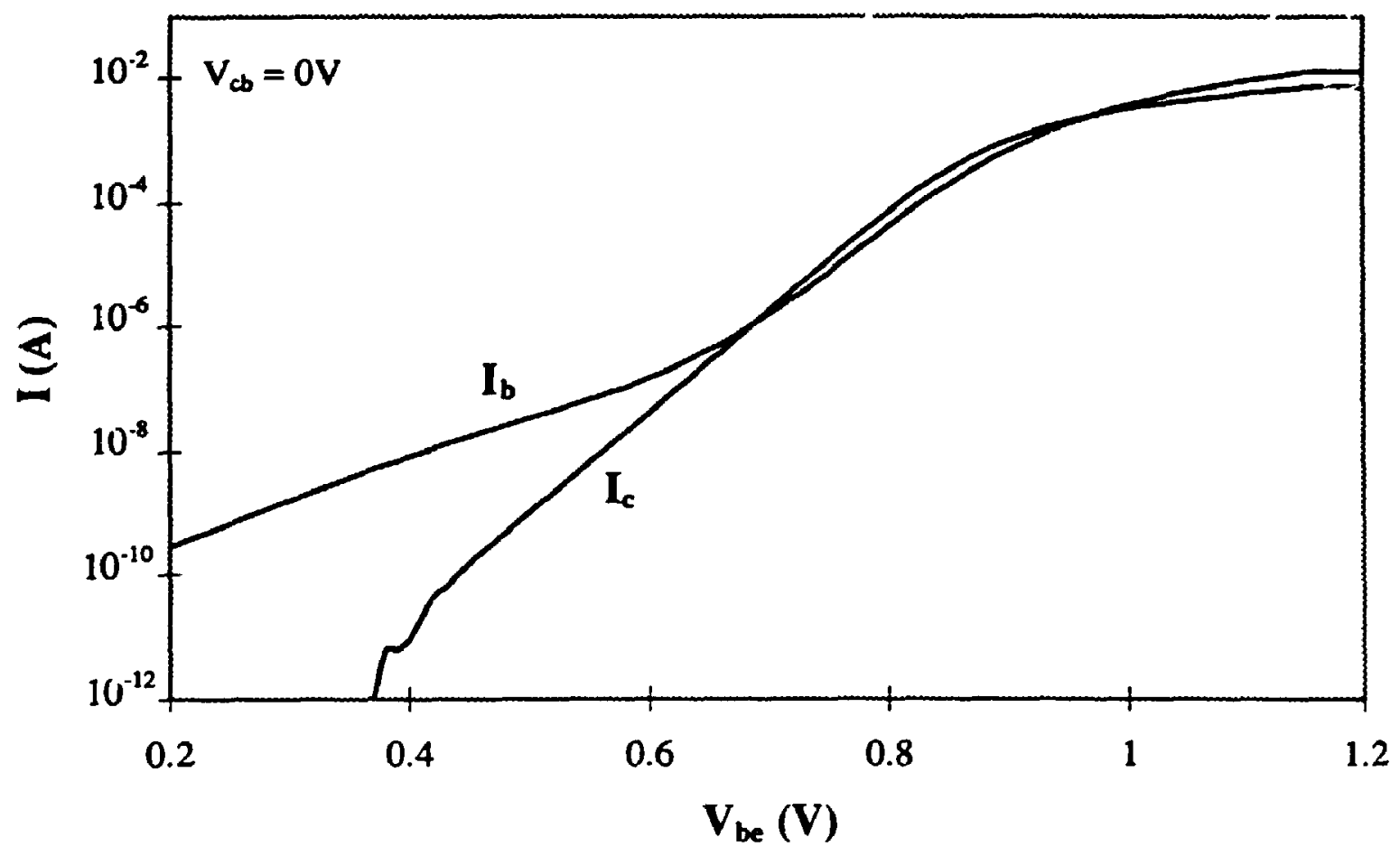

Figure 27 Gummel plot of a typical $2 \times(0.8 \times 10) \mu \mathrm{m}^{2}$ transistor from Batch IV.

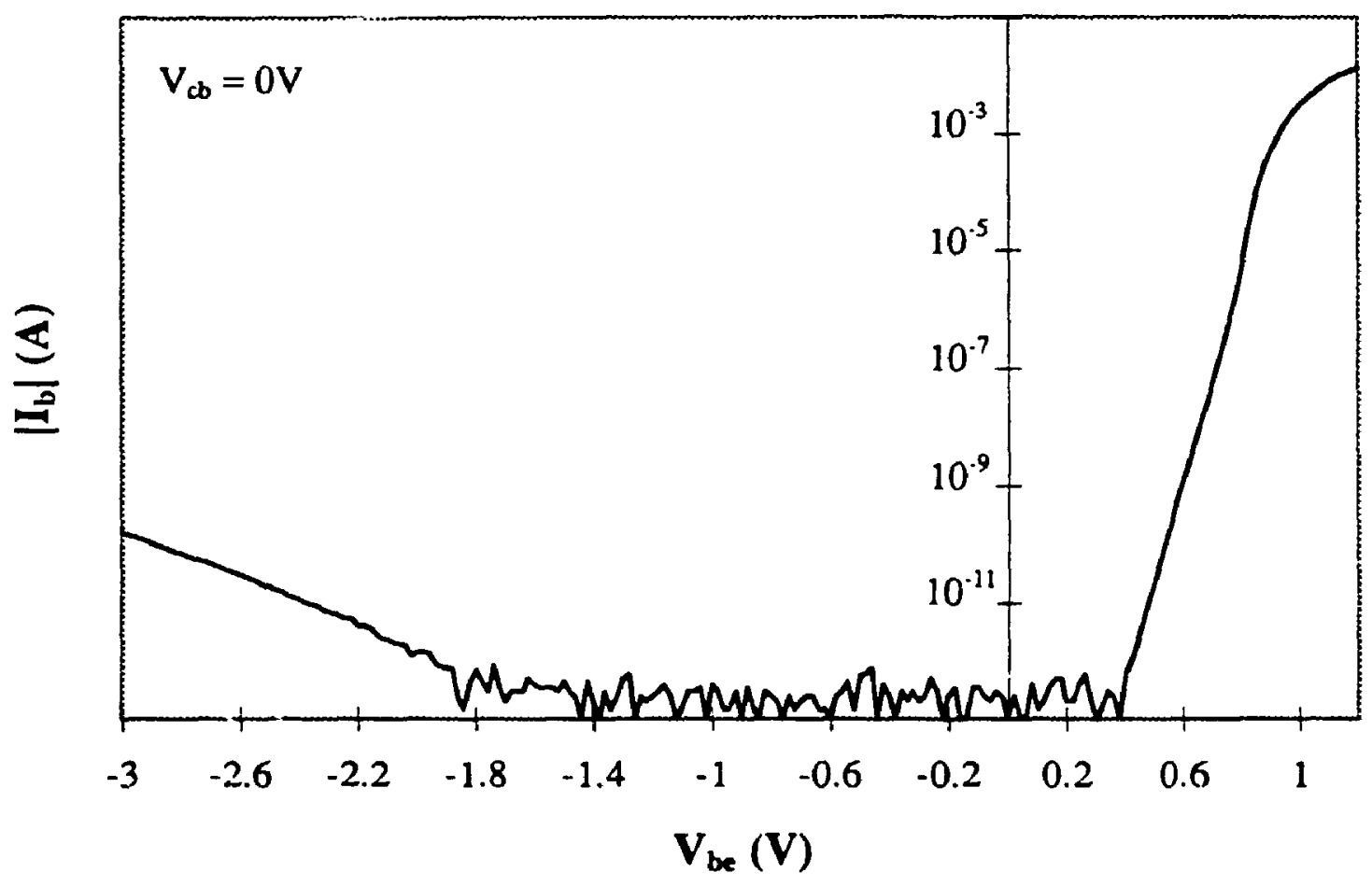

Figure 28 I-V characteristics of the base-emitter junction of a $2 \times(0.8 \times 10) \mu \mathrm{m}^{2}$ transistor with good DC characteristics from Batch IV. 
Figure 27 is a Gummel plot of a typical $2 \times(0.8 \times 10) \mu \mathrm{m}^{2}$ transistor from Batch IV. The figure shows that high base leakage current is still present. Transistors with good base current characteristics were also found on the batch. Figure 28 shows the I-V characteristics of the baseemitter juriction of a good $2 \times(0.8 \times 10) \mu \mathrm{m}^{2}$ transistor in both forward and reverse modes. The picture shows a base current with an ideality factor of 1.0 up to $1 \mathrm{pA}$ and a small leakage current of $0.2 \mathrm{nA}$ at $3 \mathrm{~V}$ reverse bias.

\subsubsection{Field Oxid : Loss}

Most of the wafers in this study ended processing with very high field oxide lost. Figure 29 is a cross-sectional SEM picture showing an extreme case for which all the field was lost. The thickness of the field oxide covered by the base poly can be used as a reference for the fielu thickness after the sacrificial oxide removal which is part of the LOCOS isolation procedure. It can be observed on figure 29 that a small area dedicated to isolation was even silicided. Field oxide loss is mainly due to two causes. First, the SWS overetch directly affects the field oxide. The field oxide loss due to this etch should be small for an optimized process. Second, after emitter poly patterning, t $~$ base oxide not covered by emitter poly must be removed in order to salicide the base poly (see figure 10). Base oxide thicknesses varying from $150 \mathrm{~nm}$ to $300 \mathrm{~nm}$ have been investigated in this study. This layer is no longer present on the field oxide at this point of the flow, since it has been removed during the base electrode patterning. Therefore, the base oxide removal done next to the emitter poly etch directly affects the field oxide thickness. In this study, no specific attempt was made to prevent the field oxide loss as the main interest was in discreet transistors. But, the addition of a photolithographic step after emitter poly patterning to selectively remove base oxide could prevent the field oxide loss. 


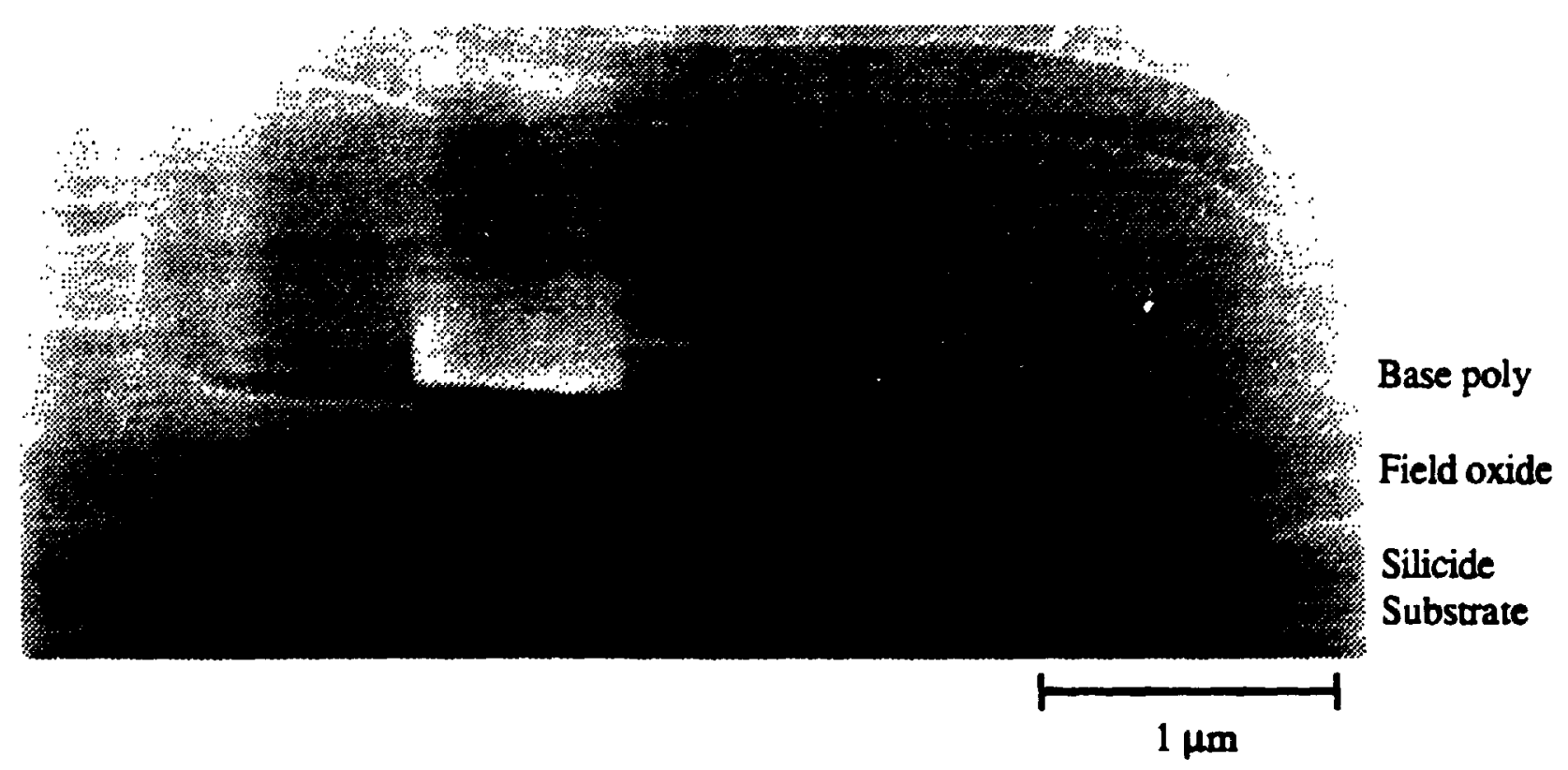

Figure 29 Cross-sectional SEM picture showing a transistor for which all the field oxide was lost (extreme case).

\subsubsection{Transistor Topography}

A source of concern with the double-poly bipolar from a metalization and contact point of view is the topography of the structure. Figure 30 is a cross-sectional SEM picture showing the overall topography which affects imaging and interconnect. A smooth and planar surface is desired to prevent metal line breakage and meet the small depth of focus required by the photoresist exposure system in order to achieve narrow lines.

Another concem is contacting to the "V" surface shape of the emitter poly. Placing the metal contact to the emitter poly on a flat area away from the junction would sacrifice integration density and increase series resistance. Most of the transistors processed in this sudy were successfully electrically contacted using the one metal level standard metalization procedure. But interconnect reliability and emitter contact resistance are of concern. An effor was made to investigate the possible improvement in this regard from a transistor structure point of view. 


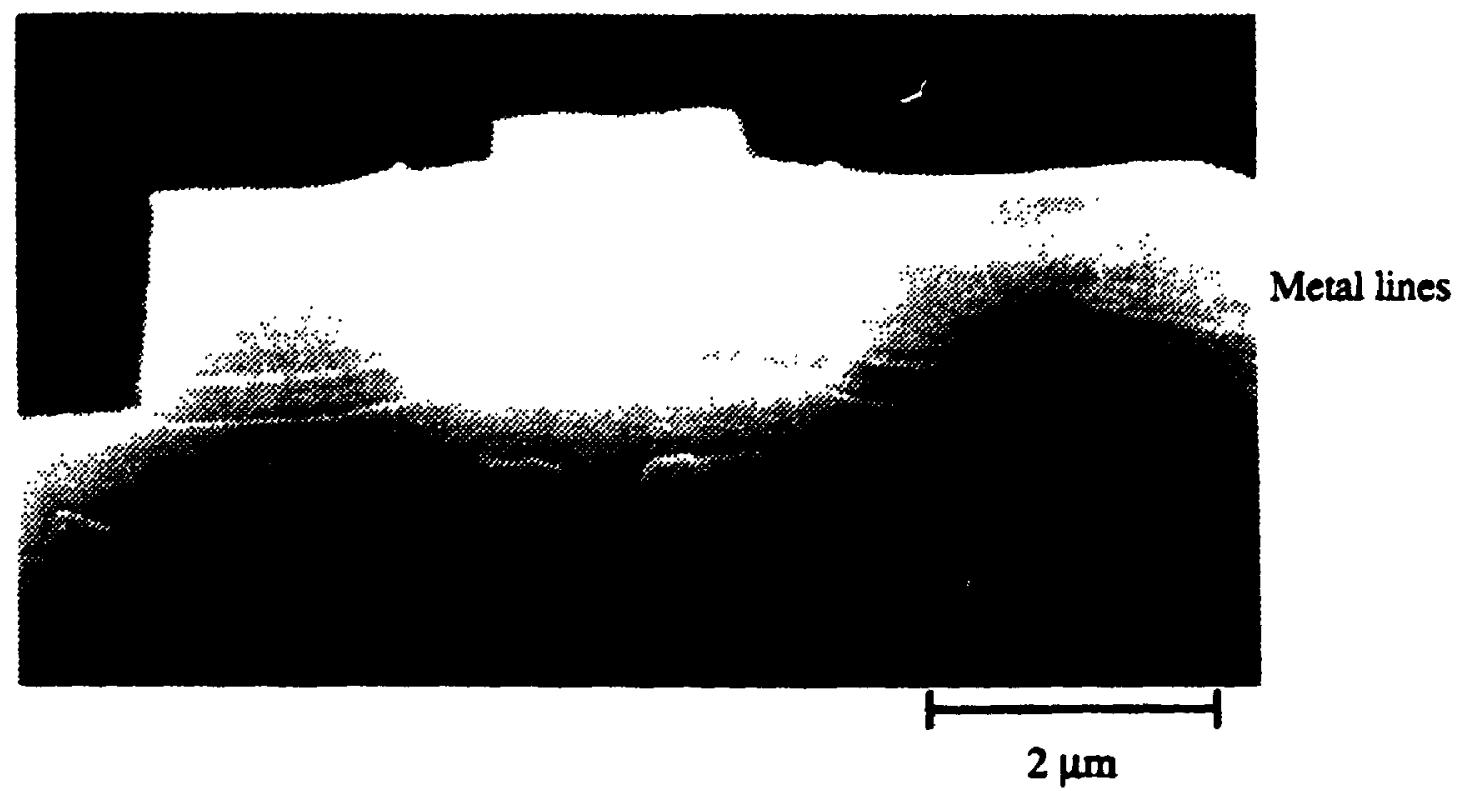

Figure 30 Cross-sectional SEM picture showing the overall topography of the fabricated double-poly bipolar.

Reducing the thickness of the stack formed by the base poly and base oxide would reduce the overall topography as well as reducing the aspect racio of the emitter opening. Reducing the base oxide thickness would reduce the margin for the problematic SWS overetch. Reducing the base poly thickness seems then a better choice. Two factors could limit the base poly thickness reduction. First, boron penetration into the Si crystal could occur during the base poly implant which could modify the surface doping in the intrinsic area of the transistor. For a boron implantation at $10 \mathrm{keV}$ a $100 \mathrm{~nm}$ amorphous-Si layer would assure that li'ss than $0.003 \%$ (4 sigma) of the implanted dose reach the crystalline $S i\left(3 \times 10^{11} \mathrm{~cm}^{-2}\right.$ for a total dose of $\left.1 \times 10^{16} \mathrm{~cm}^{-2}\right)$. A second factor that could limit the base poly thickness reduction is polysilicon consumption due to salicidation of the base poly. If the base poly is thin and the extrinsic base diffusion has a shallow profile, $\mathrm{TiSi}_{2}$ could approach the extrinsic base-collector junction causing Schottky-diode like electrical characteristics and high contact resistance. This problem is particular to the devices processed in this study, formed with a modified mask set of a conventional single poly bipolar (see section 4.2). For a mask set specially design for a double-poly bipolar, the device well would probably be made narrower than the emitter poly stripe in order to minimize the collector area. For such a scrucrure, all the salicided base poly area would be over field oxide, avoiding this problem. 
One observes from figures 18 and 21 that the standard salicidation process is robust as the salicide layer thickness is fairly uniform across the emitter poly. But, figure 15 shows that an overetched via to the emitter can cause the removal of the salicide and potentially high contact resistance due to the direct contact between the tungsten plug and the underlying silicon. This could be an important concem as BPSG and spin-on-glass are used in the standard production metalization process to planarize the surface for the interconnects. A planar BPSG surface implies thinner passivation over the emitter poly than over other areas to be contacted. For example, for the mask set used in this study, the base poly is contacted in an area where it is over the device well and not the field oxide (see section 4.2). Passivation over the emitter poly is then much thinner than over the base poly. Etching the via up to the base poiy implies an overly long etched via to the emirter.

\subsection{Double-Poly Bipolars - Batch V}

This section discusses the fabrication procedure and electrical characteristics of the last electrical batches produced in this study, Iabelled Batch V. Preservation of a thick base oxide and SWS without the presence of notches in the base oxide close to the emitter opening was realised on this baist. This improved emitter poly to base poly isolation allowed a large number of transistors with good DC characteristics to be obtained.

\subsubsection{Fabrication}

Double-poly bipolar fabrication procedures have been discussed extensively in previous sections. Section 2.1 presented repored double-poly bipolar process flows. Section 4.1 and 4.2 described the processing approach chosen, mask sets used, as well as wells, isolation and metalization technology used in the experimental part of this study. This section concentrates on specific process information for Batch V. 
The base poly layer was deposited as an amorphous material of thickness of $325 \mathrm{~nm}$ or $200 \mathrm{~nm}$ (See the table 3 for processing splits). Boron ions were implanted into the film with a dose of $1 \times 10^{16} \mathrm{~cm}^{-2}$ at $20 \mathrm{keV}$ and $7 \times 10^{15} \mathrm{~cm}^{-2}$ at $10 \mathrm{keV}$. The $220 \mathrm{~nm} \mathrm{CVD}$ base oxide was then deposited and patterned. The base electrode was defined by RIE etching at a power of $450 \mathrm{~W}$, a partial pressure of $\mathrm{Cl}_{2}$ of $433 \mathrm{mTorr}$ and a total pressure of $650 \mathrm{mT}$. The etch end-point was detected when the base poly was cleared from the oxide isolation. $\mathrm{Cl}_{2}$ based overetch of a duration varying from $30 \%$ to $70 \%$ of the main etch time was performed at a reduced power, partial pressure and total pressure of $175 \mathrm{~W}, 64 \mathrm{mTorr}$ and $150 \mathrm{mT}$, respectively. An $11 \mathrm{~nm}$ thick dry thermal oxide was grown on most of the wafer at $800^{\circ} \mathrm{C}$ for 100 minutes to protect the Si surface from contamination due to the following ion implantation. The intrinsic base was formed with a $25 \mathrm{keV}$ ion implantation of boron at a dose of $1.6 \times 10^{13} \mathrm{~cm}^{-2}$. A $285 \mathrm{~nm}$ thick SWS oxide, measured by nanospectrometer, was then deposited. The silicon dioxide film was first etched for 5 minutes 30 seconds in the Anelva removing an average oxide thickness of $230 \mathrm{~nm}$. The wafers were etched a second time in the same machine for one minute to remove the remaining oxide. Following an RCA clean, a 14 seconds vapor HF oxide etch was performed to remove the remaining oxide layer prior to emitter poly deposition. The etch rate of the Excalibur etcher is about $30 \mathrm{~nm} / 14$ seconds. A $325 \mathrm{~nm}$ thick amorphous-silicon layer was next deposited and implanted with arsenic at a dose of $1.5 \times 10^{16} \mathrm{~cm}^{-2}$ and an energy of $100 \mathrm{keV}$. After emitter poly patterning and deposition of a $220 \mathrm{~nm}$ CVD silicon dioxide film, the implanted arsenic impurities were diffused within the silicon film at a temperature of $850^{\circ} \mathrm{C}$ for 50 minutes. The $220 \mathrm{~nm}$ silicon dioxide layer was etched back by using an $\mathrm{R}: \mathrm{s}$ process to form a sidewall spacer around the recrystallized emitter electrode. A blanket boron implant $\left(3 \mathrm{X} 10^{15} \mathrm{~cm}^{-2}, 5 \mathrm{keV}\right)$ ensured ohmic contact to the base poly layer. After a thin oxide deposition, a RTA step $\left(1025^{\circ} \mathrm{C} 40\right.$ seconds) activated the implanted arsenic and boron ions. 


\begin{tabular}{|c|c|c|c|c|c|}
\hline Wafer \# & $\begin{array}{c}\text { Additional well } \\
\text { implant }\end{array}$ & $\begin{array}{c}\text { Base poly } \\
\text { thickness }(\mathrm{nm})\end{array}$ & $\begin{array}{l}\text { Base poly } \\
\text { implant }\end{array}$ & $\begin{array}{c}\text { Base poly } \\
\text { overetch } \\
(\%)\end{array}$ & oxidation \\
\hline 1 & & 325 & $\begin{array}{c}20 \mathrm{keV} \\
1 \times 10^{16} \mathrm{~cm}^{-2}\end{array}$ & 30 & $\begin{array}{c}100 \mathrm{~min} \\
800^{\circ} \mathrm{C}, \mathrm{O}_{2}\end{array}$ \\
\hline 2 & & 325 & $\begin{array}{c}20 \mathrm{keV} \\
1 \times 10^{16} \mathrm{~cm}^{-2}\end{array}$ & 30 & $\begin{array}{c}100 \mathrm{~min} \\
800^{\circ} \mathrm{C}, \mathrm{O}_{2}\end{array}$ \\
\hline$\overline{3}$ & & 325 & $\begin{array}{c}20 \mathrm{keV} \\
1 \times 1016 \mathrm{~cm}^{-2}\end{array}$ & 30 & $\begin{array}{c}100 \mathrm{~min} \\
800^{\circ} \mathrm{C}, \mathrm{O}_{2}\end{array}$ \\
\hline 4 & & 325 & $\begin{array}{c}20 \mathrm{keV} \\
1 \times 1016 \mathrm{~cm}^{2}\end{array}$ & 55 & $\begin{array}{c}100 \mathrm{~min} \\
800^{\circ} \mathrm{C}, \mathrm{O}_{2}\end{array}$ \\
\hline 5 & \begin{tabular}{|c|}
$13 \mathrm{keV}$ \\
$3 \times 1013 \mathrm{~cm}-2$ \\
\end{tabular} & 325 & $\begin{array}{c}20 \mathrm{keV} \\
1 \times 1016 \mathrm{~cm}^{-2} \\
\end{array}$ & 55 & \\
\hline 6 & \begin{tabular}{|c|}
$13 \mathrm{keV}$ \\
$3 \times 1013 \mathrm{~cm}-2$ \\
\end{tabular} & 325 & \begin{tabular}{|c|}
$20 \mathrm{keV}$ \\
$1 \times 1016 \mathrm{~cm}^{-2}$ \\
\end{tabular} & 70 & \\
\hline 7 & & 200 & $\begin{array}{c}10 \mathrm{keV} \\
7 \times 1015 \mathrm{~cm}^{-2} \\
\end{array}$ & 30 & $\begin{array}{c}100 \mathrm{~min} \\
800^{\circ} \mathrm{C}, \mathrm{O}_{2}\end{array}$ \\
\hline
\end{tabular}

Táble 3 Processing splits on Batch V of double-poly bipolar.

Note that the following was done to minimize lateral encroachment of the extrinsic-base:

1) amorphous-Si was preferred to polycrystalline-Si as the deposited material for the base electrode 2) the oxide grown after base poly patteming was limited to a small thickness 3 ) minimun overetch of the first SWS 4) other high temperature processes were limited to the standard production emitter anneals.

Figures 31 and 32, are cross-sectional SEM pictures of a transistor after emitter poly deposition (For this particular wafer a $400 \mathrm{~nm}$ thick emitter poly layer was deposited). The pictures show that the transistors have good poly to poly isolation. Only $27 \mathrm{~nm}$ of the base oxide has been etched off forming a SWS in the range of $102 \mathrm{~nm}$ wide at the bottom of the emitter stripe. The SWS width at the top of the base poly layer (where there is no effect of the poly foot on the SWS width) is $170 \mathrm{~nm}$ giving a ratio of deposited oxide thickness over SWS width of $60 \%$. 


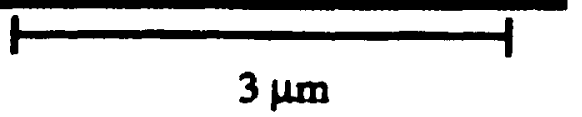

Figure 31 Cross-sectional SEM picture of a typical double-poly transistor from Batch V after emitter poly deposition.

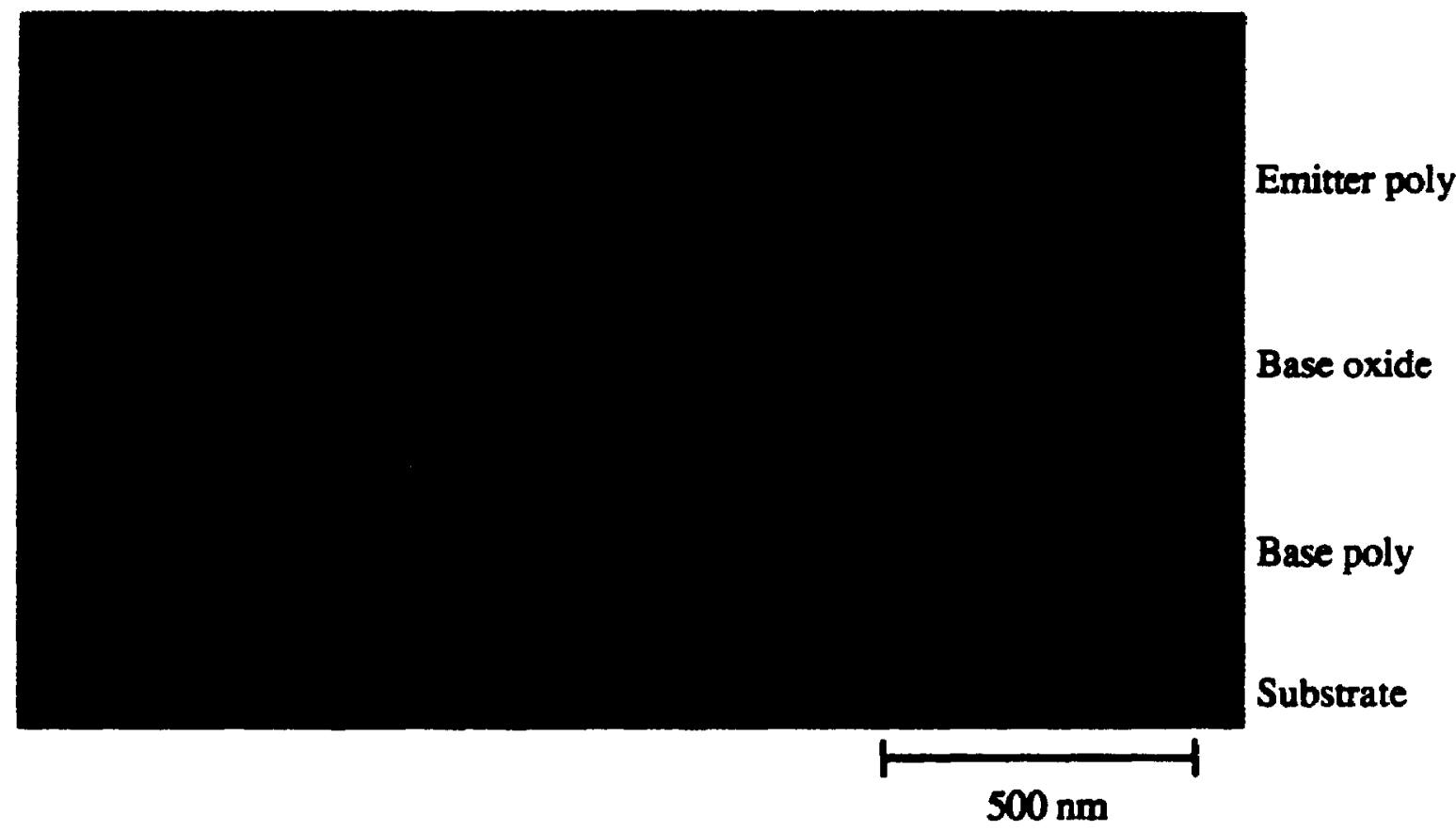

Figure 32 Cross-sectional SEM picture of a typical double-poly transistor from Batch V after emitter poly deposition.

On wafers 5 and 6 a boron dose of $3 \times 10^{13} \mathrm{~cm}^{-2}$ was implanted with an energy of $13 \mathrm{keV}$ prior to base poly deposition. The initial intent of this split was to investigate the possibility of using a low dose implant to form the extrinsic base. Although it would increase the base resistance, it could allow significant reduction in anneal temperature/time if used with an in-situ doped emitter. 
Note that it would require that the base poly etch remove most of the doped crystalline $\mathrm{Si}$ in the intrinsic area to not influence the base doping concentration.

\subsubsection{Electrical Results}

Figure 33 is a Gummel plot of a typical $2 \times\left(0.8 \times 10 \mu \mathrm{m}^{2}\right)$ transistor from wafers 1,2 and 3 . The picture shows a good collector current characteristic, but excess base current is observed for small forward bias voltage. Better characteristics were found on larger transistors. Figure 34, is a

Gummel plot of a typical $1.6 \times 8 \mu \mathrm{m}^{2}$ transistor from wafers 1,2 and 3. The picture shows a good base current characteristic with an ideality factor of 1.0 down to $1 \mathrm{pA}$. Figure 35 shows the I-V characteristics of the base-emitter junction in reverse mode. The figure shows a reasonable reverse current leakage ( $0.5 \mathrm{nA}$ at $3 \mathrm{~V}$ ). Figure 36 shows the current gain is about of 57 foi 6 orders of magnitude in $\mathrm{I}_{\mathrm{c}}$. Figure 37 shows a good $\mathrm{I}_{\mathrm{c}}$ versus $\mathrm{V}_{\mathrm{ce}}$ characteristic for different base current. The Early voltage was determined to be $60 \mathrm{~V}$. Figure 38 is a Gummel plot of a typical $1.6 \times 8 \mu \mathrm{m}^{2}$ transistor from wafer 7. Good base current characteristics were obtained for these transistors with base poly thickness reduced to $200 \mathrm{~nm}$, showing that it is possible to reduce the transistor topography. Figures 39 and 40 show the base current for $0.4 \mathrm{~V}$ forward bias and $3 \mathrm{~V}$ reverse bias applied to the base-emitter junction for the different wafers and transistor sizes. Figure 41 shows the current gain at $0.8 \mathrm{~V}$ base-emiter bias for the different wafers and device sizes. These figures show that for most wafers, lower forward bias base-emitter currents and higher gains were obtained for larger transistors. This is probably due to narrower SWS width for transistors with narrower emitter openings leading to increase tunneling current between the extrinsic base and the emitter. The data in figures 39,40 and 41 were extracted from a typical transistor which was determined by measuring a minimum of five transistors of the same size for each wafer. 


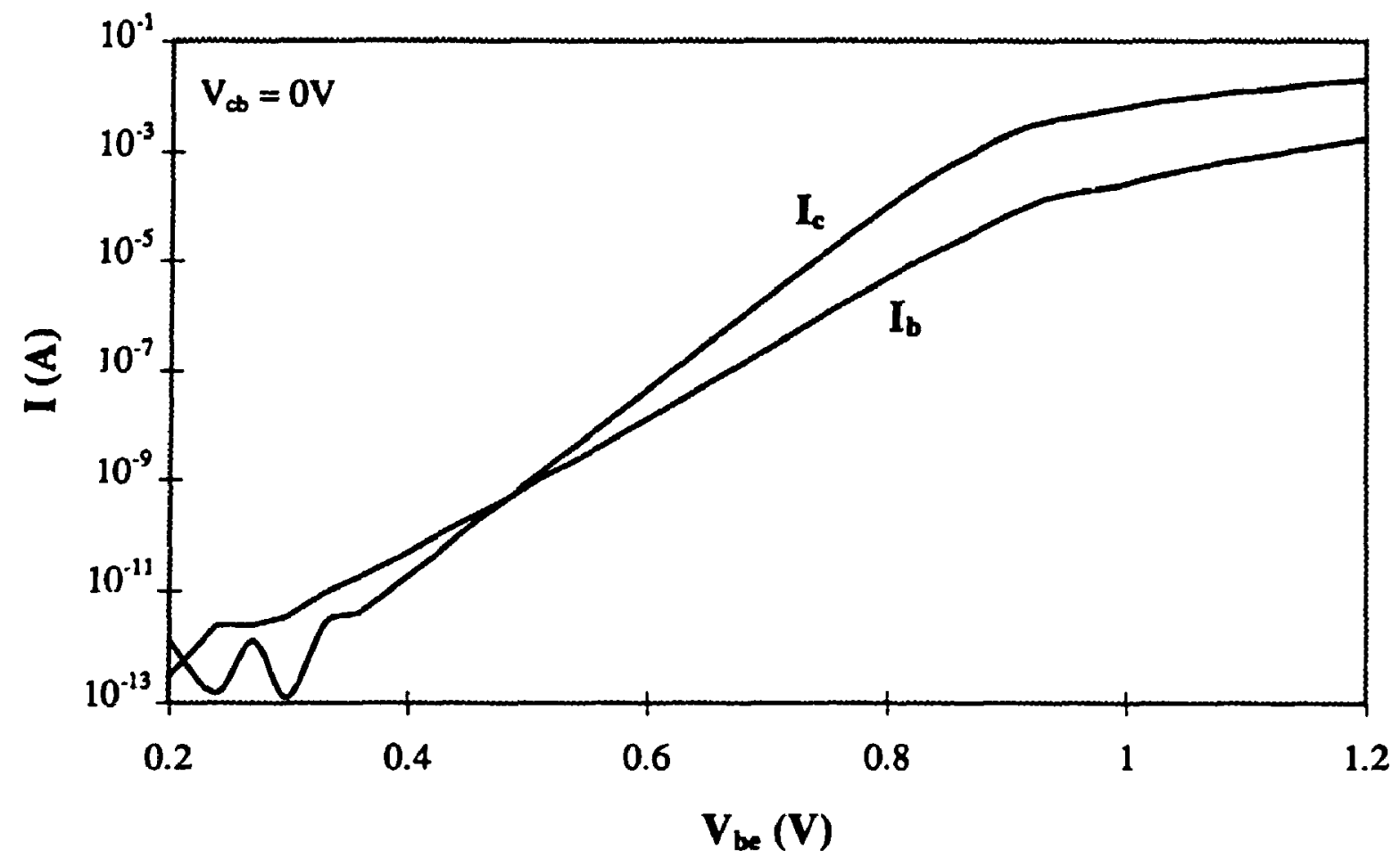

Figure 33 Gummel plot of a typical $2 \times(0.8 \times 10) \mu \mathrm{m}^{2}$ transistor from Batch V.

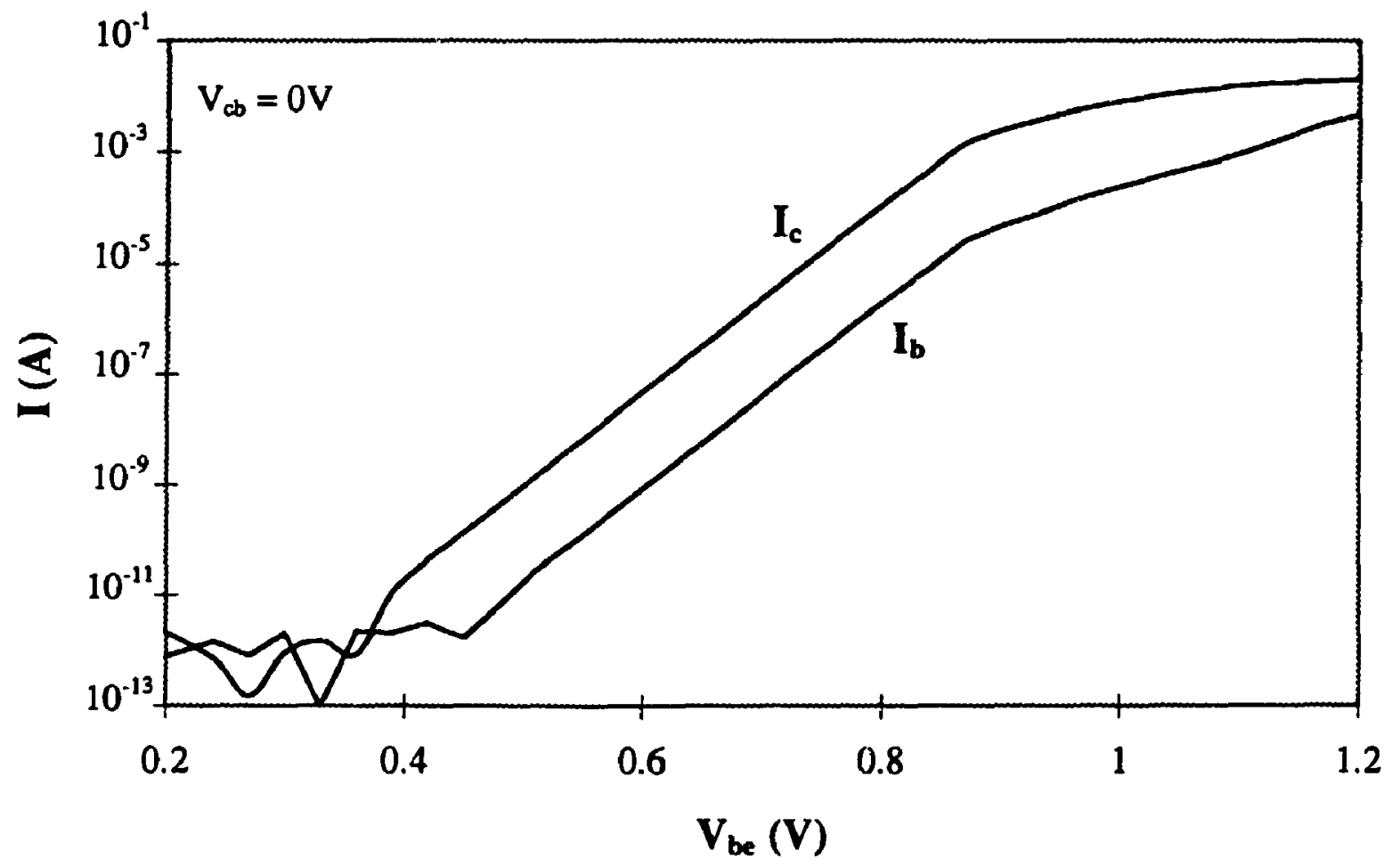

Figure 34 Gummel plot of a typical $1.6 \times 8 \mu \mathrm{m}^{2}$ transistor from Batch V wafers 1, 2 , and 3. 


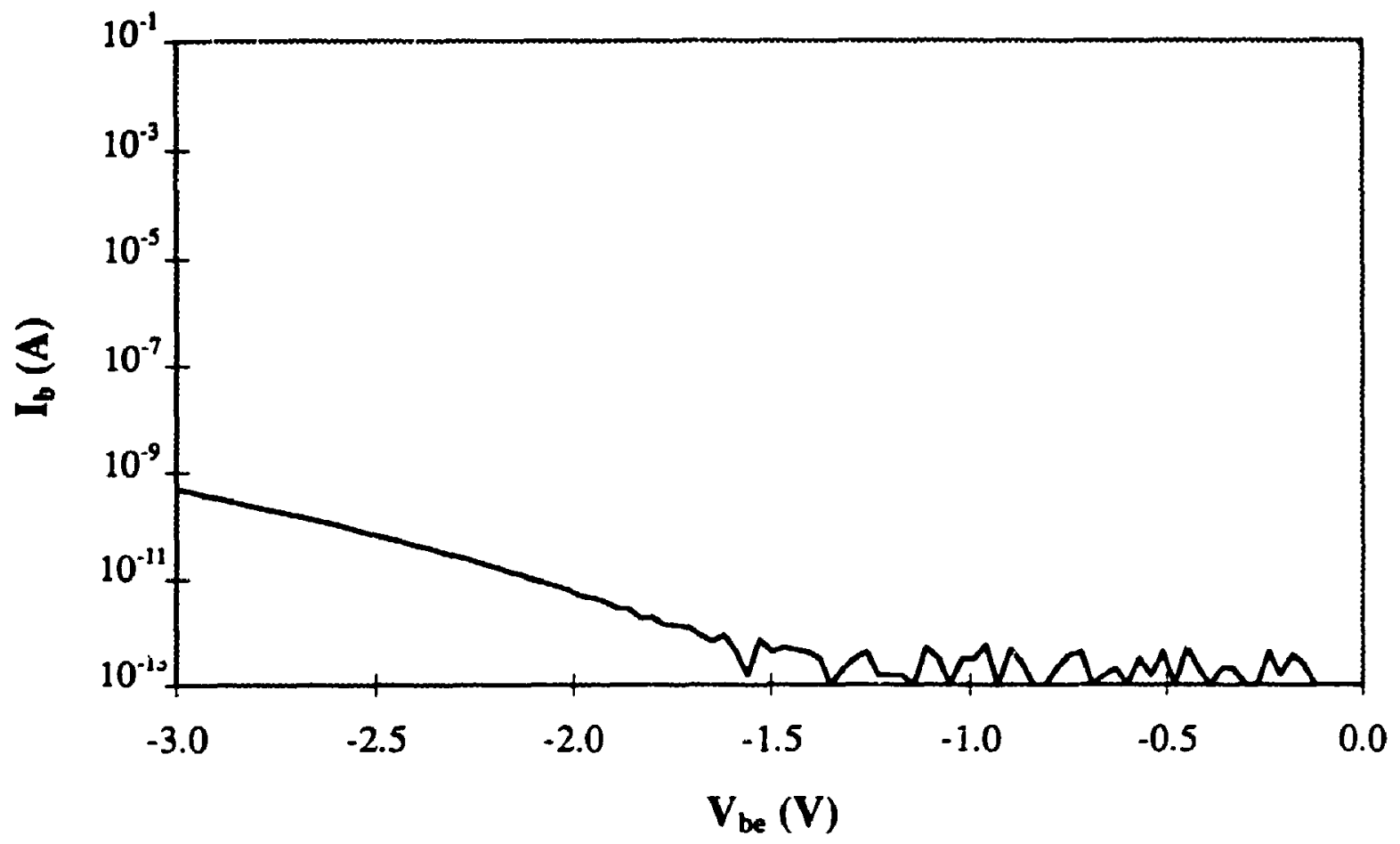

Figure 35 Reverse mode I-V characteristics of the base-emitter junction of a typical $1.6 \times 8 \mu \mathrm{m}^{2}$ transistor from Batch $V$ wafers 1,2 , and 3 .

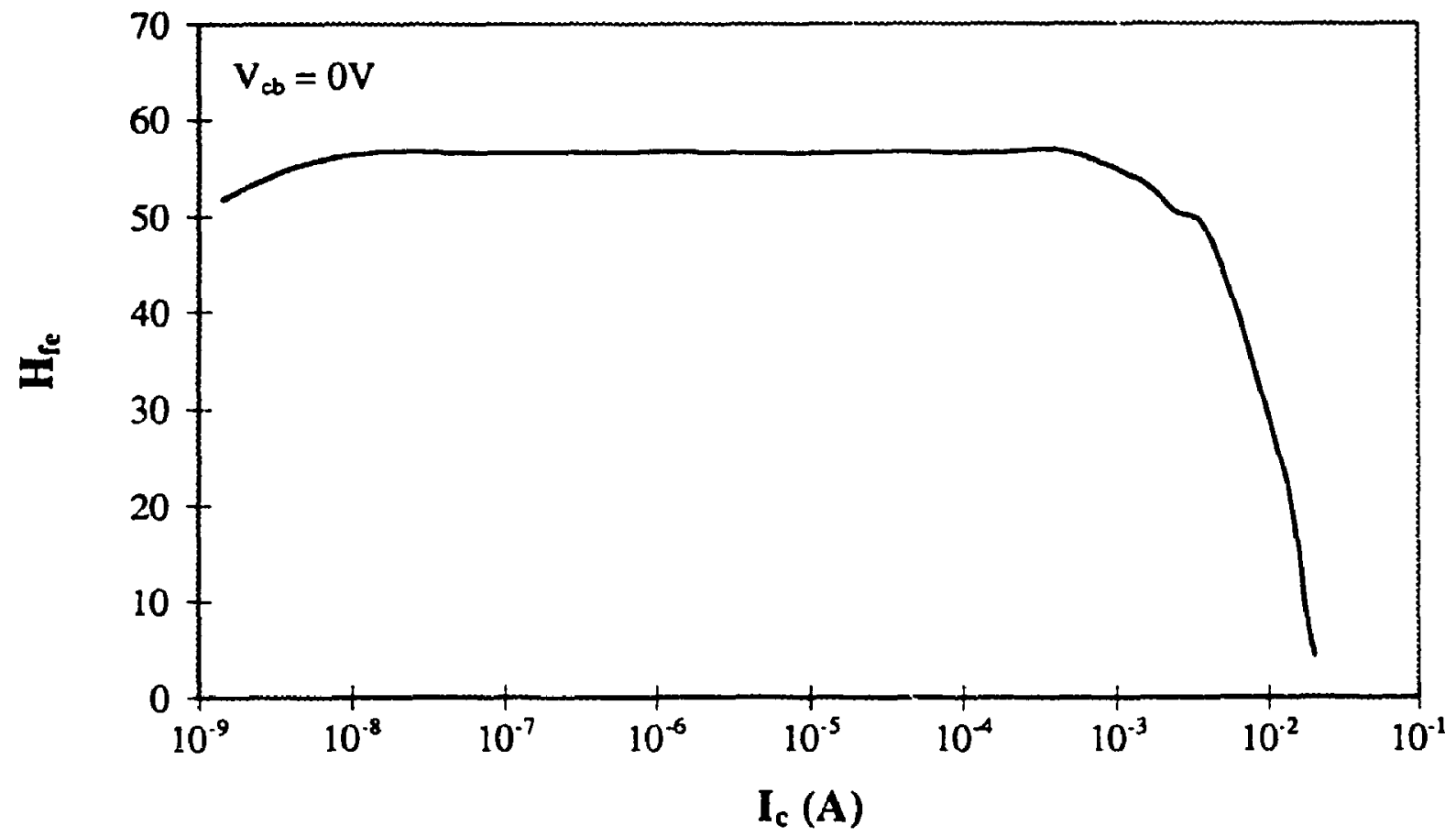

Figure $36 \quad H f e$ versus $\log \mathrm{I}_{\mathrm{c}}$ curve of a typical $1.6 \times 8 \mu \mathrm{m}^{2}$ transistor from Batch $V$ wafers 1,2 , and 3 . 


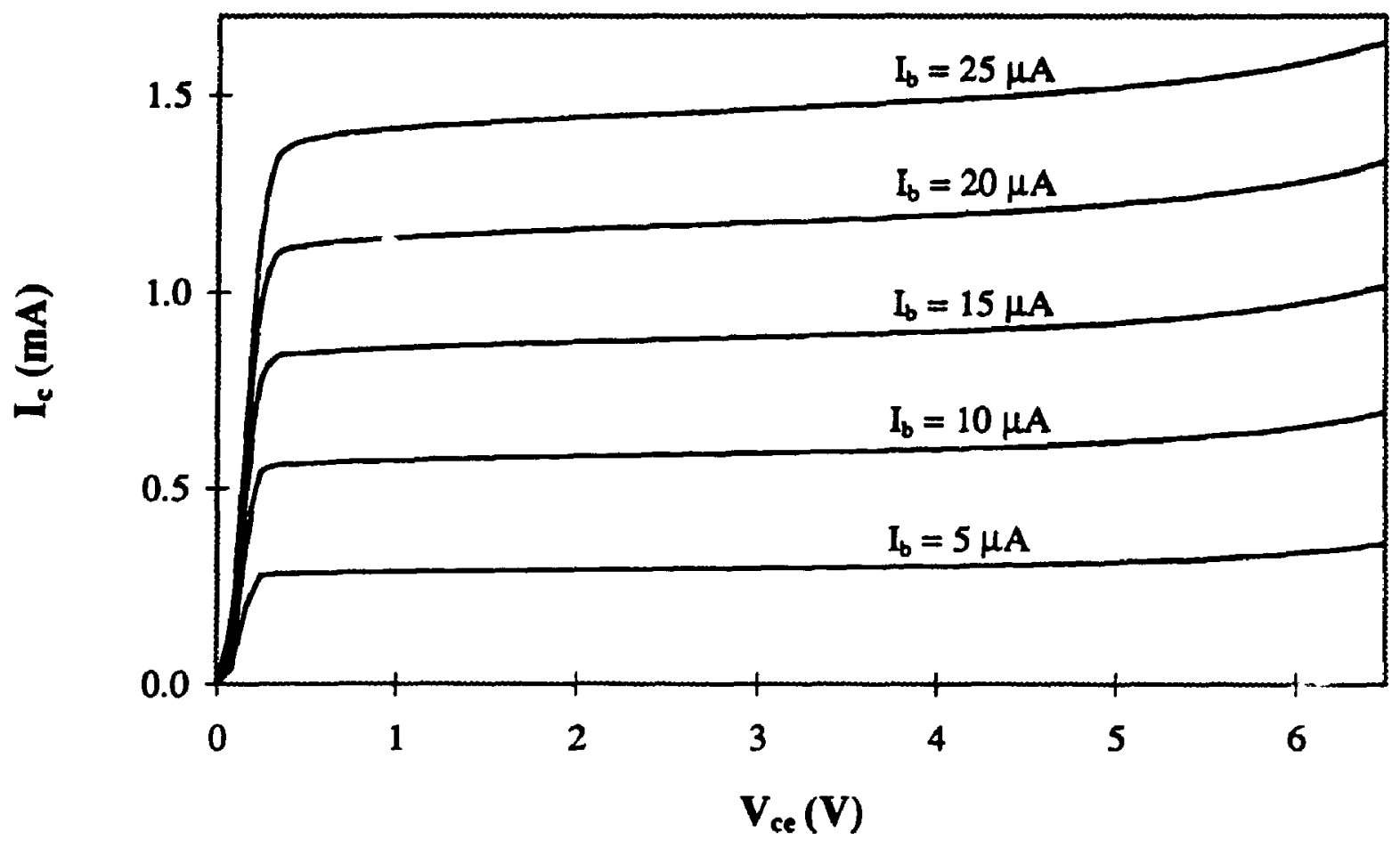

Figure $37 \quad \mathrm{I}_{\mathrm{c}}$ versus $\mathrm{V}_{c e}$ curve of a typical $1.6 \times 8 \mu \mathrm{m}^{2}$ transistor from Batch $\mathrm{V}$ wafers 1,2 , and 3.

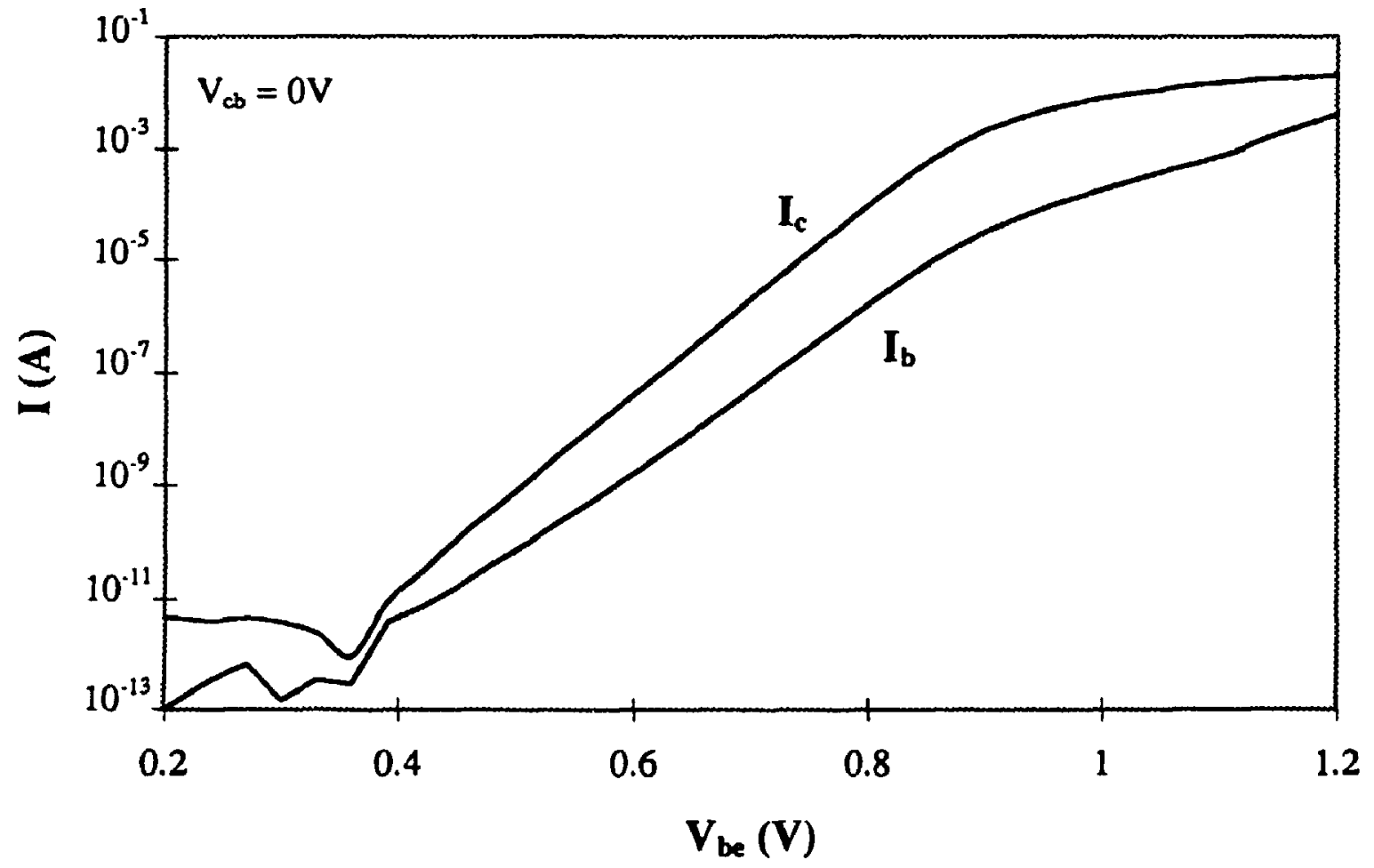

Figure 38 Gummel plot of a typical $1.6 \times 8 \mu \mathrm{m}^{2}$ transistor from Batch V wafer 7 . 


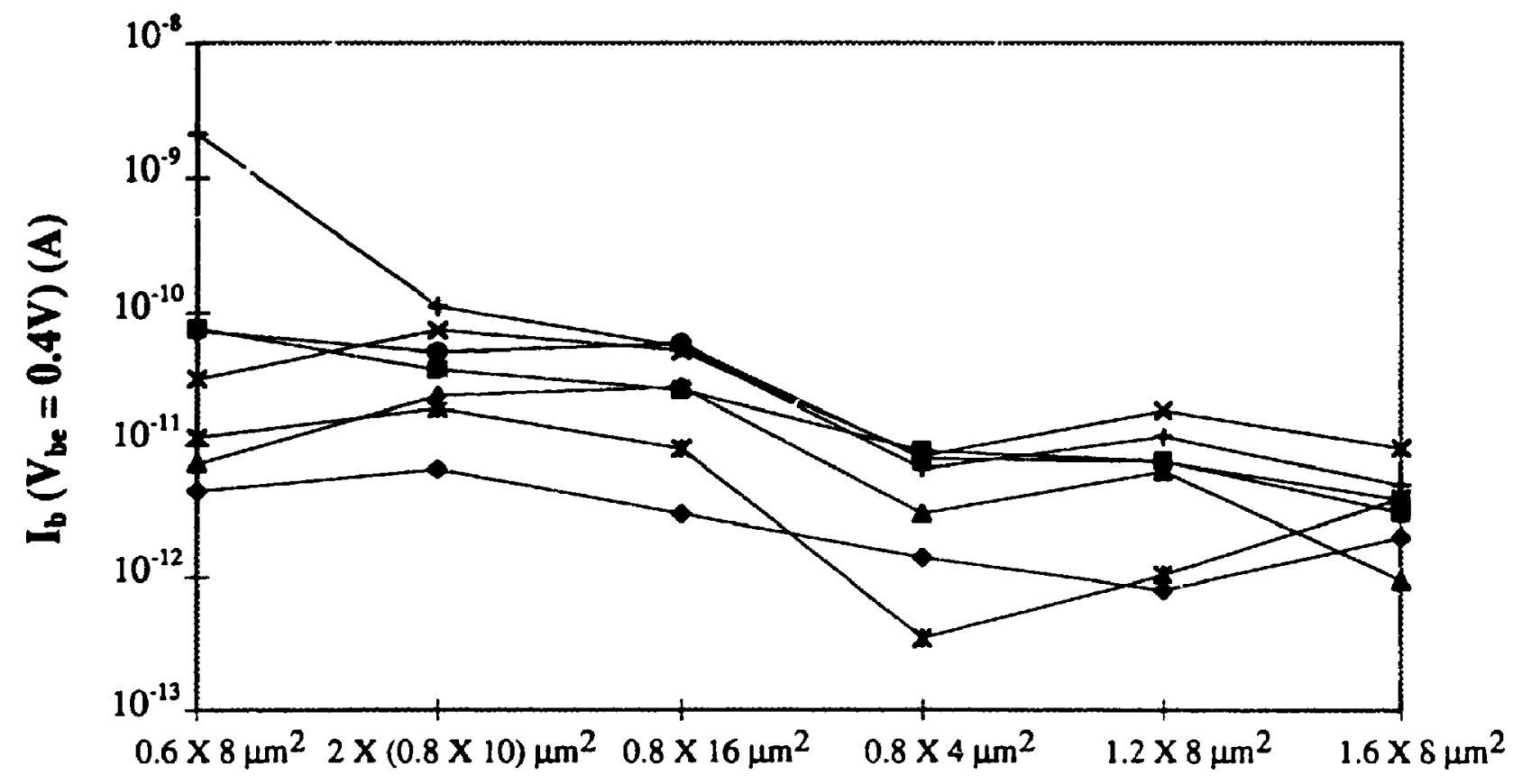

Device

Figure 39 Base current for $0.4 \mathrm{~V}$ base-emitter junction forward bias for the different wafers and transistor sizes from Batch V.

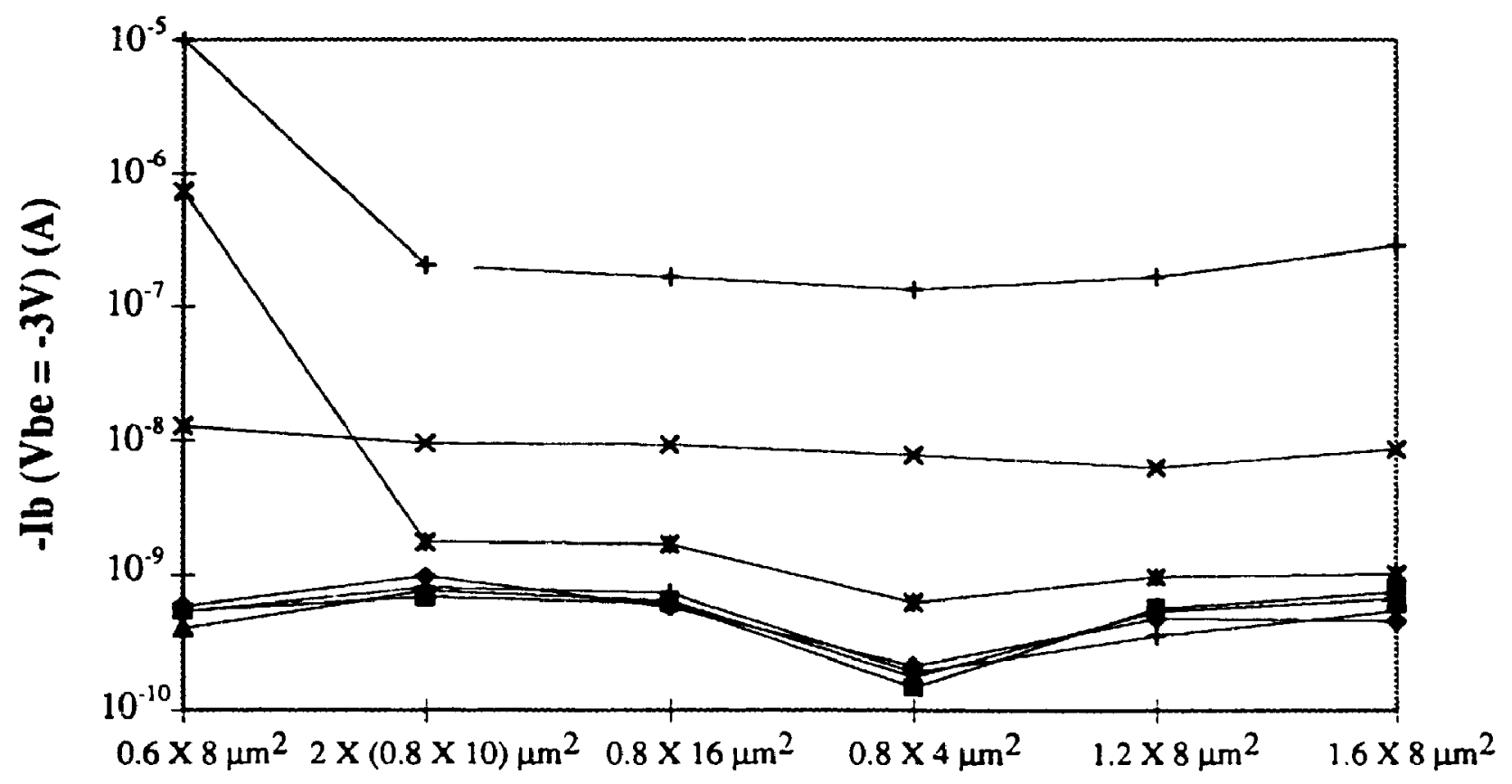

\section{Device}

Figure 40 Base current for $3 \mathrm{~V}$ base-emitter junction reverse bias for the different wafers and transistor sizes from Batch $V$.

$\begin{array}{lll}\rightarrow \text { Wofer } \# 1 & \text {-Wafer } \# 3 \quad \text { Wafer } \# 2 \quad \rightarrow \text { Wafer } \# 5 \\ - \text { Wafer } \# 4 \quad \text { Wafer } \# 6\end{array}$




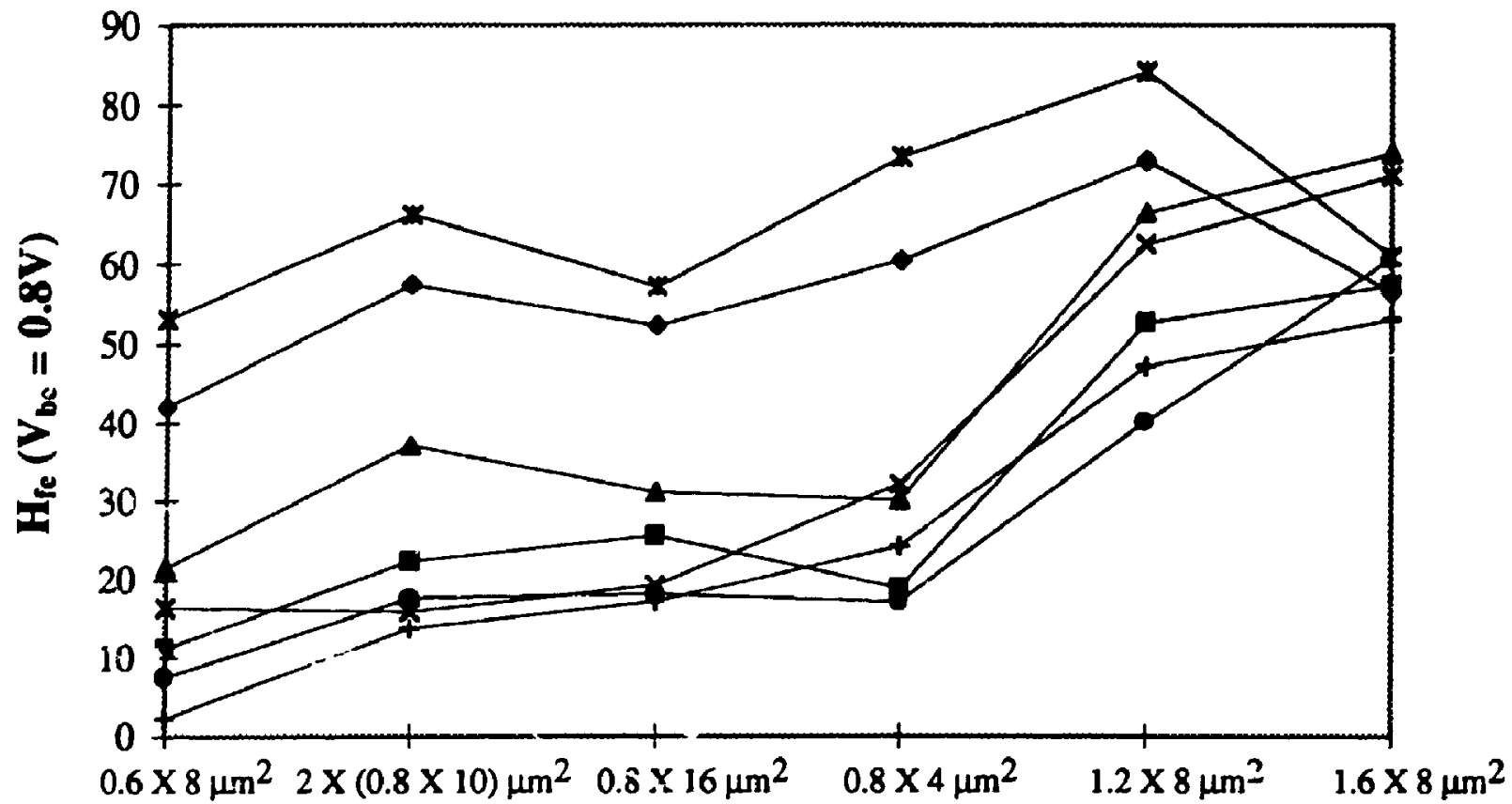

Device

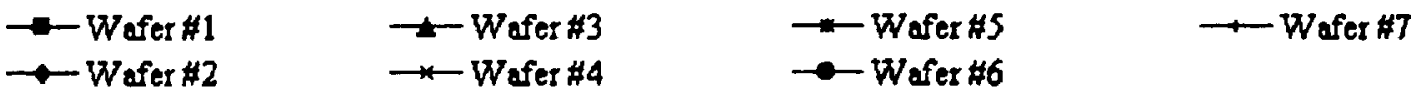

Figure 41 Current gain at $0.8 \mathrm{~V}$ base-emiter bias for the different wafers and device sizes from Batch V.

\subsection{Chapter Conclusion}

In the previous chapter, the electrical effect of etch damage on diodes formed by diffusion of arsenic from a polysilicon layer was investigated. Surprisingly the diode characteristics seemed insc nsitive to this etch, at least over the range of etch condition. examined. This result suggests that it should be possible to dry etch a base electrode directly deposited on the crystalline substrate without affecting the base-emitter junction I-V characteristics.

This chapter discussed the implementation of a double-poly bipolar process by depositing the base poly layer directly on the crystalline substrate and completly patterning it by dry etching. This processing approach was felt to be of interest because of its relative simplicity. As the measured plasma contamination is known to depend on many etch parameters and on annealing conditions, 
conditions, the base poly was patterned with the same etch parameters that were used for the removal of the sacrificial silicon layer in the diode experiment. Also, the furnace and rapid thermal anneals used in the diode experiment were incorporated in the double-poly bipolar process flow. Several transistors with nearly ideal DC characteristics were fabricated, confirming the hypothesis the diode experiment suggested. 


\subsection{CONCLLSION}

The research program described in this thesis was motivated by Northern Telecom Electronics' need for a high-speed double-poly bipolar transistor. Although it is well known that self-alignment of a polysilicon emitter to polysilicon base electrodes greatly reduces many of the extrinsic capacitances and resistances in a bipolar transistor, thereby improving speed, the double-poly electrode structure is difficult to manufacture. In particular, fabrication of the double-poly structure requires removal of the base polysilicon electrode from the silicon substrate by plasma etching prior to formation of the intrinsic base and the emitter. Plasma etching is in general known to damage the semiconductor surface, and for this structure the damage would be located along the critically sensitive base-emitter junction in the intrinsic transistor. Surprisingly, when this research program began virtually no information was available in the literature regarding the effect of etch damage on the electrical characteristics of double-poly BJTs, or on techniques required for mitigation of this damage. It was apparent that the IBM processing approach minimizes exposure of the intrinsic base region to reactive ion etching at the cost of increased manufacturing complexity. In their approach, the patterning of in-situ doped base poly is completed by preferential wet etching. A main goal of this thesis was therefore to determine what procedures for etching the base polysilicon would be required to produce a double-poly BJT with acceptable baseemitter junctions characteristics.

In the first experimental part of this study, the electrical effect of etch damage on diodes formed by diffusion of arsenic from a polysilicon layer was investigated. This was accomplished by depositing a sacrificial Si layer on the silicon substrate, and then removing this sacrificial layer by RIE. This approach demonstrated, without the need to process full double-poly bipolar transistors, that dry etching of a base electrode directly deposited on the crystalline substrate using a chlorine plasma with a partial pressure of $433 \mathrm{mTorr}$, a total pressure of $6.0 \mathrm{mT}$ Trr and a power of $450 \mathrm{~W}$ in a 
Lam Research Corporation Rainbow etcher would probably not affect the base-emitter junction I-V characteristics.

In the second experimental part of this study, the inf: . 1 nation gained in the first part was used to transform Northem Telecom's non-self-aligned single poly bipolar to a double-poly BJT. A relatively simple processing approach was chosen in which the base electrode is deposited directly on the $\mathrm{Si}$ substrate as an undoped amorphous-Si layer, implanted with boron, covered by a deposited oxide, and completely patterned by dry etching. The intrinsic base is implanted before the formation of an oxide SWS. Emitter poly is then deposited, implanted, and annealed. As the measured plasma contamination is known to depend on many etch parameters and on annealing conditions, the base poly was patterned with the same etch parameters that were used for the removal of the sacrificiaj silicon layer in the diode experiment. Also, the fumace and rapid thermal anneals used in the diode experiment were incorporated in the double-poly bipolar process flow.

Although care was taken to chose a simple processing approach, techniques particular to the processing of double-poly BJT were required. Diffusion of boron from an implanted Si layer was characterized by SIMS. Base electrode panerning was performed with small overetch (in the range of $40 \mathrm{~nm})$.

Controlling the SWS overetch in order to preserve most of the base cxide and to obtain a suitable SWS around the base electrode was found to be one of the most difficult processing steps in fabricating useful double-poly BJTs. An overly long etch removed most of the oxide causing emitter and base polysilicon layers to come into contact, leading to excessive tunneling current between the heavily doped extrinsic-base and emitter. Also, a residue was found to create notches in the base oxide at the base electode top edges, again leading to emitter poly to base poly coniact. The DC characteristics of the resulting transistors showed large leakage base current for reverse bias and large excess current at low base-emitter forward bias. 
Close monitoring of the SWS etch and the introduction of a wet resist strip before the SWS oxide deposition allowed fabrication of transistors with much improved poly to poly isolation. The DC characteristics of these transistors showed a significant improvement especially for the larger transistors ( $1.6 \mu \mathrm{m}$ wide stripe in base poly). These transistors showed gains of about 57 for 6 orders of magnitude in $I_{c}$, and reverse bias emitter-base current of $0.5 \mathrm{nA}$ at $3 \mathrm{~V}$. These results confirmed that the RIE etch described above could be used to completly patterned a base electrode directly deposited on the crystalline substrate with no effect to the base-emitter junction I-V characteristics.

The large base current leakage previously discussed could also be explained by emitter depletion but the fact that the number of transistors with acceptable DC characteristics significantly increased on the batch with improved SWS indicates that this is a minor effect.

In order to achieve low base current leakage on all transistor sizes, emitter dopant diffusion should be investigated in order to determine if the emitter could be formed with smaller anneal temperatures/times. This would reduce lateral encroachment of the extrinsic-base. Also, a calibrated oxide etcher with sensitive end-pointing capability or highly reproducible etch rate would be required to manufacture this technology.

On the last batch of wafers processed, the large transistors with base poly thickness reduced to $200 \mathrm{~nm}$ also showed good DC characteristics. Reducing the base poly thickness reduces the overall topography of the transistor as well as the aspect ratio of the emitter opening, making contacting and metalization easier. Further reduction of the base poly thickness would probably require that the silicided base poly be placed only over field oxide. A mask set designed specifically for doublepoly bipolar would be requirs 3 to accomplish this. 
Non-self-aligned bipolar transistors with implanted intrinsic base have been reported to show increased noise level compared to transistors with diffused intrinsic bases [65]. The increased noise level was atributed to damage to the crystalline substrate caused by the ion implantation.

Although crystalline damage due to ion implantation and reactive ion etching may show different effect, it suggests that noise measurements should be done on the fabricated double-poly bipolars to ensure that its level is appropriate to circuit applications. 


\section{REFERENCES}

(1) C. Yamaguchi, Y. Kobayashi, M. Miyake, K. Ishii, H. Ichino, "0.5- $\mu \mathrm{m}$ Bipolar Technology Using a ivew Base Formation Method: SSTIC", IEEE Bipolar Circuits and Technology Meeting, 1993, pp. 63-66.

(2) S. Konoka, Y. Yamamoto, T. Sakai, "A 30-ps Si Bipolar IC Using Super Self-Aligned Process Technology", IEEE Transactions on Electron Devices, Vol. ED-33, No. 4, April 1986, pp. 526-531.

(3) J. Middelhoek, A. Kooy, "Polycristalline Silicon as a Diffusion Source and Interconnect Layer in I2L Realizations", IEEE 'ournal of Solid-State Circuits, Vol. SC-12, No. 2, April 1977, pp. 135-138.

(4) I. Ishida, K. Aomura, T. Nakamura, "An Advanced PSA Process for High Speed Bipolar VLSI", International Electron Devices Meeting, 1979, pp. 336-339.

(5) H. Nakashiba, I. Ishida, K. Aomura, T. Nakamura, "An Advanced PSA Technology for High-Speed Bipolar LSI", IEEE Transactions of Electron Devices, Vol. ED-27, No. 8 , August 1980, pp. 1390-1394.

(6) S. Konaka, Y. Yamamoto, T. Sakai, "A 30 ps Si Bipolar IC Using Super Self-Aligned Process Technology", Extended Abstracts of the 16th Conjerence on Solid State Devices and Materials, Kobe, 1984, pp. 209-212.

(7) T. Sakai, S. Konaka, Y. Kobayashi, M. Suzuki, Y. Kawai, "Gigabit Logic Bipolar Technology: Advanced Super Self-Aligned Process Technology", Electronics Letters, April 1983, Vol. 19, No. 8, pp. 283

(8) T. Sakai, S, Konaka, Y. Yamoto, M. Suzuki, "Prospects of SST Technology for High Speed LSI", International Electron Devices Meeting, 1985, pp. 18-21.

(9) M. Suzuki, K. Hagimoto, H. Ichino, S. Konaka, "A 9-GHz Frequency Divider Using Si Bipolar Super Self-Aligned Process Technology", IEEE Electron Device Letters, Vol. EDL-6, No. 4, April 1985, pp. 181-183.

(10) S. Konaka, Y. Amemiya, K. Sakuma, T. Sakai, "A 20 ps/G Si Bipolar IC Using Advanced SST with Collector Ion Implantation", Extended Abstracts of the 19th Conference on Solid State Devices and Materials, Tokyo, 1987, pp. 331-334.

(11) S. Konaka, E. Yamamoto, K. Sakuma, Y. Amemiya, T. Sakai, "A 20-ps Si Bipolar IC Using Advanced Super Self-Aligned Process Technology with Collector Ion Implantation", IEEE Transactions on Electron Devices, Vol. 36, No. 7, July 1989, pp. 1370-1375. 
(12) H. Ichino, M. Suzuki, S. Konaka, T. Waklimoto, T. Sakai, "Super Self-Aligned Process Technology and its Applications", IEEE Bipolar Circuits \& Techonology Meeting, $1^{1^{\circ}}$. pp. 15-18.

(13) T.H. Ning, R.D. Isaac, P.M. Solomon, D.D. Tang and H.N. Yu, "Self-Aligned NPN Bipolar Transistors", International Electron Devices Meeting, 1980, pp. 823-824.

(14) T.H. Ning, R.D. Isaac, P.M. Solomon, D.D.-L. Tang, Hwa-Nien Yu, G.C. Feth, S.K. Wiedmann, "Self-Aligned Bipolar Transistors for High-Performance and Low-PowerDelay VLSI", IEEE Transactions on Electron Devices, Vol. ED-28, No. 9, September 1981, pp. 1010-1013.

(15) D.D. Tang, P.M. Solomon, T.H. Ning, R.D. Isaac, R.E. Burger, "1.25 $\mu \mathrm{m}$ Deep-GrooveIsolated Self-Aligned Bipolar Circuits", Journal of Solid-State Circuits, Vol. SC-17, No. 5, October 1982, pp. 925-931.

(16) J. Warnock, J.D. Cressler, K.A. Jenkins, T.-C. Chen, J.Y.-C. Sun, D.D. Tang, "50-GHz Self-Aligned Silicon Bipolar Transistors with Ion-Implanted Base Profiles", IEEE Electron Device Letters, Vol. 11, No. 10, October 1990, pp. 475-4?7.

(17) T.-C. Chen, K.Y. Toh, J.D. Cressler, J. Warnock, P.-Fei Lu, D.D. Tang, G.P. Li, C.-T. Chuang, T.H. Ning, "A Submicrometer High-Performance Bipolar Technology", IEEE Electron Device Letters, Vol. 10, No. 8, August 1989, pp. 364-366.

(18) J. Warnock, J.D. Cressler, K.A. Jenkins. C. Stanis, J.Y.C. Sun, D.D. Tang, E. Petrillo, C.K. Hu, "High performance Bipolar Technology for Improved ECL Power Delay", IEEE Electron Device Letters, Vol. 12, No. 6, June 1991, pp. 315-317.

(19) J. Warnock, G.G. Shahidi, Bijan Davari, B. Wu, Y. Taur, C. Wong, K. Jenkins, C.-L. Chen, "BiCMOS Technology with 60-GHz n-p-n Bipolar and 0.25- $\mu \mathrm{m}$ CMOS", IEEE Electron Device Letters, Vol 13, No 11, Nov. 1992. pp. 578-580.

(20) G.P. Li, T.H. Ning, C.T. Chuang, M.B. Ketchen. D.D.-L. Tang, J. Mauer, "An advanced High-Performance Trench-Isolated Self-Aligned Bipolar Technology", IEEE Transactions on Electron Devices, Vol. Ed-34, No 11, .Nov. 1987, pp 2246-2253

(21) T. Yamaguchi, S. Uppili, J.S. Lee, G.H. Kawamoto, T. Dosluoglu, S. Simpkins, "Process and Device Characterization for a $30-\mathrm{GHz} \mathrm{f}_{\mathrm{T}}$ Submicrometer Double Poly-Si Bipolar Technology Using $\mathrm{BF}_{2}$-Implanted Base with Rapid Thermal Process", IEEE Transactions on Electron Devices, Vol. 40, No. 8, August 1993, pp. 1484-1495.

(22) H.K. Park, K. Boyer, C. Clawson, G. Eiden, A. Tang, T. Yamaguchi, J. Sachitano, "HighSpeed Polysilicon Emitter-Base Bipolar Transistor", IEEE Electron Device Letters, Vol. EDL-7, No. 12, December 1986, pp. 658-660. 
(23) T. Yuzuriha, T Yamaguchi, J. Lee, "Submicron Bipolar-CMOS Technology Using $16 \mathrm{GHz}$ $\mathrm{f}_{\mathrm{T}}$ Double Poly-SI Bipolar Devices", International Electron Devices Meeting, 1988, pp. 748-751.

(24) T. Yamaguchi, T.H. Yuzuriha, "Processe Integration and Device Performance of a Submicrometer BiCMOS with 16-GHz f $\mathrm{T}$ Double Poly-Bipolar Devices", IEEE Transactions on Electron Devices, Vol 36, No. 5, May 1989, pp. 890-896.

(25) T, Yamaguchi, Y.-C. Simon Yu, E.E. Lane, J.S. Lee, E.E. Patton, R.D. Herman, D.R. Ahrendt, V.F. Drobny, T.H. Yuzuriha, V.E. Garuts, "Process and Device Performance of a High-Speed Double Poly-Si Bipolar Technology Using Borosenic-Poly Process with Coupling-Base Implant", IEEE Transactions on Electron Devices, Vol. 35, No. 8, August 1988, pp. 1247-1255.

(26) P.J. Zdebel, R.J. Balda, B.-Y. Hwang, V.d.l. Torre, A. Wagner, "MOSAIC III - A High Performance Bipolar Technology with Advanced Self-Aligned Devices", IEEE Bipolar Circuits and Technology Meeting, 1987, pp. 172-175.

(27) V. dela Torre, J. Foerstner, B. Lojek, K. Sakamoto, S.L. Sundaram, N. Tracht, B. Vasquez and P. Zdebel, "MOSAIC V - A Very High Performance Bipolar Technology", IEEE Bipolar Circuits and Techonology Meeting, 1991, pp. 21-24.

(28) J.D. Hayden, J.D. Bumett, J.R. Pfiester, and M.P. Woo, "An Ultra_Shallow Link Base for a Double Polysilicon Bipolar Transistor", IEEE Bipolar Circuits and Technology Meeting, 1992, pp. 96-99.

(29) R.C Taft, J.D. Hayden, D.J. Denning, and H.C. Kirsch, "A High-Performance LowComplexity Bipolar Technology using Selective Collector Compensation", International Electron Devices Meeting, 1992, pp. 405-408.

(30) M. Nakamae, "Recent Progress and Future Prospect for VLSI Si Bipolar Transistors", IEEE Bipolar Circuits and Techonology Meeting, 1987, pp. 5-6.

(31) J.E. Brighton, D.P. Verret, T.T. Ten Eyck, M.T. Welch, R.E. McMann, M.L. Torreno, A.T. Appel, M.P. Keleher, "Scaling Issues In The Evolution of ExCLTM Bipolar Technology", IEEE 1988 Bipolar Circuits \& Technology Meeting, Paper, pp. 121-124.

(32) A. Tahara, K. Hashimoto, H. Katakura, I. Amano, T. Deguchi, and Satoshi Sudo, "Lowpower High-speed ECL Circuit with 0.5- $\mu \mathrm{m}$ Rule and 30-GHz $\mathrm{f}_{\mathrm{T}}$ Technology", IEEE 1989 Bipolar Circuits \& Technology Meeting, 1989, pp. 169-172.

(33) K. Ueno, H. Goto, F. Sugiyama and H. Tsunoi, "A Sub-40 ps Circuit at a Switching Current of 1.28 mA", International Electron Devices Meeting, 1987, pp. 371-374.

(34) M. Vora, Y.L. Ho, S. Bhamre, F. Chien, G. Bakker, H. Hingar, C. Schmitz, "A Sub-100 Picosecond Bipolar ECL Technology", International Electron Devices Meeting, 1985, pp. 34-37. 
(35) H. Nishizawa, S. Azuma, T. Yoshitake, K. Yamada, T. Ikeda, H. Masuda, A. Anzai, "A fully $\mathrm{SiO}_{2}$-Isolated Self-Aligned SOI-Bipolar Transistor for VLSIs", IEEE 1991 Bipolar Circuits and Technology Meeting, pp. 53-55.

(36) T. Hiramoto, N. Tamba, M. Yoshida, T. Hashimoto, T. Fujiwara, K. Watanabe, M. Odaka, M. Usami, T. Ikeda, "A $27 \mathrm{GHz}$ Double Polysilicon Bipolar Technology on Bonded SOI with Embedded $58 \mu \mathrm{m}^{2}$ CMOS Memory Cells for ECL-CMOS SRAM Applications", International Electron Devices Meeting, 1992, pp. 39-42.

(37) H. Kaza, K. Ehinger, T.F. Meister, H.-W. Meul, P. Weger, I. Kerner, M. Miura-Mattausch, R. Schreiter, D. Hartwig, M. Reisch, M. Ohnemus, R. Köpl, J. Weng, H. Schaber, L. Treitinger, "A 1- $\mu \mathrm{m}$ Polysilicon Self-Aligning Bipolar Process for Low-Power High Speed Integrated Circuits", IEEE Electron Device Letters, Vol 10, No. 8, Aug. 1989, pp 344-346.

(38) E. Bertagnolli, K. Ehinger, H. Klose, J. Weng, D. Hartwig, "Modular Deep Trench Isolation Scheme for $38 \mathrm{GHz}$ Self-Aligned Double Polysilicon Bipolar Devices, IEEE 1991 Bipolar Circuits and Technology Meeting, pp. 25-28.

(39) C.T. Chuang, D. D.-L. Tang, G.P. Li, and E. Hackbarth, "On the Punchthrough Characteristics of Advanced Self-Aligned Bipolar Transistors", IEEE Transactions on Electron Devices, Vol. 34, No. 7, July 1987, pp. 1519-1524.

(40) P.-F. Lu, G.P. Li, D.D. Tang, "Lateral Encroachment of Extrinsic-Base Dopant in Submicrometer Bipolar Transistors", IEEE Electron Device Letters, Vol. EDL-8, No. 10, October 1987, pp. 496-498

(41) G.P. Li, C.T. Chuang, T.-C. Chen, and T.H. Ning, "On the Narrow-Emitter Effect of Advanced Shallow-Profile Bipolar Transistors, IEEE Transactions on Electron Devices, Vol 35, No. 11, Nov 1988, pp. 1942-1949.

(42) D.D. Tang, T.-C. Chen, C.-T. Chuang, G.P. Li, J.M.C. Stork, M.B. Ketchen, E. Hackbarh, T.H. Ning, "Design Considerations of High Performance Narrow-Emitter Bipolar Transistors", IEEE Electron Device Letters, Vol. EDL-8, No. 4, April 1987, pp. 174-175.

(43) E. Hackbarth, G.P. Li, and T.C. Chen, "Tunneling Component in Polysilicon Self-Aligned Bipolar Transistors", IEEE Transactions on Electron Devices, Vol. 33, No. 11, Nov. 1986, p. 1853

(44) G.P. Li, E. Hackbarth, T.-C. Chen, "Identification and Implication of a Perimeter Tunneling Current Component in Advanced Self-Aligned Bipolar Transistors", IEEE Transactions on Electron Devices, Vol. ED-35, No. 1, January 1988, pp. 89-95.

(45) G.P. Li, E. Hackbarth, C.-T. Chuang, D.D.-L. Tang and T.-C. Chen, "Methodology for Bipolar Process Diagnosis and Its Application to Advanced Self-Aligned Bipolar 
Transistors", IEEE Transactions on Electron Devices, Vol. 34, No. 8, Aug 1987, pp. 1736-1740.

(46) B.-Y. Hwang, P.J. Zdebel, R.J. Baldal, G.G. Sweeney, V. d.I. Torre, "Lateral Scaling Effects of Double-Polysilicon Advanced Self-Aligned Bipolur NPN Transistors", IEEE Bipolar Circuits and Techonology Meeting, 1987, pp. 176-179.

(47) B.H. Yun, B. Cunnigham, J. Snare, K. Bames, R.C. Lange, "Base-Dopant Density Variation with Emitter Size in Polysilicon-Emitter Transistors", IEEE Bipolar Circuits and Technology Meeting, 1991, pp. 267-270.

(48) J.N. Burghartz, J.Y.-C. Sun, C.L. Stanis, S.R. Mader, J.D. Wamock, "Identification of Perimeter Depletion and Emitter plug Effects in Deep-Submicrometer, Shallow-Junction Polysilicon Emitter Bipolar Transistors", Transactions on Electron Devices, Vol. 39, No. 6, June 1992, pp. 1477-1489.

(49) C.-T. Chuang, G.P. Li, T.H. Ning, "Effect of Off-Axis Implant on the Characteristics of Advanced Self-Aligned Bipolar Transistor", IEEE Electron Device Letters, Vol. EDL-8, No. 7, July 1987, pp. 321-323.

(50) T. Gu, M. Okandan, O.O. Awadelkarim, S.J. Fonash, J.F. Rembetski, P. Aum, and Y.D. Chan, "Impact of Polysilicon Dry Etching on $0.5 \mu \mathrm{m}$ NMOS Transistor Performance: The Presence of Both Plasma Bombardment Damage and Plasma Charging Damage", IEEE Electron Device Letters, Vol. 15, No. 2, Febuary 1994, pp. 48-50

(51) P.H. Singer, "Evaluating Plasma Etch Damage", Semiconductor International, May 1992, pp. 78-81

(52) F.K. Moghadam and X.C. Mu, "A Study of Contamination and Darnage on Si Surface Induced by Dry Etching", IEEE Transactions on Electron Devices, Vol. 36, No. 9, September 1989, pp. 1602-1609

(53) S.J. Fonash, "Damage Effect in Dry Etching", Solid State Technology, April 1985, pp. 201-205

(54) H. Weman, J.L. Lindstrom, G.S. Oehrlein, B.G. Svensson, "Reactive-ion- and plasmaetching-induced extended defects in silicon studied with photoluminescence", J. Appl. Physics, Vol. 67, No. 2, january 1990, pp. 1013-1020

(55) S.J. Fonash, Ranbir Singh, A. Rohatgi, P. Rai-Choudhuzy, P.J. Caplan, and E.H. Poindexter, "Silicon Damage Caused by $\mathrm{CCl}_{4}$ Reactive Ion Etching: Its Characterization and Removal by Rapid Thermal Annealing", J.Appl. Phys., Vol. 58, No. 2, July 1985, pp. $862-866$

(56) X.C. Mu and J. Fonash, "High-Barrier Schottky Diodes on p-Type Silicon Due to Dry-Etching Damage", IEEE Electron Device Letters, Vol. 6, No. 8, August 1985, pp. 410-412 
(57) D. Misra, C.R. Selvakumar, E.L. Heasell, D.J. Roulston, "Effect of Reactive Ion Etching on the Electrical Characteristics of Poly-Emitter Bipolar Transistors", Solid Sta'e Electronics, Vol 31, No. 11, 1988, pp. 1647-1649.

(58) K. Washio of Hitachi Central Research Labs, Seminar at Northern Telecom Electronics, June 1992

(59) J.N. Burghartz, B.J. Ginsberg, S.R. Mader, T.C. Chen, D.L. Harame, "Selective Epitaxy Base Transistor ", IEEE Electron Device Letters, Vol. 9, No 5, May 1988, pp. 259-261.

(60) J.N. Burghartz and Y.-J. Mii, "Reliability Imposed Design Aspects of Submicrometer Polysilicon-Emitter Bipolar Transistors", IEEE Electron Device Letters, Vol. 14, No. 7, July 1993, pp. 363-365.

(61) J.D. Cressler, J. Warnock, P.J. Coane, K. N. Chiong, M.E. Rothwell, K.A. Jenkins, J.N. Burghartz, E.J. Petrillo, N.J. Mazzeo, A.C. Megdanis, F.J. Hohm, M.G. TTomson, J.Y.-C. Sun, D.D. Tang, "A Scaled 0.25- $\mu \mathrm{m}$ Bipolar Technology Using Full e-Beam Lithography", IEEE Electron Device Letters, Vol. 13, No 5, May 1992, pp. 262-264

(62) T.C. Chen, J.D. Cressler, K.Y. Toh, J. Wamock, P.F. Lu, K.A. Jenkins, S. Basavaiah, M.P. Manny, H.Y. Ng, D.D. Tang, G.P. Li, C.T. Chuang, M.R. Polcari, M.B. Ketchen T.H. Ning, "A Submicron High Performance Bipolar Technology", 1989 Symposium on VLSI Technology, 1989, pp. 87-88.

(63) T. Yamaguchi, Y.-C. Simon Yu, V.F. Drobny, A.M. Witkowski, "Emitter Resistance and Performance Tradeoff of Submicrometer Self-Aligned Double-Polysilicon Bipolar Devices", IEEE Transactions on Electron Devices, Vol. 35, No. 12, Dec. 1988, pp. 2397-2405.

(64) P.-F. Lu and J.D. Warnock, "On the Perimeter Base Leakage of Double-Poly Self-Aligned p-n-p Transistors", IEEE Transactions on Electron Devices, Vol. 39, No. 12, Dec 1992, pp. 2823-2826.

(65) Y.Akasaka, K. Tsukamoto, M. Kawaguchi, H. Sato, K. Horie, and H. Komiya, "Application of a diffusion from implanted polysilicon to bipolar transistors", Proc. $7^{\text {th }}$ Conf. Solid State Devices, Tokyo, Sept. 1975, pp. 49. 

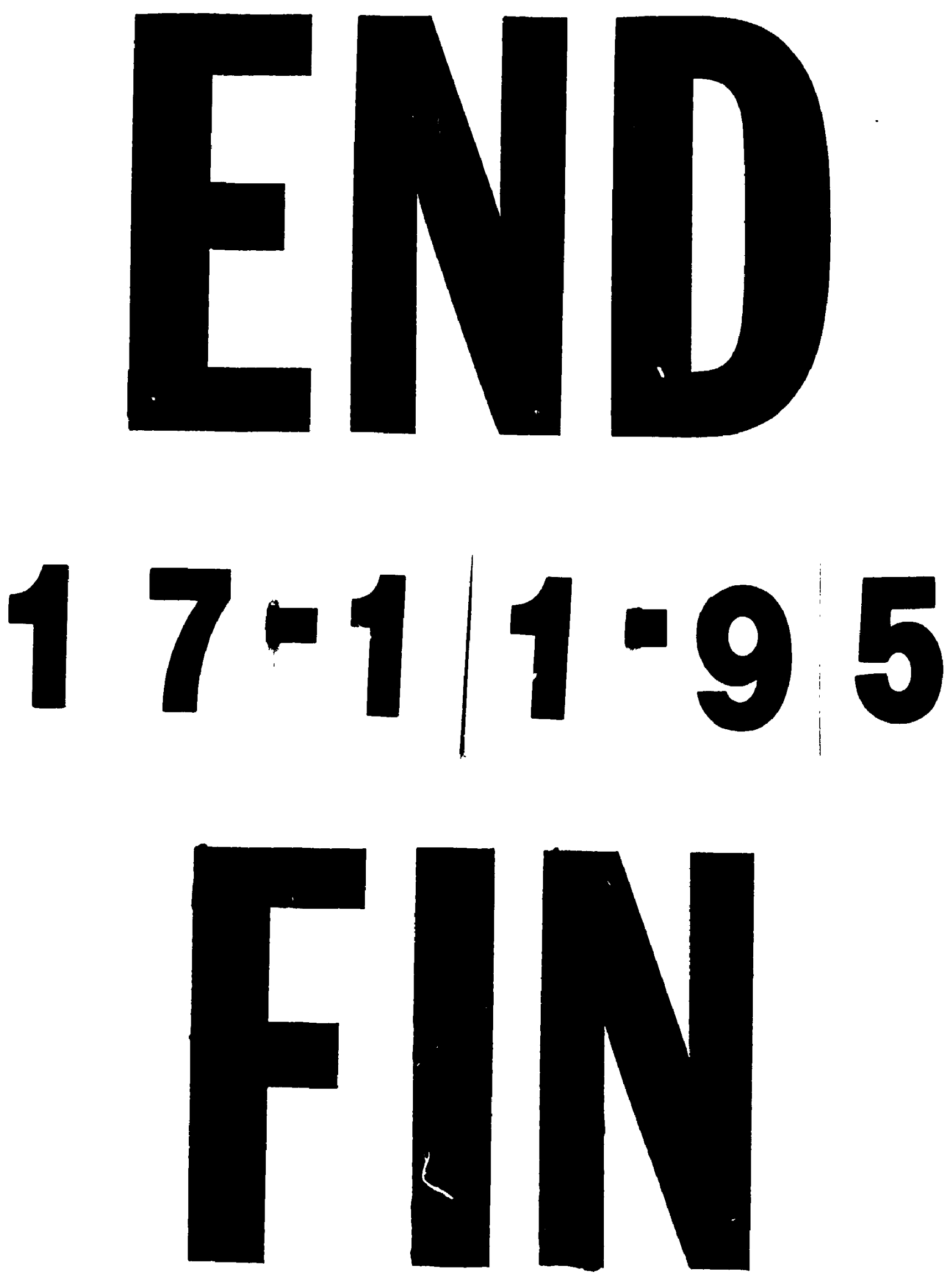